\title{
Technical Letter Report: Evaluation and Analysis of A Few International Periodic Safety Review Summary Reports
}

Environmental Science Division 


\begin{abstract}
About Argonne National Laboratory
Argonne is a U.S. Department of Energy laboratory managed by UChicago Argonne, LLC under contract DE-AC02-06CH11357. The Laboratory's main facility is outside Chicago, at 9700 South Cass Avenue, Argonne, Illinois 60439. For information about Argonne and its pioneering science and technology programs, see www.anl.gov.
\end{abstract}

\title{
Availability of This Report
}

This report is available, at no cost, at http://www.osti.gov/bridge. It is also available on paper to the U.S. Department of Energy and its contractors, for a processing fee, from:

U.S. Department of Energy

Office of Scientific and Technical Information

P.O. Box 62

Oak Ridge, TN 37831-0062

phone (865) 576-8401

fax (865) 576-5728

reports@adonis.osti.gov

\section{Disclaimer}

This report was prepared as an account of work sponsored by an agency of the United States Government. Neither the United States Government nor any agency thereof, nor UChicago Argonne, LLC, nor any of their employees or officers, makes any warranty, express or implied, or assumes any legal liability or responsibility for the accuracy, completeness, or usefulness of any information, apparatus, product, or process disclosed, or represents that its use would not infringe privately owned rights. Reference herein to any specific commercial product, process, or service by trade name, trademark, manufacturer, or otherwise, does not necessarily constitute or imply its endorsement, recommendation, or favoring by the United States Government or any agency thereof. The views and opinions of document authors expressed herein do not necessarily state or reflect those of the United States Government or any agency thereof, Argonne National Laboratory, or UChicago Argonne, LLC. 


\section{Technical Letter Report: Evaluation and Analysis of A Few International Periodic Safety Review Summary Reports}

Date Published: December 2013

prepared by

Omesh Chopra, ${ }^{1}$ Dwight Diercks, ${ }^{2}$ David Ma, ${ }^{1}$ and Yogen Garud ${ }^{1}$

1 Environmental Science Division

2 Nuclear Engineering Division

Environmental Science Division, Argonne National Laboratory

Makuteswara Srinivasan, NRC Technical Monitor and Contracting Officer Representative

Prepared for

Division of Engineering Office of Nuclear Regulatory Research

U.S. Nuclear Regulatory Commission

Washington, DC 20555 


\section{ABSTRACT}

At the request of the United States (U.S.) government, the International Atomic Energy Agency (IAEA) assembled a team of 20 senior safety experts to review the regulatory framework for the safety of operating nuclear power plants in the United States. This review focused on the effectiveness of the regulatory functions implemented by the NRC and on its commitment to nuclear safety and continuous improvement. One suggestion resulting from that review was that the U.S. Nuclear Regulatory Commission (NRC) incorporate lessons learned from periodic safety reviews (PSRs) performed in other countries as an input to the NRC's assessment processes.

In the U.S., commercial nuclear power plants (NPPs) are granted an initial 40-year operating license, which may be renewed for additional 20-year periods, subject to complying with regulatory requirements. The NRC has established a framework through its inspection, and operational experience processes to ensure the safe operation of licensed nuclear facilities on an ongoing basis. In contrast, most other countries do not impose a specific time limit on the operating licenses for NPPs, they instead require that the utility operating the plant perform PSRs, typically at approximately 10-year intervals, to assure continued safe operation until the next assessment.

The staff contracted with Argonne National Laboratory (Argonne) to perform a pilot review of selected translated PSR assessment reports and related documentation from foreign nuclear regulatory authorities to identify any potential new regulatory insights regarding license renewal-related topics and NPP operating experience (OpE). A total of 14 PSR assessment documents from 9 countries were reviewed. For all of the countries except France, individual reports were provided for each of the plants reviewed. In the case of France, three reports were provided that reviewed the performance assessment of thirty-four 900-MWe reactors of similar design commissioned between 1978 and 1988. All of the reports reviewed were the regulator's assessment of the PSR findings rather than the original PSR report, and all but one were English translations from the original language.

In these reviews, it was found that most of the countries base their regulatory guidance to some extent (and often to a large extent) on U.S. design codes and standards, NRC regulatory guidance, and U.S. industry guidance. In addition, many of the observed operational technical issues and OpE events reported for U.S. reactors are also cited in the PSR reports. The PSR reports also identified a number of potential technical material/component performance issues and OpE events that are not commonly reported for U.S. plants. 


\section{TABLE OF CONTENTS}

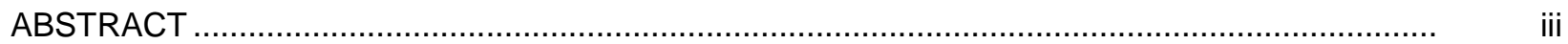

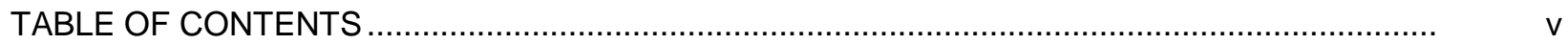

ACRONYMS AND ABBREVIATIONS ............................................................................ ix

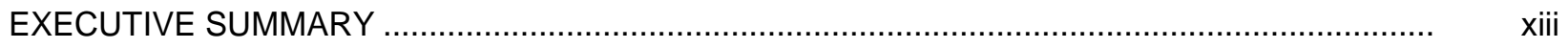

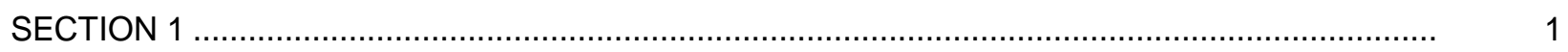

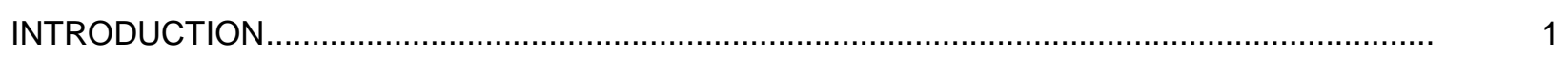

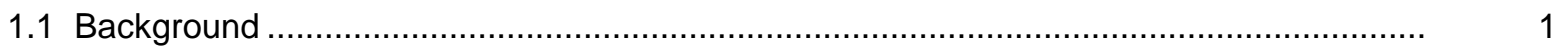

1.2 Integrated Regulatory Review Service Mission to the United States................................. 3

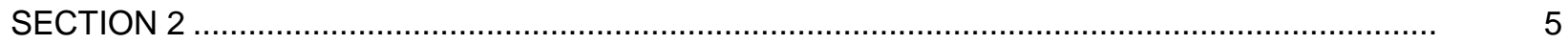

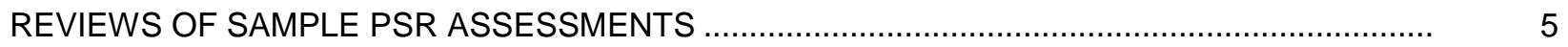

2.1 Scope of Present Report ......................................................................................

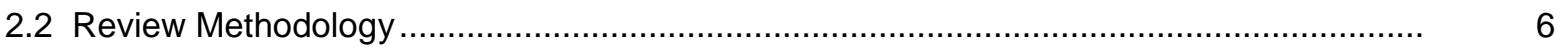

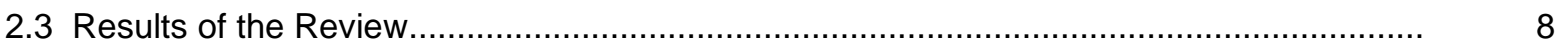

2.4 Summary of Observations from a Review of PSR Assessments ..................................... 8

2.4.1 Example PSR Technical Issues that Have Been Observed at U.S. Plants of Similar Design

2.4.2 Example PSR Technical Issues that Merit Further Consideration for Future Regulatory Guidance .................................................................... 11

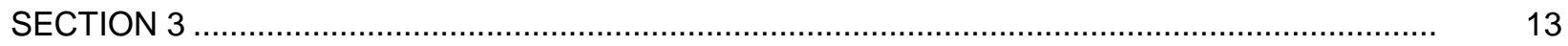

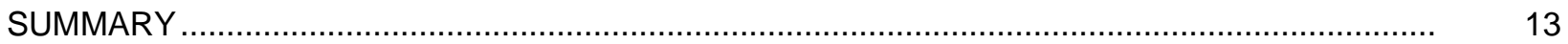

APPENDIX A

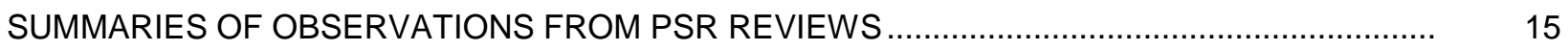

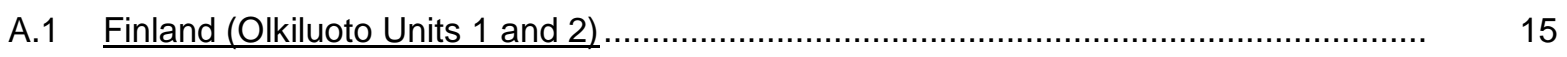

A.1.1 Plant Modifications................................................................................ 15

A.1.2 Improvements and Enhancements ........................................................ 16

A.1.3 Aging Degradation and Management.......................................................... 18

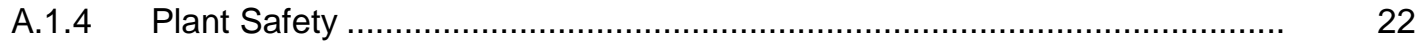

A.1.5 Performance and Feedback of Experience .................................................. 27

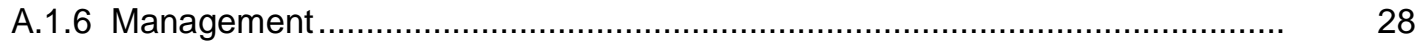

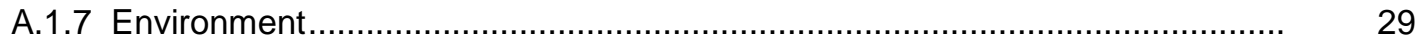

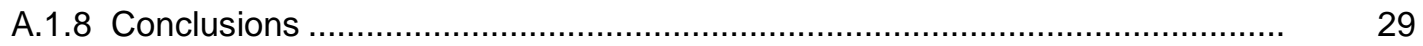

A.2 France (900-MWe Pressurized Water Reactors, Types CP0, CP1, and CP2) …............... 30

A.2.1 Plant Modifications..................................................................................... 31

A.2.2 Plant Design ................................................................................... 31

A.2.3 Aging Degradation and Management......................................................... 34 
A.2.4 Performance and Feedback of Experience ................................................ 34

A.2.5 Comparison of Operating Experience with U.S. Plant of Similar Design ......... 35

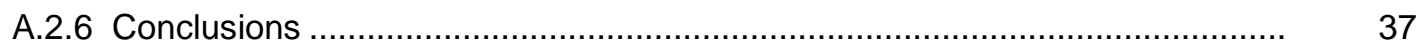

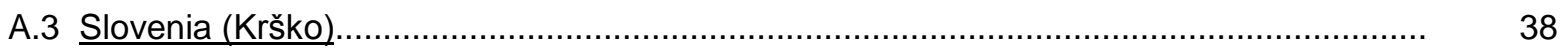

A.3.1 Plant Modifications and Improvements....................................................... 38

A.3.2 Aging Degradation and Management.......................................................... $\quad 39$

A.3.3 Performance and Feedback of Experience ................................................. $\quad 42$

A.3.4 Comparison of Operating Experience with U.S. Plant of Similar Design ......... 42

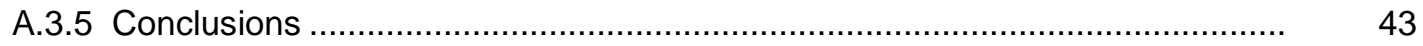

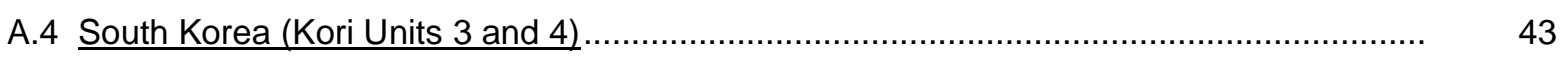

A.4.1 Plant Modifications................................................................................ 44

A.4.2 Aging Degradation and Management....................................................... 44

A.4.3 Plant Safety .......................................................................................... 46

A.4.4 Performance and Feedback of Experience ............................................... 48

A.4.5 Management ...................................................................................... 50

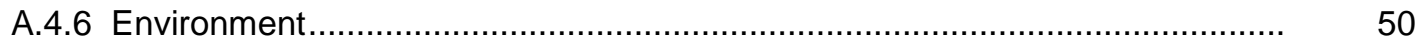

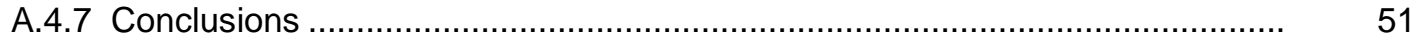

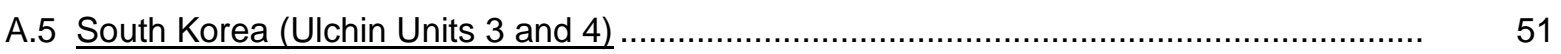

A.5.1 Plant Modifications............................................................................. 52

A.5.2 Aging Degradation and Management..................................................... 52

A.5.3 Safety Analysis ................................................................................. 54

A.5.4 Performance and Feedback of Experience ................................................ 56

A.5.5 Conclusions ................................................................................... 57

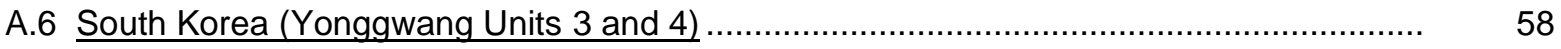

A.6.1 Plant Design ................................................................................ 58

A.6.2 Aging Degradation and Management ..................................................... 59

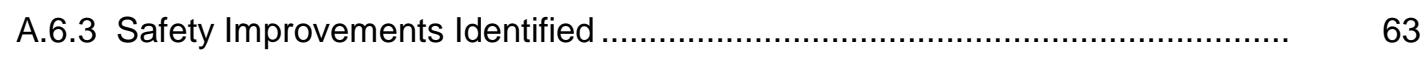

A.6.4 Safety Analyses .................................................................................... 64

A.6.5 Performance and Feedback of Experience ................................................ 65

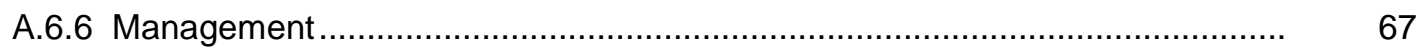

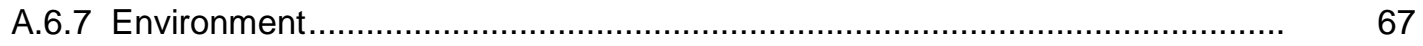

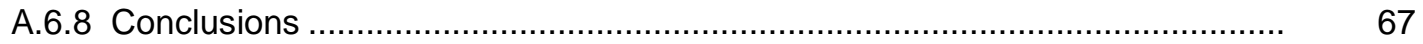

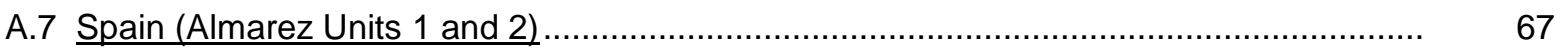

A.7.1 Plant Modifications .............................................................................. 68

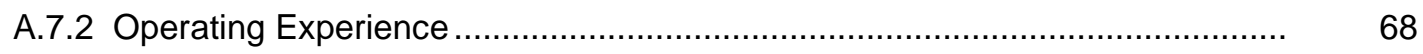

A.7.3 Findings Resulting from the PSR …................................................. 69 
A.7.4 Required Improvements and Enhancements ........................................... 69

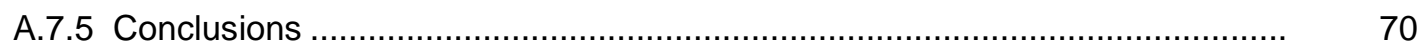

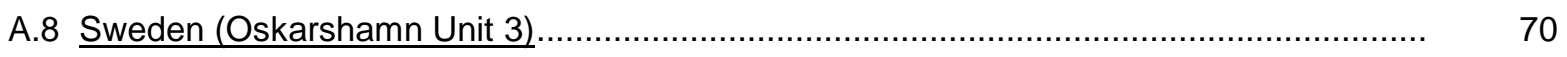

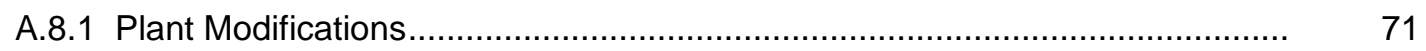

A.8.2 Improvements and Enhancements ........................................................ 72

A.8.3 Safety Analyses ...............................................................................

A.8.4 Performance and Feedback of Experience ................................................ $\quad 75$

A.8.5 Management ................................................................................... 76

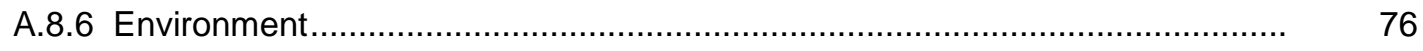

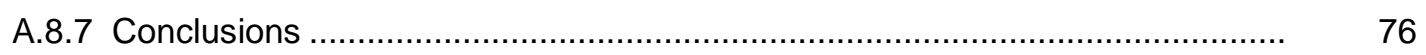

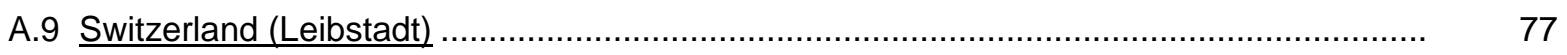

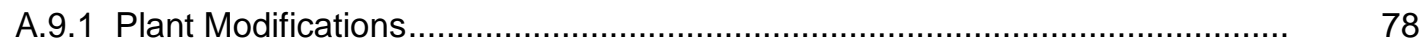

A.9.2 Aging Degradation and Management......................................................... $\quad 80$

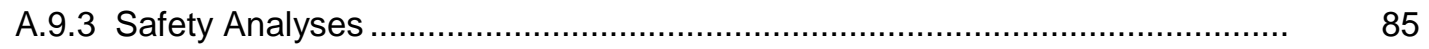

A.9.4 Performance and Feedback of Experience ................................................. 87

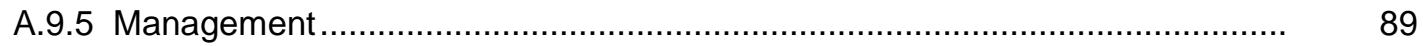

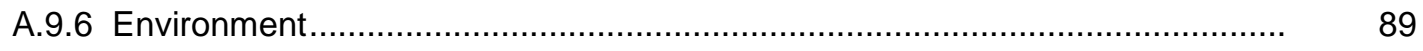

A.9.7 Conclusions .................................................................................... 89

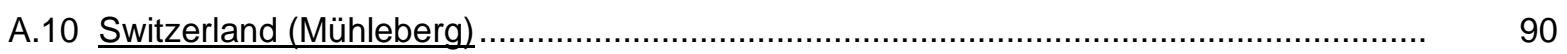

A.10.1 Plant Modifications.............................................................................. 91

A.10.2 Aging Degradation and Management....................................................... 92

A.10.3 Safety Analyses ................................................................................. 96

A.10.4 Performance and Feedback of Experience ............................................... 97

A.10.5 Management ................................................................................. 99

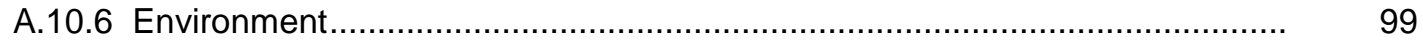

A.10.7 Conclusions ................................................................................ 100

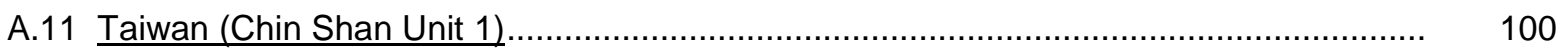

A.11.1 Plant Modifications................................................................................ 101

A.11.2 Aging Degradation and Management...................................................... 103

A.11.3 Safety Analyses ................................................................................... 106

A.11.4 Performance and Feedback of Experience …........................................... 106

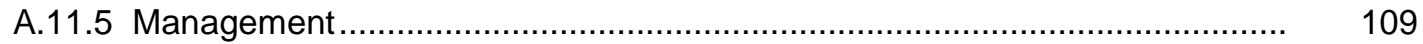

A.11.6 Environment................................................................................. 109

A.11.7 Conclusions ……............................................................................ 109

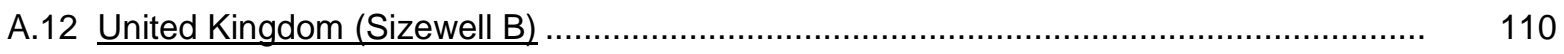

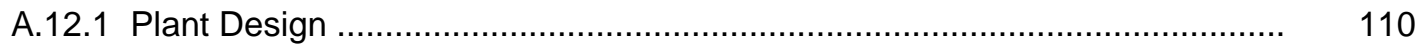


A.12.2 Aging Degradation and Management..................................................... 111

A.12.3 Performance and Feedback of Experience ................................................ 113

A.12.4 Conclusions ........................................................................................ 115

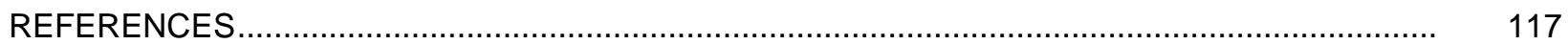




\section{ACRONYMS AND ABBREVIATIONS}

\begin{tabular}{|c|c|}
\hline ALARA & as low as reasonably achievable \\
\hline Act & Atomic Energy Act of 1954, as amended \\
\hline AEC & Atomic Energy Council (Taiwan) \\
\hline AFS & auxiliary feedwater system \\
\hline AG & Aktiengesellschaft \\
\hline AMP & aging management program \\
\hline AMR & aging management review \\
\hline ANSI & American National Standards Institute \\
\hline Argonne & Argonne National Laboratory \\
\hline ASME & American Society of Mechanical Engineers \\
\hline ASN & Autorité de Sûreté Nucléaire or Nuclear Safety Authority (France) \\
\hline ASTM & American Society for Testing and Materials \\
\hline AVR & auto voltage regulator \\
\hline $\mathrm{BE}$ & British Energy \\
\hline BL & (NRC) Bulletin \\
\hline BOP & balance of plant \\
\hline BVPS & Beaver Valley Power Station \\
\hline BWR & boiling water reactor \\
\hline BWROG & Boiling Water Reactor Owner's Group \\
\hline BWRVIP & Boiling Water Reactor Vessels and Internals Project \\
\hline CCF & common cause failure \\
\hline CFR & Code of Federal Regulations \\
\hline CRD & control rod drive \\
\hline CSCW & combined service \& cooling water system \\
\hline CSN & Consejo de Seguridad Nuclear or Nuclear Security Council (Spain) \\
\hline DCR & design change request \\
\hline DE & Division of Engineering \\
\hline ECCS & emergency core cooling system \\
\hline EdF & Électrcité de France \\
\hline EDG & emergency diesel generator \\
\hline EDP & electronic data processing \\
\hline ENSI & $\begin{array}{l}\text { Eidgenössisches Nuklearsicherheits-inspektorat or Federal Nuclear Safety } \\
\text { Inspectorate (Switzerland) }\end{array}$ \\
\hline $\mathrm{EQ}$ & environmental qualification \\
\hline EPRI & Electric Power Research Institute \\
\hline ESWS & essential services water system \\
\hline EU & European Union \\
\hline Euratom & European Atomic Energy Community \\
\hline
\end{tabular}




\begin{tabular}{|c|c|}
\hline $\begin{array}{l}\text { FAC } \\
\text { FSAR }\end{array}$ & $\begin{array}{l}\text { flow-accelerated corrosion } \\
\text { final safety analysis report }\end{array}$ \\
\hline $\begin{array}{l}\text { GALL } \\
\text { GL }\end{array}$ & $\begin{array}{l}\text { Generic Aging Lessons Learned } \\
\text { (NRC) Generic Letter }\end{array}$ \\
\hline HEPA & high-efficiency particulate air \\
\hline HMI & human-machine interface \\
\hline $\mathrm{HPCl}$ & high-pressure cooling injection \\
\hline HSE & Health and Safety Executive (U.K.) \\
\hline HSK & $\begin{array}{l}\text { Hauptabteilung für die Sicherheit der Kernanlagen or Principle Nuclear Safety } \\
\text { Division (Switzerland) }\end{array}$ \\
\hline HTG & Högsta Tillåtna Gränsvärde or maximum allowed temperature limit (Sweden) \\
\hline HWC & hydrogen water chemistry \\
\hline HWC-M & moderate hydrogen water chemistry \\
\hline IAEA & International Atomic Energy Agency \\
\hline I\&C & instrumentation and control \\
\hline IGSCC & intergranular stress corrosion cracking \\
\hline IN & (NRC) Information Notice \\
\hline INES & International Event Scale \\
\hline INPO & Institute of Nuclear Power Operations \\
\hline IOF & incredibility of failure \\
\hline IRRS & Integrated Regulatory Review Service \\
\hline ISI & inservice inspection \\
\hline IRSN & $\begin{array}{l}\text { Institut de Radioprotection et de Sûreté Nucléaire or Institute for Radiation } \\
\text { Protection and Nuclear Safety (France) }\end{array}$ \\
\hline IST & inservice testing \\
\hline KHNP & Korea Hydro \& Nuclear Power \\
\hline KINS & Korea Institute of Nuclear Safety \\
\hline KKL & Kernkraftwerk Leibstadt, or Leibstadt Nuclear Power Station (Switzerland) \\
\hline KSNP & Korean Standard Nuclear Power Plant \\
\hline LBB & leak before break \\
\hline LER & Licensee Event Report \\
\hline LOCA & loss of coolant accident \\
\hline LRA & license renewal application \\
\hline LTO & $\begin{array}{l}\text { long-term operation (in this context, operation beyond initial or first license } \\
\text { renewal, namely beyond } 60 \text { years of reactor operation) }\end{array}$ \\
\hline LTOP & low-temperature overpressure \\
\hline LWR & light water reactor \\
\hline
\end{tabular}




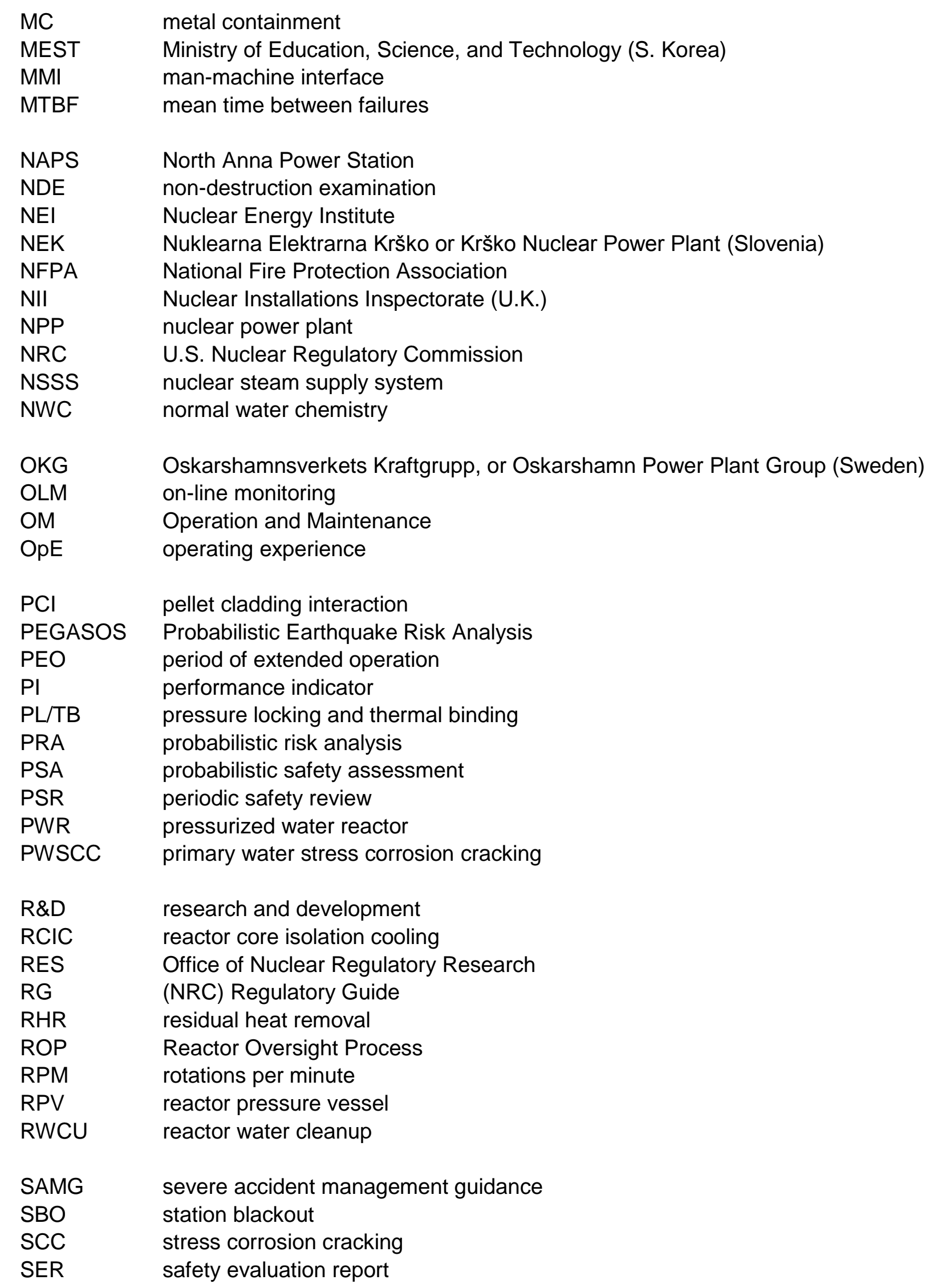




$\begin{array}{ll}\text { SFP } & \text { spent fuel pool } \\ \text { SG } & \text { steam generator } \\ \text { SKI } & \text { Statens Kärnkraftinspektion or Nuclear Power Inspectorate (Sweden) } \\ \text { SNSA } & \text { Slovenian Nuclear Safety Administration } \\ \text { SNUPPS } & \begin{array}{l}\text { Standardized Nuclear Unit Power Plant System } \\ \text { systems, structures, and components }\end{array} \\ \text { SSCs } & \begin{array}{l}\text { NRC staff } \\ \text { Staff }\end{array} \\ \text { STF } & \begin{array}{l}\text { Säkerhetstekniska drifttörutsättningar or Technical Specifications, Operational } \\ \text { Limits and Conditions (Sweden) }\end{array} \\ \text { STUK } & \begin{array}{l}\text { Säteilyturvakeskus Strålsäkerhetscentralen or Radiation and Nuclear Safety } \\ \text { Authority (Finland) }\end{array} \\ \text { SUSAN } & \begin{array}{l}\text { Selbstständiges, unabhängiges System zur Abfuhr der Nachzerfallswärme } \\ \text { (Freestanding Independent System for the Removal of Decay Heat) }\end{array} \\ \text { TLAA } & \begin{array}{l}\text { time-limited aging analysis } \\ \text { TR }\end{array} \\ \text { TU } & \begin{array}{l}\text { Topical Report } \\ \text { tons of uranium }\end{array} \\ \text { TVO } & \text { Teollisuuden Voima Oyj or Industrial Power Corporation (Finland) } \\ \text { UPS } & \text { uninterruptible power supply } \\ \text { UT } & \text { ultrasonic testing } \\ \text { VD3 900 } & \text { Third decennial periodic safety review of French 900-MWe PWRs } \\ \text { VT } & \text { visual (inspection) technique } \\ \text { WANO } & \text { World Association of Nuclear Operators }\end{array}$




\section{EXECUTIVE SUMMARY}

This technical letter report (TLR) provides the results of a brief study conducted after the Integrated Regulatory Review Service (IRRS) mission to review the nuclear safety regulatory framework in the United States. The objective of this study was to gather information related to the IRRS Mission Safety Suggestion S9, which advocated the study of international PSR practices to develop lessons learned that could be used as an input to the NRC's assessment processes.

In the United States (U.S.), commercial nuclear power plants (NPPs) are granted an initial operating license for a 40-year term in accordance with the Atomic Energy Act (Act) of 1954, as amended, and based on fulfilling the requirements of Title 10 of the Code of Federal Regulations (10 CFR) Part 50, and other regulations cited therein. 10 CFR Part 54, "Requirements for Renewal of Operating Licenses for Nuclear Power Plants," known as the license renewal rule, was adopted by the U.S. Nuclear Regulatory Commission (NRC) allowing it to renew these licenses for a period up to an additional 20 years, also known as the period of extended operation (PEO). Neither the Atomic Energy Act of 1954, as amended, nor the subsequent NRC regulations for renewal include any specific limitations as to the number of times a license may be renewed.

The NRC has established a framework through its regulatory processes to ensure the safe operation of licensed nuclear facilities on an ongoing basis. For example, the NRC has established inspection processes to ensure that licensees maintain continuous vigilance to ensure plant safety, manage aging, and maintain safety of their facilities and their licensing bases in lieu of performing periodic safety reviews. NRC had provided information on NRC's Reactor Oversight Process (ROP) in Module 11a "Periodic Safety review", to the IRRS Mission (NRC 2010b). The ROP plays a significant role in ensuring the continual safe operation of nuclear plants in the U.S., particularly with respect to assessing the current condition of systems, structures, and components and managing any degradation of operating performance.

In contrast to the NPP licensing process in the U.S., most other countries do not impose a time limit on the operating licenses for NPPs. Instead, they typically require the utility operating the plant to perform periodic safety reviews (PSRs) to assure continued safe operation until the next review period. The PSR process is well established among the International Atomic Energy Agency (IAEA) Member States, and is, a legal requirement in a number of them. The PSRs are typically conducted by the plant staff at 10-year intervals and include an assessment of plant design and operation against current safety standards and practices in five areas, which are in turn divided into a total of 14 elements (known as safety factors), as defined in the IAEA Safety Guide NS-G.2.10 (IAEA 2003a). In addition, there is a global assessment to integrate the results of the review of individual safety factors.

One of the services offered by the IAEA to its member countries is the IRRS, which compares the member country's nuclear regulatory approach against international safety standards and good practices. At the request of the U.S. government, an IRRS review of the NRC regulatory processes was conducted by an international team of 20 senior safety experts during October 18-29, 2010. The purpose of this IRRS mission was to review the regulatory framework for the safety of operating nuclear power plants in the U.S. and the effectiveness of regulatory functions implemented by the NRC. During this review, the IRRS Review Team considered a number of areas, including long-term operation (LTO) and aging management of nuclear power plants, the periodic safety review process, and feedback of operating experience (OpE) of NPPs. The IAEA final report (IAEA 2011) on the IRRS review was published on 
March 1, 2011, and included 2 recommendations, 20 suggestions, and 25 good practices. Among these was the Suggestion S9 that the NRC incorporate lessons learned from PSRs performed in other countries as an input to the NRC's assessment processes.

On June 27, 2011, the NRC issued NRC Commission Paper SECY-11-0084 (NRC 2011c) to inform the Commissioners of the actions planned by the staff to address the recommendations and suggestions of the IAEA Final Report, including the Suggestion S9 stated above. In response to this suggestion, SECY-11-0084 (NRC 2011c) stated that the staff will conduct a limited scope pilot effort to obtain some example PSRs performed in other countries where an English version of the PSR results is available (or as a minimum, the regulator's review and assessment of the PSR). These will be reviewed for potential insights regarding nuclear power plant OpE topics similar to the review performed prior to the IRRS mission. As a part of this pilot effort, and in conjunction with other efforts related to license renewal beyond 60 years, the staff contracted Argonne National Laboratory (Argonne) to perform a review of selected translated PSR assessment reports and related documentation from foreign nuclear regulatory authorities to identify any potential new insights regarding license renewal-related topics and nuclear power plant OpE. A total of 14 PSR documents from 9 countries were provided for review. All of the reports reviewed were the regulator's assessment of the PSR findings rather than the original PSR report, and all but one were English translations from the original language. The observations resulting from the reviews of the PSR documents for each of the plants considered are summarized in this report.

It was found in these reviews that most of the countries base their regulatory guidance to at least some extent (and often to a large extent) on U.S. design codes and standards, NRC regulatory guidance, and U.S. industry guidance. For example, the American Society of Mechanical Engineers (ASME) Code is cited in the PSR assessment reports reviewed for Finland, Slovenia, South Korea, Switzerland, and Taiwan, and NRC guidance is referenced in the documents from Finland, Slovenia, South Korea, Sweden, Switzerland, and Taiwan. Many of the technical material/component performance issues and OpE events reported for U.S. reactors are also cited in the PSR assessment reports. These include primary water stress corrosion cracking of Alloy 600 and Alloy 82/182 components, reactor vessel head replacement, steam generator replacement, boiling water reactor (BWR) recirculation piping replacement, core shroud cracking, concerns about containment sump strainer performance under severe accident conditions, and the need for improved seismic hazard analyses.

With respect to aging-related issues, international operational experience is occasionally cited in the NRC's Generic Aging Lessons Learned (GALL) report (NRC 2001a, 2005b, 2010c) for its license renewal program; however, the PSRs or the PSR assessment reports identified a number of technical operational experiences that were not cited in the GALL. A sample of such experience includes the failure of a steam isolation valve due to the weakening of permanent magnets, aging-related embrittlement of emergency diesel generator seals, the possible radiation-induced degradation of coatings inside containment, the aging-related management of fillers and sealants in safety-related watertight and blast-proof doors, and the use of greaseless fiber ceramic bearings. However, the PSR assessment reports, in general, do not provide sufficient information on the assessment of the safety significance of these experiences, and further evaluation in this regard may be appropriate. In contrast, it is noted in this study that U.S licensees usually assess the safety significance of important technical OpE during their evaluation and provide such information for NRC staff review.

The PSR assessment reports do not generally address maintenance-related and aging-related technical issues separately. In the U.S., the OpE events are evaluated based on adherence to 
both operation and maintenance (OM) and inservice testing (IST) codes. Typically, for active components IST codes apply. In addition, for active components, which may be subjected to degradation, and for passive components, which are expected to undergo aging degradation, the inservice inspection (ISI) codes are mandated; licensees' performance against these standards are also verified, in part, through the NRC's oversight process. This review has identified a number of international OpE events that are not usually reported at U.S. plants and may be areas for further consideration as maintenance-related and aging-related technical issues. Examples include the failure of a steam line isolation valve because of time-dependent weakening of the permanent magnet used to hold it in the open position (Olkiluoto), the need to develop a long-term plan to monitor the radiation-induced degradation of protective coatings inside containment (Kori), and the aging embrittlement of some emergency diesel generator seals (Olkiluoto). Other examples are listed in Section 2.4.2. 


\section{SECTION 1}

\section{INTRODUCTION}

\subsection{Background}

In the United States (U.S.), commercial nuclear power plants (NPPs) are granted an initial operating license for a 40-year term in accordance with the Atomic Energy Act (Act) of 1954, as amended, and based on fulfilling the requirements of Title 10 of the Code of Federal Regulations (10 CFR) Part 50, and other regulations cited therein. 10 CFR Part 54, "Requirements for Renewal of Operating Licenses for Nuclear Power Plants," known as the license renewal rule, was adopted by the NRC, allowing it to renew these licenses for a period up to an additional 20 years. This license renewal rule addresses the safety and technical requirements for extended license term, and the renewal is based on the NRC's assessment of the plant's operational safety, including environmental protection, being assured during the 20-year period of extended operation (PEO). Neither the Act nor the subsequent NRC regulations for renewal include any specific limitations as to the number of times a license may be renewed.

The U.S. regulation does not require its licensees to summarize performance with, for example, a recurring 10-year submittal to the regulator, as other countries do, as per International Atomic Energy Agency (IAEA) periodic safety review (PSR) guidance (NRC 2011d). Rather, the NRC has established inspection processes to ensure that licensees maintain continuous vigilance to ensure plant safety, manage aging, and maintain safety of their facilities and their licensing bases in lieu of performing periodic safety reviews.

The licensing basis for NPPs in the U.S. is established upon issuance of the license, and it evolves throughout the term of the operating license because of the continuing regulatory activities of the NRC, as well as the activities of the licensee. Licensees implement quality assurance program requirements (10 CFR 50, Appendix B) and the maintenance rule (10 CFR 50.65) for active structures and components. Licensees are also required to perform assessments of modifications under 10 CFR 50.59 and submit license amendments under 10 CFR 50.90. As a routine function, the NRC evaluates licensee's operating experience $(\mathrm{OpE})$, assesses self-identified and reported occurrences during routine plant operation by the licensees, and evaluates information gathered from inspections, audits, investigations, and regulatory research. As necessary, the NRC requires changes to the licensing basis for licensees through the issuance of new or revised regulations, the issuance of orders modifying licenses, and acceptance of licensee voluntary commitments to modify NPP designs and procedures (e.g., in response to licensee events or generic communications). In such cases, the NRC follows established processes that ensure the appropriate NRC actions are taken with full consideration of the safety significance of the issue, and opportunity for stakeholder involvement (e.g., rulemaking, hearing process, backfit analysis). In addition, the NRC also requires the implementation of aging management programs (AMPs) for passive components as part of the license renewal process.

In contrast to the NPP licensing process in the U.S., most other countries do not impose a time limit on the operating licenses for NPPs. Instead, they typically require the utility operating the 
plant to perform PSRs at prescribed intervals. The responsible regulatory agency then reviews and assesses the PSR to verify that safe operation can be assured until the next review period. The PSR process is well established among the IAEA Member States and is a legal requirement in a number of them (IAEA 2010). In 2003, the IAEA published a safety guide, NS-G.2.10, "Periodic Safety Review of Nuclear Power Plants" (IAEA 2003a), to provide guidance on how to conduct PSRs. The objective of a PSR, as stated in this safety guide, is to "to deal with the cumulative effects of aging, modifications, OpE, technical developments, and siting aspects, and is aimed at ensuring a high level of safety throughout the operating lifetime of the plant."

The PSRs are typically conducted by the plant staff at 10-year intervals and include an assessment of plant design and operation against current safety standards and practices in five areas, which are in turn divided into a total of 14 elements (known as safety factors), as defined by IAEA (2003a). In addition, there is a global assessment to integrate the results of the review of individual safety factors. 


\subsection{Integrated Regulatory Review Service Mission to the United States}

One of the services offered by the IAEA to its member countries is the IRRS, which compares that member country's nuclear regulatory approach against international safety standards and good practices. At the request of the U.S. government, an IRRS review of the NRC was conducted by an international team of 20 senior safety experts during October 18-29, 2010. The purpose of this IRRS mission was to review the regulatory framework for the safety of operating NPPs in the U.S. and the effectiveness of regulatory functions implemented by the NRC. The review compared NRC standards against IAEA safety standards as the international benchmark for safety. The mission was also used to exchange information and experience between the IRRS Review Team and the U.S. counterparts in the areas covered by IRRS.

As a part of the IRRS mission activities in preparation for the October 18-29, 2010, review, the $\mathrm{NRC}$ prepared a series of technical modules addressing various aspects of the nuclear safety assurance process in the U.S. as compared with the IAEA approach. Table 1 of Module 11A ("Periodic Safety Review"), presents a sample crosswalk between selected PSR safety factors and the corresponding U.S. program elements, and Attachment 1 to Module $11 \mathrm{~A}$ includes a more complete comparison between the PSR's 14 safety factors and global assessment to the comparable U.S. program elements (NRC 2010b). Table 1 from Module 11A is reproduced below for illustration.

Table 1. A Brief Crosswalk of Selected PSR Safety Factors to U.S. Program Elements (from IRRS Mission to the United States, Module 11A: Periodic Safety Review)

\begin{tabular}{|c|c|}
\hline $\begin{array}{c}\text { IAEA NS-G-2.10 Safety } \\
\text { Factor }\end{array}$ & U.S. Program Elements \\
\hline Actual Condition of SSCs & $\begin{array}{l}\text { 1. In-depth daily inspections by resident inspectors } \\
\text { 2. Focused routine inspections by specialist (e.g., Maintenance Rule, } \\
\text { Corrective Action Program) } \\
\text { 3. Reactor Oversight Process (ROP) Performance Indicators }\end{array}$ \\
\hline Equipment Qualification & $\begin{array}{l}\text { 1. Inspections tied to Environmental Qualification Rule (10 CFR 50.49) } \\
\text { - Component Design-Basis Inspections } \\
\text { - Permanent plant modifications } \\
\text { 2. License Event Reports }\end{array}$ \\
\hline Aging & $\begin{array}{l}\text { 1. Aging Management Programs (10 CFR 54) } \\
\text { 2. License Renewal inspections (passive components) } \\
\text { 3. Maintenance Rule and other ROP inspections (active components) }\end{array}$ \\
\hline Deterministic Safety Analysis & $\begin{array}{l}\text { 1. Evaluation of changes to design and licensing basis } \\
\text { 2. Changes to the Final Safety Analysis Report ( } 10 \text { CFR } 50.59) \\
\text { 3. Daily inspections that compare everyday operation to design bases }\end{array}$ \\
\hline $\begin{array}{l}\text { Probabilistic Safety } \\
\text { Assessment (PSA) }\end{array}$ & $\begin{array}{l}\text { 1. PSAs used in selecting inspection samples } \\
\text { 2. Plant-specific PSAs for internal and some external events } \\
\text { 3. PSAs can be used in lieu of deterministic assessments (RG 1.174) } \\
\text { 4. Maintenance Rule ( } 10 \text { CFR } 50.65 \text { ) } \\
\text { 5. PSAs not required to be updated in the U.S. }\end{array}$ \\
\hline
\end{tabular}


During the October 18-29, 2010 review, the IRRS Review Team evaluated a number of areas, including long-term operation (LTO) and aging management of NPPs, the periodic safety review process, and feedback of OpE of NPPs. The IAEA final report (IAEA 2011) on the IRRS review was published on March 1, 2011, and it included 2 recommendations, 20 suggestions, and 25 good practices. Among these was the following suggestion:

Suggestion S9: "NRC should incorporate lessons learned from PSRs performed in other countries as an input to the NRC's assessment processes."

On June 27, 2011, the NRC issued NRC Commission Paper SECY-11-0084 (NRC 2011c) to inform the Commissioners of the actions planned by the staff to address the recommendations and suggestions of the IAEA Final Report, including Suggestion S9 stated above.

SECY-11-0084 (NRC 2011c) stated that, with respect to Suggestion S9,

[T] he NRC will conduct a limited scope pilot effort to obtain some example PSRs performed in other countries where an English version of the PSR results is available (or as a minimum, the regulator's review of the PSR). These will be reviewed for potential insights regarding nuclear power plant OpE topics similar to the review performed prior to the IRRS mission. The pilot effort will review example PSRs for potential insights to be assessed by the NRC's regulatory processes, which could include, for example, issuing a nuclear power plant generic communication or future revisions to NRC license renewal guidance documents. The pilot effort will seek to establish the value added from the review of the example PSRs. In addition, the NRC will use bilateral meetings with other international regulatory bodies as a forum to obtain significant PSR findings from those countries for further evaluation by the NRC.

As a part of the pilot effort described in SECY-11-0084 (NRC 2011c), and in conjunction with other efforts related to license renewal beyond 60 years, the NRC's Office of Nuclear Regulatory Research, Division of Engineering, contracted Argonne to perform the present review of selected translated PSR reports and related documentation from foreign nuclear regulatory authorities to identify any potential new regulatory insights regarding license renewal-related topics and NPP OpE. 


\section{SECTION 2}

\section{REVIEWS OF SAMPLE PSR ASSESSMENTS}

\subsection{Scope of Present Report}

A total of 14 PSR documents from nine countries were provided for the present review, all of which were the regulator's assessment of the PSR findings rather than the original PSR report from the plant operator or the utility. Aside from the U.K. report, the other reports were English translations from the original language, performed either by the originating country (Finland, France, and Slovenia), or by outside contractors to the NRC in the case of the reports from South Korea, Spain, Sweden, Switzerland, and Taiwan. These documents varied considerably with respect to the technical content and detail and were not comparable. These documents are:

Finland (Olkiluoto 1 and 2):

STUK (Säteilyturvakeskus Strålsäkerhetscentralen), 2010, Safety Assessment of Olkiluoto NPP Units 1 and 2, STUK-B 111, Helsinki, February.

France (900-MWe Pressurized Water Reactors [PWRs], Types CP0, CP1, and CP2):

Lacoste, A.C., 2009, communication from André-Claude Lacoste (Autorité de Sûreté Nucléaire) to the President of Électrcité de France, EDF's Pressurised-water Nuclear Reactors (PWR); ASN's Position on the Generic Aspects for the Extension of the Operating Lifetime of 900-MWe Reactors after the Third Decennial Visit (DEP-PRES-0077-2009), July 1.

Autorité de Sûreté Nucléaire, 2011, Opinion No. 2011-AV-0120 of ASN (Nuclear Safety Authority) Dated 4 July 2011 Concerning the Continued Operation of Reactor No. 1 of the Fessenheim Nuclear Power Plant after 30 Years of Operation, Paris, July 4.

IRSN (Institut de Radioprotection et de Sûreté Nucléaire), 2009, The Safety Review of 900 MWe Pressurized Water Reactors Associated with their Third Ten-Yearly Outage, DSR REPORT No. 285, Paris.

The above 3 reports are treated as one PSR report for the purpose of this study.

Slovenia (Krško)

NEK (Nuklearna Elektrarna Krško), 2004, Nuclear Power Plant Krško Periodic Safety Review Project Summary Report, PSR-NEK-8.0, Rev. 0, Krško, Slovenia. 
South Korea (Kori 3 and 4, Uljin 3 and 4, and Yonggwang 3 and 4)1:

Ministry of Science and Technology, 2006, Kori 3 and 4 Periodic Safety Evaluation Assessment Results, Korea Institute of Nuclear Safety (KINS), S. Korea, Daejeon, March.

Ministry of Science and Technology, 2007, Yonggwang Units 3 \& 4 Periodic Safety Evaluation Assessment Results, Korea Institute of Nuclear Safety (KINS), S. Korea, Daejeon, June.

Ministry of Science and Technology, 2010, Uljin Units 3 \& 4 Periodic Safety Evaluation Assessment Results, Korea Institute of Nuclear Safety (KINS), S. Korea, Daejeon, April.

Spain (Almarez Units 1 and 2):

CSN (Consejo de Seguridad Nuclear), undated, Periodic Safety Review Report, Sections 4.2 and 5, Spanish Nuclear Safety Council.

Sweden (Oskarshamn 3):

SKI (Statens Kärnkraftinspektion), 2008, Study of OKG PLC's Periodic Overall Assessment of Security in Oskarshamn 3, SKI 2005/40, May 5.

Switzerland (Leibstadt and Mühleberg):

ENSI (Eidgenössisches Nuklearsicherheits-inspektorat), 2009, Report Concerning the Periodic Safety Review of the Leibstadt Nuclear Power Plant, ENSI 12/1300, Würenlingen, Switzerland, August 10.

HSK (Hauptabteilung für die Sicherheit der Kernanlagen), 2007, Safety Statement on the Periodical Safety Inspection of the Mühleberg Nuclear Power Station (KKM), HSK 11/1100, Würenlingen, Switzerland, November 12.

Taiwan (Chinshan Unit 1):

Taiwan Atomic Energy Council, 2009, The Third Ten-Year Overall Safety Assessment Review Report of Nuclear Power Plant 1, Unit 1, NRD-SER-98-03, New Taipei City, Taiwan, June.

United Kingdom (Sizewell):

Stationery Office, 2006, Sizewell B Nuclear Power Station: The Findings of NII's Assessment of British Energy's Periodic Safety Review, Health and Safety Executive, Norwich, U.K., June.

\subsection{Review Methodology}

Our review methodology of these documents consisted of the following four elements:

1 Korea Hydro and Nuclear Power (KHNP) Co., Ltd., changed the name of Uljin to 'Hanul' and Yonggwand to "Hanbit", according to requests from local residents. See: KHNP pres release No. 98, dated 2013.05.07, https://cms.khnp.co.kr/eng/changing-the-names-of-nuclear-power-plants-to-create-local-win-win-management-inpractice/. 
1. Review of the PSR reports for technical content, format, organization, and level of detail.

2. Analysis of the regulatory process employed for the country and plant reviewed and identification of practices similar to those used in the NRC regulatory process. For example, to what extent did the regulator invoke NRC guidance, including the CFR, regulatory guides, generic communications, NUREG-1800 and NUREG-1801 (NRC 2001a, 2005b, 2010c)? In addition, to what extent were U.S. industry standards invoked, including the ASME Code, ASTM International and American National Standards Institute (ANSI) standards, Electric Power Research Institute (EPRI) reports, and Nuclear Energy Institute (NEI) guidance documents? This review did not include a review of PSR information that may pertain to ASME OM code, although a cursory review did not indicate PSRs mentioning this aspect.

3. Identification of PSR observations that relate to the NRC's ROP cornerstones and performance indicators. The salient aspects of the ROP are provided below.

4. Identification of novel PSR assessment safety-related observations that potentially lie outside of U.S. practice and experience. These include the use of components, materials, and maintenance and inspection procedures that are not commonly employed and OpE events that have not been observed in this country. These observations may require further research for their potential applicability in the future development of modified or new guidance documents.

Our review method also noted the following as background for assessment:

- The NRC regulates the safe operation of commercial NPPs by mandating requirements for the design, construction, and maintenance and operation of such plants. It provides ongoing oversight of plant operations to verify that they are being performed in accordance with regulations. The NRC also establishes plant-specific technical specifications that the licensees must follow to ensure that the proper combination of safety-related equipment is available to safely shut down the plant in the event of an accident.

- The ROP is NRC's program to inspect, measure, and assess the safety performance of commercial NPPs, and to respond to any decline in performance. It reflects the NRC's strategic goals for safety, security, openness, and effectiveness. The mission of the ROP is to ensure public health and safety in the operation of commercial NPPs. This is achieved by monitoring plant performance in the following three areas:

1. Reactor Safety: avoiding accidents and reducing the consequences of accidents if they occur;

2. Radiation Safety: protecting both plant workers and the public from unnecessary radiation exposure during routine operations; and

3. Safeguards: protecting the plant against sabotage or other security threats.

- To monitor and measure plant performance, the ROP focuses on seven "cornerstone" areas that support the safety of plant operations in the above three key areas. These cornerstones are (1) initiating events; (2) mitigating systems; (3) barrier integrity, and (4) emergency preparedness, all of which support the reactor safety area; (5) occupational 
radiation safety, and (6) public radiation safety, both of which support the radiation safety area; and (7) physical protection, which supports the safeguards area. Our review also recognized that the licensee's meeting of each of these cornerstones is checked by monitoring established performance indicators (PIs) during plant operation and, therefore, we tried to identify and cross-check PSR observations to the respective PIs/cornerstones.

- The GALL Report contains the staff's generic evaluation of the existing plant programs and documents the technical basis for determining where existing programs are adequate without modification and where existing programs should be augmented for the period of extended operation.

The Argonne reviews of these documents emphasized IAEA safety factors 1 (plant design), 2 (actual condition of SSCs), 3 (equipment qualification), 4 (aging), 8 (safety performance), and 9 (use of experience from other plants and research findings), because these elements are most closely related to aging degradation and aging management. In addition, for each of the plants listed above, the reviews noted common areas of concern and compared OpE with the corresponding U.S. plant of similar design (as identified by Gavrilas et al. 2000). However, a caution in making this comparison is the possibility that the component equipment manufacturer and the manufacturing process may vary from plant to plant, thus limiting the value of such direct comparison. The information obtained from the reviews of these documents was supplemented with additional information from other sources, including websites and the technical literature.

\subsection{Results of the Review}

The detailed observations resulting from the reviews of the PSR assessment documentation for each of the plants considered are summarized in Appendix A. Because the PSR assessment documents provided for review varied in format, content, and level of detail, the information presented in these summaries likewise varies from one country to the next. Except for the U.K. document, the PSR assessment documents were English translations from the original language, and the contents were interpreted as translated. Depending upon the quality of these translations, the interpretations and conclusions could, in some cases, potentially differ from the original intent of the authors of the PSR assessment document and from the exact meaning with respect to the PSR reviews and assessments.

\subsection{Summary of Observations from a Review of PSR Assessments}

A total of 14 PSR documents from 9 countries were reviewed to identify potential new technical insights regarding license renewal-related topics and NPP OpE. It was noted that most of the countries reviewed base their regulatory guidance to at least some extent (and often to a large extent) on U.S. design codes and standards, NRC regulatory guidance, and U.S. industry guidance. For example, the ASME Code is cited in the PSR reports reviewed for Finland, Slovenia, South Korea, Switzerland, and Taiwan, and NRC guidance is referenced in the documents from Finland, Slovenia, South Korea, Sweden, Switzerland, and Taiwan. In addition, many of the operational technical safety issues and OpE events reported for U.S. reactors are also cited in the PSR reports.

As indicated in Table 1 in Section 1.2 above, the NRC's ROP plays a significant role in ensuring the continued safe operation of nuclear plants in this country, particularly with respect to 
assessing the current condition of systems, structures, and components (SSCs) and managing any degradation of operating performance (NRC 2006b). The objective of the ROP is to monitor reactor performance in three key areas, namely reactor safety, radiation safety, and safeguards. To monitor and measure plant performance, the oversight process focuses on seven "cornerstones" that support the safety of plant operations in the three key areas, as described in the previous section.

Our review of the PSRs or the PSR assessment reports also identified a number of technical operational experiences that are not cited in GALL. These include the failure of a steam isolation valve due to the weakening of permanent magnets, aging-related embrittlement of emergency diesel generator seals, the possible radiation-induced degradation of coatings inside containment, the aging-related management of fillers and sealants in safety-related watertight and blast-proof doors, and the use of greaseless fiber ceramic bearings. The PSR assessment reports also do not provide sufficient information on the assessment of safety significance of these experiences, and generally do not make explicit distinction between aging-related technical performance issues and component/equipment maintenance issues. Examples of the operational technical safety issues identified by PSRs that overlap the ROP cornerstones and others that are not cited in the NRC GALL Report are noted in the two subsections below.

\subsubsection{Example PSR Technical Issues that Have Been Observed at U.S. Plants of Similar Design}

The PSR reports describe a number of technical issues that have also been observed in U.S. plants of similar design, as described in item 2 of the Review Methodology (Section 2.2). Some of these issues, which are described in more detail in the PSR review summaries provided in Appendix $A$, are listed here in bullet format as follows:

\section{$\underline{\text { Reactor Pressure Vessel (RPV), Piping, and Vessel Internals }}$}

- Core shroud cracking is reported at Mühleberg (Switzerland).

- Primary water stress corrosion cracking (PWSCC) of Alloy 600 components is cited in the PSRs for the French 900-MWe reactors, Krško (Slovenia), Kori 3 and 4 and Yonggwang 3 and 4 (South Korea), Leibstadt (Switzerland), and Sizewell B (U.K.).

- Cracking of Ni-base alloy safe ends has been seen at Olkiluoto 1 and 2 (Finland) and Leibstadt.

- Reactor vessel head replacement is reported for Krško and Sizewell B.

- Boiling water reactor (BWR) recirculation piping replacement is reported for Olkiluoto 1 and 2, Oskarshamn 3 (Sweden), and Mühleberg.

Fuel and Cladding

- $\quad$ The Oskarshamn PSR notes that, during the period from 1995 through 2005, Oskarshamn 3 had more than 20 fuel element failures associated with cladding 
perforation. In one isolated case, this was due to pellet cladding interaction (PCI), but the main cause was abrasion by small metal fragments in the coolant.

\section{Water Chemistry}

- The Mühleberg PSR states that one open issue is the verification of the effectiveness of hydrogen water chemistry (HWC) and noble metal additions for protecting the RPV components. The goal of hydrogen-noble metal additions, first instituted in 2000, was to prevent the initiation of new cracks and to reduce the speed of propagation of existing cracks, but the original procedure did not appear to be effective. Mühleberg has used an altered procedure since the 2005 annual audit (OnLine-NobleChem) in order to achieve this goal; its effectiveness is currently being evaluated. Problems with the implementation of HWC and noble metal additions have also been observed at some U.S. plants.

- The Leibstadt PSR notes that since 1997 an elevated boron concentration in the coolant has been detected that was attributed to control rod damage due to washing out of the boron absorber material. Since then, more than 80 control rods have been replaced, returning the boron concentration in the reactor water to its original value. NRC Information Notice (IN) 2011-13 (NRC 2011e) notes that the control rod blade design at some U.S. plants is susceptible to cracking.

- The Olkiluoto PSR states that the primary coolant has, from time to time, contained more antimony-bearing alloys than in comparable plants and antimony-bearing alloys are being replaced in the primary circuit to reduce the background radiation level.

\section{Steam Generator (SG), Steam Dryer, and Turbine Issues}

- Steam generator replacement is underway for all 34 French 900-MWe plants and has been completed at Krško.

- Power uprates are reported for Olkiluoto 1 and 2, Kori 3 and 4, Almarez 1 and 2 (Spain), Oskarshamn 3, Leibstadt, Mühleberg, and Chin Shan 1 (Taiwan). Reported problems associated with these power uprates include steam turbine vibrations at Oskarshamn 3 and steam dryer vibrations at Leibstadt. Flow-induced vibration and cracking problems in steam dryers have also been reported for several U.S. plants after power uprates, including Quad Cities 1 and 2 and Dresden 2 and 3.

\section{$\underline{\text { Containment and Structures }}$}

- Concerns about containment sump strainer performance under severe-accident conditions is cited for all 34 French 900-MWe plants, with the sump strainers replaced, as well as for Kori 3 and 4, Ulchin 3 and 4, and Yonggwang 3 and 4.

- The need for improved seismic analyses of plant SSCs is cited in almost all of the PSRs. 


\section{Electrical Components}

- The Chin Shan PSR states that cables in the high-temperature areas of the buildings experienced accelerated thermal aging due to high temperature at reactor drywell and in the main steam tunnel. After the licensee took appropriate measures, the temperature in these areas decreased from $55^{\circ} \mathrm{C}$ to approximately $45^{\circ} \mathrm{C}$. The project also involved replacement of the susceptible cables with high-temperature-resistant silicone insulation cables.

\subsubsection{Example PSR Technical Issues that Merit Further Consideration for Future Regulatory Guidance}

The PSR reports also describe a number of technical issues that have not generally arisen for U.S. plants and may merit further consideration for future regulatory guidance, as described in item 4 of the Review Methodology (Section 2.2). A few issues are provided below as a few examples, with no preference for selecting as examples. For other issues and details on these issues, the reader is referred to the information provided in Appendix $A$, as follows:

\section{$\underline{\text { RPV, Piping, and Vessel Internals }}$}

- The Leibstadt PSR reported that limited tests on reactor vessel surveillance specimens have indicated that the ductility appeared to increase with radiation. The Swiss regulatory agency KKL determined that additional tests on unirradiated material are needed to clarify this unlikely finding.

- The Olkiluoto PSR report describes the failure of a steam line isolation valve because of time-dependent weakening of the permanent magnet used to hold it in the open position.

- The Kori PSR refers to the proactive preventive replacement of coolant pump "turning vane cap screws" and "diffuser adapter cap screws," based upon international industry experience.

- The Mühleberg PSR states that, on the basis of good international experience with fiber ceramic bearings without grease lubrication, the bearings of the main coolant pump $A$ and auxiliary coolant pump B at Mühleberg were converted to this type of bearing. Through this conversion and optimization of the lubrication intervals for the remaining pumps, the amount of grease discharged to the Aare River was reduced by 85 percent. The remaining pumps were to be converted in stages by 2008.

\section{$\underline{\text { Containment and Structures }}$}

- The Kori PSR refers to a need to develop a long-term plan to monitor the radiation-induced degradation of protective coatings inside containment. Such degraded coatings could potentially contribute to containment sump strainer clogging in the event of a severe accident.

- The Kori PSR report mentions a need to develop a monitoring program to evaluate the possible degradation of subsurface concrete structures and subsurface concrete piping. 
- The Ulchin and Yonggwang PSRs noted a need to develop a plan to increase the reliability of the Schmidt Hammer test for determining the compressive strength of concrete.

- The Yonggwang PSR noted the need to develop a plan to periodically maintain and manage the filler and sealants in safety-related watertight doors and blast-proof doors.

\section{Electrical Components}

- The Krško PSR states that the licensee measures should be taken to ensure the long-term integrity of hermetic seals on instrumentation and other electrical equipment.

- The Sizewell PSR found that parts of the station grounding system are not normally accessible and the licensee had no plans to inspect them. The British regulators found that the integrity of the grounding system is important to the electrical protection equipment, and the licensee was required to expand the scope of the inspections to include the locations in question.

\section{Plant Cooling and Safety}

- The Olkilouto PSR describes problems with the formation of frazil ice as a result of the sudden freezing of super-cooled seawater (the ultimate heat sink) under severe winter conditions.

- The Olkilouto PSR states that aging embrittlement was detected in some emergency diesel generator seals. If allowed to continue, this could have prevented the simultaneous startup of several diesel generators.

- The Yonggwang PSR stated the need to develop a plan to examine the corrosion status of reinforcing rod in the seawater intake structures for equipment cooling water.

- The Krško PSR states that differential movements at building interfaces due to thermal, loss of coolant accident (LOCA), and seismic effects should be reviewed to assess their possible effects on safety related piping.

\section{$\underline{\text { Other }}$}

- The Sizewell PSR identified coastal erosion near the plant as an issue that needed to be addressed, and a steering group was set up to oversee the various inspections and surveys that are undertaken on coastal erosion.

- The Oskarshamn PSR states that, in its future analysis, the licensee has identified several areas for improvement in order to ensure continuing compliance with regulatory requirements. One of these areas is to expand their aging management program to include the management of active components. 


\section{SECTION 3}

\section{SUMMARY}

This technical letter report entitled "Technical Letter Report: Evaluation and Analysis of a Few International Periodic Safety Review Summary Reports," contains detailed technical information of the results of a review conducted of several international periodic safety review assessment documents and provides detailed comparison with current U.S. practice. This information will enable NRC staff to extract the lessons learned from PSRs performed in other countries and may consider relevant aspects as potential input to the NRC's assessment processes in the future. A total of 14 PSR evaluation summary reports from nine countries have been reviewed, and the review results for each summary document are summarized in Appendix A. Each review report includes a list of specific issues with potential significance to aging management during LTO.

Brief descriptions are presented of the IAEA PSR process and the U.S. license renewal and reactor oversight processes that are used to ensure that the licensing basis of all currently operating plants provides and maintains an acceptable level of safety so that operation will not be inimical to public health and safety or common defense and security. The U.S. license renewal review process is focused on mitigation of the detrimental effect of aging-related degradation of passive long-lived SSCs that are safety significant, or non-safety SSCs that could affect the safety significant SSCs, or for specific event mitigation. In some instances the guidance recommended in the aging management programs in the NRC GALL Report have also been used in the PSR process of foreign plants. A detailed comparison of the two approaches was conducted to establish the strengths of each process and identify potential differences or gaps between the two approaches. The comparison was based on six of the 14 IAEA safety factors (or elements) that are closely related to aging degradation and aging management.

A review and assessment of the PSR summary documents and related IAEA safety guides resulted in several new technical material/component performance issues and insights or considerations that could potentially enhance existing license renewal guidance for LTO. A summary of these technical insights is presented along with the principal common aspects of the PSR approach. The summary reflects lessons learned and key observations within each of the six groups of IAEA safety factors. A sample of OpE and licensee/regulatory action items is also included. Specific potentially new technical issues and considerations for LTO are provided in the areas of plant design, aging degradation and management, safety analyses, and performance and feedback from OpE. The assessment of the PSR summary reports also identified several potential aging effects and degradation mechanisms that are not currently covered in the GALL Report. 


\section{APPENDIX A}

\section{SUMMARIES OF OBSERVATIONS FROM PSR REVIEWS}

\section{A.1 Finland (Olkiluoto Units 1 and 2)}

The Finnish Olkiluoto Units 1 and 2 nuclear power plants (NPPs) are boiling water reactors (BWRs) of the ASEA-Atom BWR 75 design, and each are rated at $860 \mathrm{MWe}$. Unit 1 was commissioned in October 1979 and Unit 2 in July 1982. The plants are located in Eurajoki, Finland, and are operated by the Industrial Power Corporation, or Teollisuuden Voima Oyj (TVO). The Finnish Radiation and Nuclear Safety Authority, or Säteilyturvakeskus Strålsäkerhetscentralen (STUK), conducted a periodic safety review (PSR) assessment of these plants for the period from 1999 to 2008, and the results are presented in their report STUK-B 111 (STUK 2010), which is listed in Section 2.1 above.

The STUK report provides a summary of the reviews, inspections, and continuous oversight carried out by STUK as a part of this safety review, as well as the conclusions reached regarding the extension of the plant's operating license for the next 10-year period. The major sections of the report contain information on (1) overall plant safety, including transient and accident analysis, probabilistic risk analysis, and aging management; (2) radiation exposure and release; (3) plant systems safety, including fuel integrity, cooling circuit integrity, containment, and protections and internal and external events; (4) plant operations and maintenance, including operating experience (OpE); (5) organization and personnel; (6) physical protection and security; (7) emergency response and preparedness; (8) nuclear waste management; and (9) nuclear materials safeguards.

\section{A.1.1 Plant Modifications}

Power Uprates: The STUK report mentions power uprates for Olkiluoto 1 and 2 but provides few details. Other references indicate that the first power uprate for both units, from the initial 660-MWe design to $710 \mathrm{MWe}$, took place during 1983-1984. An additional uprate up to 840 MWe was accomplished during the 1994-1998 modernization projects. This modernization included the installation of new low-pressure turbines and modifications to the high-pressure turbines, new steam separators, and modifications to the condensate and feedwater pumps as well as the preheaters. In May-June 2010, Olkiluoto 1 completed plant modifications to achieve an additional 20-MWe power uprate. The most significant modification was the replacement of the low-pressure turbine to increase plant efficiency by about 1 percent. Other modifications included (1) installation of a new generator cooling water system in preparation for future replacement of the generator's water-cooled stator and rotor; (2) modernization of four $8-\mathrm{m}^{3} / \mathrm{s}$ seawater pumps; (3) replacement of carbon steel extraction pipes that carry steam from the low pressure turbine to the condensate pre-heaters with stainless steel piping; and (4) replacement of inner main steam line isolation valves inside containment (Nuclear Engineering International 2011a; TVO 2010).

Recirculation Piping Intergranular Stress Corrosion Cracking (IGSCC): Because of the occurrence of IGSCC in portions of the stainless steel recirculation loop piping, during the 
1980s, more than 200 m of piping were replaced in both units using a more resistant low-carbon nuclear grade stainless steel (STUK 2010, Section 4.3.2).

Major Component Replacement: The steam dryers were replaced during 2005-2006 in order to reduce the humidity content and the resulting dispersion of radioactivity, and the feedwater manifolds displaying thermally induced cracking were replaced during 2004-2005. (STUK 2010, Section 2.3).

\section{A.1.2 Improvements and Enhancements}

The STUK-B 111 report (STUK 2010) states that the following enhancements have been implemented at Olkiluoto Units 1 and 2 in the past 10 years, or will be implemented because of the PSF findings. Improvements and enhancements related to aging management are discussed in the next section.

1. The risk of fire spreading in the cable spaces will be mitigated by the modifications in progress where the nozzles of the sprinkler system are replaced with new, faster-operating nozzles. The efficiency of the fire extinguishing system will also be improved by revising the layout of the nozzles (STUK 2010, Section 2.1.3).

2. Significant modification work planned for the electrical equipment includes the replacement of low-voltage switchgear, as well as improvement of the overvoltage protection of electrical drives of reactor coolant pumps, the possible replacement of these electrical drives over the longer term, and the replacement of cabling inside the containment (STUK 2010, Section 2.3).

3. TVO has carried out modifications at both plant units in order to improve the earthquake resistance of safety-classified electrical cabinets and battery banks by upgrading their mechanical supports (STUK 2010, Section 2.4).

4. STUK found that TVO must produce a plan regarding necessary modifications to improve the overvoltage resistance of reactor coolant pumps. TVO delivered the plan to STUK in September 2009. (STUK 2010, Section 4.4)

5. Severe accidents were not taken into account in the original containment design. TVO has made modifications to improve the ability to control severe accidents. The key safety functions in place are primary circuit pressure reduction, cooling of core melt in the lower dry well, and the controlled reduction of containment pressure (STUK 2010, Section 4.4).

6. STUK determined that TVO must implement plant modifications for improving safety in a situation where the turbine bypass valves suddenly and unnecessarily open (STUK 2010, Section 4.8).

7. Modernization of the radiation monitoring systems is being implemented. The largest project started in 2006 consists of the modernization of the plants' 550 fixed radiation monitors. As part of this project, the radiation monitoring systems are being assessed and modernized into a digital instrumentation and control (I\&C) system, if necessary. This will improve the reactor scram function and the containment isolation function in the event of significant nuclear fuel damage (STUK 2010, Section 5.5). 
8. TVO assessed the safety of the spent nuclear fuel interim storage in 2002 . The assessment resulted in the preparation of a condition-monitoring program for the roof girders of the interim storage for spent fuel, a revision of the spent fuel transport cask handling procedures and improving the flood prevention system. Some improvements in the fuel transfer machine's operation have been implemented, but, according to the plan, the actual modernization of the machine will take place at the end of the current operating license period (STUK 2010, Section 9.2).

9. STUK required TVO to draw up a plan on long-term modifications needs to improve the surge protection of the main coolant pump drives. TVO submitted a plan to STUK in September 2009 and STUK has initiated the document review process (STUK 2010, Section 12.1).

10. During the current operating license period, TVO implemented plant modifications that will ensure the quick detection of floods and shutdown of seawater pumps to reduce the likelihood of major flooding of seawater systems in the turbine hall and in the coolant water intake building (STUK 2010, Section 2.1.3).

11. During the operating license period, it was determined that the impulse lines, important to safety, may freeze if the ventilation intake air heating fails when the outside temperature is well below freezing. The risk of impulse lines freezing was substantially reduced through modifications to the plant and procedures (STUK 2010, Section 2.1.3).

12. Plant modifications were carried out to reduce earthquake damage susceptibility, including providing better support for safety-critical electrical equipment. In addition, the main control room was provided with capabilities to cancel unnecessary protection functions activated because of earthquakes (STUK 2010, Section 2.1.3).

13. During the current operating license period, TVO has provided all working shifts with training on the flooding of the lower drywell and has reinforced the access opening of the lower drywell for the eventuality of a steam explosion. In addition, modifications reducing the probability of severe accidents have been carried out, such as reducing the risk of dropping heavy loads during lifts taking place above the fuel pools or the reactor (STUK 2010, Section 2.1.3).

14. The reheaters, 6.6-kV switchgear, and I\&C equipment for the turbine plant and the reactor steam dryers were replaced (STUK 2010, Chapter 2.3, Section 5).

15. Major modifications in the electrical systems during the current operating license period included the basic overhaul of a $400-\mathrm{kV}$ switchgear, upgrades of $6.6-\mathrm{kV}$ equipment, drawing of cable connections for the new gas turbine plant, replacement of rotations per minute (RPM) control equipment of the diesel generators, replacements of aged contactor output contacts, the commissioning of new uninterruptible power supply (UPS) equipment, and the commissioning of new rectifiers. Significant modification work planned for the electrical equipment includes the replacement of low-voltage switchgear, improvement of the overvoltage protection of electrical drives of reactor coolant pumps, and the possible replacement of these electrical drives over the longer term and the replacement of cabling inside the containment (STUK 2010, Section 2.3). 
16. Certain I\&C systems have been replaced during the current operating license period. These include the computerized metering system, the control and position indication systems of reactor control and shutdown elements, the process measurement data logging system, and the process automation system of the turbine plant. The computer systems for process control and certain other monitoring systems have also been upgraded (STUK 2010, Section 2.3).

17. Significant aging-related modifications to buildings during the current license period included the repair of a leak in the condensate pool lining of Unit 1, replacement of expansion joint gaskets in the containment partition floor, reopening of the expansion joint between the containment and reactor building in Unit 2 after it had come into contact with the concrete as a result of concrete creep and relaxation of pre-stressed steel reinforcements, and the cathodic protection of seawater structures against chloride-induced corrosion (STUK 2010, Section 2.3).

18. In 1988 and 1989, new blowdown lines fitted with filters were installed in both units for blowing out steam and non-condensed gases from the containment, thus preventing uncontrolled over-pressurization (STUK 2010, Section 3.4).

19. Because elevated temperature contributes to the decomposition of condensate filters, the temperature of water entering the condensate cleaning filters was reduced by changing the location of the condensate system pre-heater. This modification took place at Unit 2 in 2003 and at Unit 1 in 2004 and resulted in better control of sulfate levels in the reactor coolant (STUK 2010, Section 4.3.3).

20. To facilitate the reduction of primary circuit pressure in the event of a severe accident, two relief valves providing this function were modified in 1999 to permit them to be kept open with pressurized nitrogen through actions taken from outside the containment building (STUK 2010, Section 4.3.4).

21. TVO agreed to implement an upgraded emergency control room in two stages. In the first stage, the functions available in the current emergency control room are to be implemented in the new, separate emergency control room. The necessary modifications and required equipment installations would be completed during 2011-2014. The second stage, related to the upgrade of reactor operation and protection automation, would take place during 2016-2019 (STUK 2010, Section 4.8).

\section{A.1.3 Aging Degradation and Management}

Finnish regulatory requirements state that a nuclear power plant must have an aging management program comprising the design and qualification of components and structures, their operation and $\mathrm{OpE}$, inservice inspections and periodic tests, and maintenance. The program is to identify all significant aging and wear mechanisms, and potential degradation owing to aging. The periodic safety review assesses the experience of the facility aging and aging management.

The licensee's aging management program covers all plant systems. When determining monitoring procedures, factors taken into account include the applicable regulatory 
requirements, safety class, maintenance class, probabilistic risk analysis (PRA), known aging phenomena, OpE, and the ability to repair or replace the aged component. The monitoring procedures include leak test and online monitoring as well as periodic inspections and tests and preventive maintenance programs. The report cited a number of examples of component replacement and modernization activities as a part of the overall aging management program. These activities encompassed the mechanical, electrical, instrumentation, and structural systems of the plant. STUK found that aging management at the Olkiluoto has been implemented in conformance with regulatory requirements. However, certain operating events have occurred in recent years where inadequate aging management has been the main cause or a contributing factor. STUK will continue to monitor these trends.

\section{A.1.3.1 Nuclear Fuels}

Fuel Integrity: Corrosion of the fuel cladding is managed by maintaining the coolant water chemistry in conformance with Electric Power Research Institute (EPRI) guidelines. Maintenance of fuel integrity during power level changes associated with reactor normal operation is ensured by limitations on the rate at which reactor power can be adjusted. Limits have been set during normal operation for the linear power of fuel rods and the so-called dry out factor. The number of fuel damage occurrences during normal operation has remained small at Olkiluoto Units 1 and 2.

The maintenance of fuel integrity during anticipated operational transients and postulated accident situations is demonstrated using computational analyses and the safety-critical limit values for normal operation. In conjunction with the PSR, TVO has revised the analyses for operational transient and accident situations, taking into account the plant modifications carried out during the operating license period and the development of programs used for the calculations. The events analyzed are the unnecessary closure of turbine control valves, loss of offsite power and failure in switching to house load operation, as well as the unnecessary triggering of the reactor protection system condition (shutdown of primary coolant pumps). The conclusion is that the integrity of fuel at the Olkiluoto Units 1 and 2 has been ensured in conformance with regulatory requirements, and STUK did not identify any follow-on actions.

Fuel Handing and Storage: In 2009, TVO was found to be in violation of STUK guidelines when it failed to submit required inspection report information before the manufacture of fuel was initiated, and corrective actions were undertaken by TVO. In order to verify criticality safety during refueling operations, TVO submits to STUK, for its approval, a reactor refueling application providing, among other information, the layout of fuel rods in the reactor (loading pattern) and the analyses to be performed during the refueling operation to demonstrate criticality safety. Other than the inspection report violation noted above, STUK found Olkiluoto in compliance with regulatory requirements.

\section{A.1.3.2 Mechanical Systems}

Pipe Cracking: Piping degradation was experienced relatively early in the operation of the plant for primary coolant circuit piping due to IGSCC. More than $200 \mathrm{~m}$ of piping was replaced with low-carbon nuclear grade steel of unspecified type. More recently, IGSCC indications were being detected in nickel-base safe ends and welds, and preparations have been made for possible replacement of the affected components. Overall, STUK finds Olkiluoto in compliance with its requirements in this area. 
Main Steam Line Isolation Valves: A major project initiated with respect to functional equipment is the replacement of inner isolation valves in the main steam line in response to the increased flow rate of steam brought about by the recent power uprates. One of the valves currently in use closed in 2006 as a result of a higher than normal flow rate after the other isolation valve had closed by itself because the permanent magnet keeping it open had grown weaker.

Water Chemistry: Coolant water chemistry is maintained in accordance with EPRI guidelines. Sulfates released from ion exchange resins were a problem early in plant life, but this situation appears to have been largely corrected. A turbine condenser leak in 2004 resulted in excessive chloride levels, but this situation was also corrected. Several fuel bundle leaks have occurred during the most recent operating period, resulting in slight increases in coolant radioactivity. All of the above excursions were judged by STUK to be minor, and Olkiluoto was found to be in overall conformance with regulatory requirements.

Strength Analysis: The strength analyses for Class 1 pressure boundary components were found to generally conform to regulatory requirements. In the case of the fatigue analysis, the TVO elected to follow the guidance of NRC Regulatory Guide 1.207 in taking environmental effects into account for the main feedwater piping and certain associated auxiliary systems, even though this guidance applies to only new plants in the U.S. This represented a departure from current Finnish regulatory standards, but the approach was determined to be an acceptable alternative.

Condition Monitoring and Maintenance: In addition to its preventive maintenance program, TVO monitors systems, components, and facilities during normal operation and daily inspections. Some of the most critical components, such as reactor coolant pumps and turbines, are equipped with continuous online condition monitoring systems. Inspections concerning the operability and the condition of components are also carried out as required on the basis of the accumulated OpE. STUK found this program to conform to regulatory requirements.

The condition of pressure-boundary components is assessed by means of inservice inspections performed during outages at regular intervals using non-destructive examination (NDE) methods governed by STUK regulatory requirements. A risk-informed inservice inspection procedure is being developed, and inspection procedures and schedules will be optimized on the basis of risk-informed methods when the next inspection period programs are developed. In addition, physical inspections concerning the condition and reliability of pressure equipment are performed at regular intervals in accordance with the requirements of Finnish pressure equipment legislation. STUK found this program to conform to regulatory requirements.

Qualification of Structures, Systems, and Components: STUK requires that NPPs have systematic procedures for qualifying equipment and structures important to safety and for maintaining the documentation current, demonstrating qualification. This qualification is to ensure that the equipment and structures are capable of performing their intended functions during design-basis operating conditions and accidents, with a sufficient margin. These requirements apply to mechanical as well as electrical and instrumentation and control systems and components. STUK found TVO's qualification procedures to be generally adequate. However, qualification information still needs to be developed for certain electrical and I\&C components, as well as for special components like pneumatic actuators, that have unique operational requirements under conditions, such as during or after transients and accidents. 


\section{A.1.3.3 Structural Systems}

Containment Integrity: Structures at Olkiluoto Units 1 and 2, including containment, are subjected to periodic inspections, and the lengths of cracks in the concrete containment are monitored. TVO replaced the expansion joint gaskets in the containment partition floor during 2005-2006. The material and construction of the gaskets was also altered so that they can withstand larger movements and higher temperatures. In addition, the rubber bellows in the expansion joint of the transport shaft were replaced with bellows having better material properties. Severe accidents were not taken into account in the original design of the Olkiluoto containment, and several modifications have been made to address this initial deficiency. Following these modifications, STUK found that steam explosions and the behavior of iodine in the containment remained key issues for Olkiluoto, and these issues have been subsequently addressed. In the present review, STUK found that containment integrity meets regulatory requirements.

\section{A.1.3.4 Electrical Systems}

(See paragraph on Qualification of Structures, Systems and Components in Section A.1.3.2 on Mechanical Systems above. See also items 2, 3, 7, 12, 14, 15, and 16 in Section A.1.2.)

\section{A.1.3.5 Auxiliary Systems}

Handling, Storage, and Disposal of Nuclear Waste: In general, reactor waste is taken care of at the Olkiluoto plant site, including its final disposal. No significant safety-related problems have emerged in the management of intermediate and low-level waste generated during the operation of the Olkiluoto NPP the current operating license period. At the end of 2008, there was approximately $6,240 \mathrm{~m}^{3}$ of intermediate and low-level waste. Approximately 80 percent of the waste has been finally disposed. The total activity, excluding activated metal waste, was approximately $73 \mathrm{TBq}$. Processing of low-level and intermediate level waste has been developed during the current operational license period. The final repository for radioactive waste was commissioned in 1992, and it has a separate operating license that is valid until the end of 2055. A periodic safety review took place in 2006. STUK found this program to conform to regulatory requirements.

Processing, Storage, and Disposal of Spent Nuclear Fuel: Spent fuel from Olkiluoto is retained in storage pools in the plant until it can be disposed of at the disposal facility constructed by Posiva Oy. At the end of 2008, there was approximately 1,225 metric tons of uranium (tU) of spent nuclear fuel at Olkiluoto, not including the fuel inside the reactors. The interim storage contained approximately $995 \mathrm{tU}$ of spent fuel. The interim storage is sized to accommodate spent fuel resulting from about 30 years of operation. According to TVO's estimate, the interim storage will have to be expanded by 2014. TVO assessed the safety of the spent nuclear fuel interim storage in 2002. During the present operating license period, cracks were observed at the bottom surface of the reinforced concrete roof girders of the interim storage facility. A structural analysis verified that the roof structures meet durability requirements, but TVO decided to support the roof by installing steel trusses in 2004. Olkiluoto also has spent fuel condition monitoring programs in place. The permanent spent fuel disposal facility at Posiva Oy will apply for a construction license in 2012 and an operating license in 2018, and the disposal 
of spent nuclear fuel could begin by 2020 . STUK found this program to conform to regulatory requirements.

\section{A.1.4 Plant Safety}

\section{A.1.4.1 Safety Analyses}

Transient and Accident Analysis: The required analyses were generally performed in accordance with regulatory requirements. However, the loss-of-coolant accident analyses did not conform to the most recent requirements that at least two emergency cooling system trains always be available in the event of a loss-of-coolant accident. TVO agreed to present a plan to submit an updated analysis by December 31, 2009.

Probabilistic Risk Analysis (PRA): Level 1 PRA was applied to initiating events for significant core damage, flood risks, weather phenomena and other external events, fire risks, and earthquakes. Level 2 PRA was applied to a number of other lesser risk events. STUK found that the loss of off-site power remains the most significant initiating event from risk perspective. STUK required TVO to submit, in conjunction with the PSR, a report on measures for reducing the risk caused by the loss of off-site power, as well as an action plan required for reducing this risk. In addition, STUK required TVO to submit a report on factors related to core damage risk resulting from shutdowns, as well as a report on the risks associated with oil spills. Overall, STUK found that TVO has justified the plant safety and provided safety-engineering solutions in accordance with regulatory requirements.

Safety Classification: The purpose of safety classification is to ensure that the quality level applied to the design, manufacture, installation, commissioning, and operation of systems, structures, and components (SSCs) important to safety, as well as required assessments, inspections and tests, are consistent with the safety significance of those items. STUK found TVO in compliance with applicable regulatory requirements.

Residual Heat Removal: STUK determined that there are no diverse systems in case of a loss of ultimate heat sink or a common cause failure in the systems of the Olkiluoto Units 1 and 2 used to remove residual heat and concluded that they have not been designed in compliance with the diversity principle. STUK therefore imposed the requirement that TVO shall submit to STUK for approval a comprehensive survey on the sufficiency of diversity at the Olkiluoto 1 and 2 NPP units and a plan on measures to develop diverse systems by the end of 2010.

Ultimate Heat Sink: Provisions have been made for the eventuality of seawater systems (the ultimate heat sink) from becoming blocked. These provisions consist of alternative water supply arrangements. The plant also seeks to prevent the formation of frazil ice because of super-cooled seawater suddenly freezing by channeling warm condensate water into the seawater intake opening.

Management of Human Factors: The protection systems of the Olkiluoto 1 and 2 have been designed on the basis of the "30-minute rule." This rule requires that in transient or accident situations, the operating personnel do not have to take any controlling action within the first 30 minutes because the plant safety systems automatically bring the plant to a safe state. This prevents any human errors made under time pressure and stress. The Olkiluoto human factors program also includes the use of documented plans and procedures, a reporting system for 
errors and "close calls," training classes, a work order system, control room shift management, and initiatives to combat worker fatigue that could contribute to human errors. STUK found TVO's human factors program to conform to regulatory guidance, and it continues to oversee the program through its periodic inspections.

\section{A.1.4.2 Radiation Safety}

Radiation Monitoring: Olkiluoto employs continuously operating online radiation monitoring systems for external radiation of the plants and their associated activities. In addition to fixed installed radiation and radioactivity measuring systems, there are several portable radiation monitoring devices. As part of a modernization project started in 2006 , the radiation monitoring systems are being assessed and modernized into a digital I\&C system, if necessary. In accordance with new requirements from STUK, stack iodine and particle monitoring will be implemented using continuously operated online radiation monitoring in addition to sampling and laboratory analyses.

The potential migration of radioactive materials into the surrounding environment is being continuously monitored by analyzing the radionuclide concentrations in food items produced in the area surrounding the plant, as well as in other samples. Samples include milk, meat, fish, crops, and vegetables, as well as water and airborne aerosols. The radioactive releases from the Olkiluoto nuclear power plant have been well below regulatory and plant technical specification limits. The radioactive constituents originating from the Chernobyl accident have been predominant in the environmental samples taken by Olkiluoto. STUK found this program to conform to regulatory requirements.

Radiation Safety of Plant Workers: Finnish regulatory requirements mandate the application of the as low as reasonably achievable (ALARA) principle, and the effective radiation dose for plant workers should not exceed an average of 20 millisieverts (mSv) per year accumulated over a period of 5 years, or $50 \mathrm{mSv}$ in any single year. Olkiluoto radiation limits are even tighter, with the worker dose not to exceed $10 \mathrm{mSv}$ per year and the ingestion dose not to exceed $0.5 \mathrm{mSv}$ per year. The highest individual radiation dose received by any employee at Olkiluoto in 2008 was $8.1 \mathrm{mSv}$. Regarding radiation sources, the primary coolant in Olkiluoto has, from time to time, contained more antimony than in comparable Swedish plants. As a result, TVO will replace antimony-bearing alloys in the primary circuit with new low-antimony-content alloys. Overall, STUK found the TVO radiation safety program satisfactory.

Radiation Safety of General Population: Finnish regulatory requirements limit the radiation dose resulting from the operation of a NPP to no more than $0.1 \mathrm{mSV}$ per year for the general population. STUK estimates that the radiation exposure from Olkiluoto to the population of approximately 500,000 living within a $100-\mathrm{km}$ radius of the plant is about one-hundred-thousandth of the radiation exposure from naturally occurring background radiation and medical use of radiation sources. STUK found the Olkiluoto radiation program to conform to regulatory requirements.

Radiation Limits for an Anticipated Operational (Transient) Occurrence: The Finnish regulatory limit for the annual dose as the result of an anticipated operational occurrence is $0.1 \mathrm{mSv}$ for an individual. Analysis of the postulated operational transients at Olkiluoto indicates that no significant releases of radioactive substances are anticipated because the fuel will not be 
damaged. Any releases into the environment would only consist of the radioactive constituents normally present in the primary circuit water or purification systems, and the plant systems are capable of efficiently containing these radioactive substances.

Radiation Limits for an Accident: Finnish regulations limit the annual dose to $1 \mathrm{mSv}$ for Class 1 postulated accidents, $5 \mathrm{mSv}$ for Class 2 postulated accidents, and $20 \mathrm{mSv}$ for a "design extension condition" for an individual as a result of an accident. The most severe postulate Class 1 accident (expected frequency of once in every 100 to 1,000 years) is a fire involving solid waste containing ion exchange resin in the waste building of the plant unit. This is estimated to cause a maximum dose of $0.024 \mathrm{mSv}$. Of the postulated Class 2 accidents (occurring no more than once every 1,000 years), the most significant releases result from a scenario where a transfer vessel full of fuel is dropped in the reactor building, resulting in a maximum dose of $2.2 \mathrm{mSv}$ to the general population. A second scenario is one in which a fuel channel in the reactor becomes totally blocked, resulting in the partial meltdown of one fuel bundle. This is estimated to cause a maximum dose of $2.0 \mathrm{mSv}$ to the general population. No "design extension condition" resulting in severe fuel damage was identified for Olkiluoto.

\section{A.1.4.3 Accident Prevention and Mitigation}

Plant Siting: A formal emergency plan is in place for alerting and, if necessary, evacuating the population from the regions surrounding the Olkiluoto plants in the event of a severe accident. STUK has determined that the TVO plant siting and emergency preparedness plans meet regulatory requirements.

Accident Prevention and Mitigation: The safety systems built into the reactor design are periodically updated by TVO, and STUK judged these systems to meet their accident prevention and mitigation requirements.

Ensuring Safety Functions: STUK states that the most important safety functions of a nuclear power plant are (1) reactor shutdown; (2) residual heat removal from the reactor to the ultimate heat sink; and, (3) functioning of the containment building. In 2008, an overvoltage transient at Olkiluoto 1 resulted in the stoppage of all six reactor coolant pumps. The reactor was running at 60 percent power at the time and no fuel damage occurred. TVO carried out modifications to protect the coolant pumps from future overvoltage events, but STUK found that additional measures were required, and TVO has submitted a plan for carrying out these measures. STUK found in the present audit that Olkiluoto meets the regulatory requirement in this area, subject to the completion of further modifications related to overvoltage events and to improving the diversity (probably means redundancy) of certain safety system functions.

Protection against External Events: External events to be accounted for include exceptional weather conditions, seismic events, airplane crashes, and other factors resulting from the environment or human activity. TVO analyses indicate that the most significant external events include a storm with a simultaneous loss of offsite power, mussels breaking the internal walls of the seawater channels to the plant, deposits of algae blocking the seawater intake channels, and simultaneous high levels of seawater and ambient temperature. Other concerns, all related to severe winter weather conditions, include freezing of the impulse lines and freezing of the seawater systems and consequent partial or complete loss of the ultimate heat sink. Modifications were undertaken to address the above concerns and to improve protection against seismic events. STUK found Olkiluoto to be in compliance, except that a plan still 
needs to be developed for dealing with an oil spillage event from shipping in the bay near the plant.

Protection from Internal Events: Internal events to be considered include fire, flood, explosion, pipe breaks, container breakages, missiles, falling of heavy objects, and component failures. The fire protection system at Olkiluoto did not initially meet STUK guidelines, and a number of upgrades were undertaken. In this latest assessment, STUK found that fire protection has improved, but compartmentalization of safety systems and insufficient structural fire resistance remain issues. TVO is presently addressing the fire safety of cable rooms. Plant modifications were also made to address potential problems related to flooding of the cooling water intake building and turbine hall. With the exception of the need for further improvements in fire protection, STUK found Olkiluoto to comply with its requirements in this area.

Plant Monitoring and Control: In 2000, TVO drew up a general plan regarding the development of control rooms at Olkiluoto, based on the Human-Machine Interface (HMI) engineering approach. STUK found that the planning and implementation of control room modification work should be further specified and updated, and TVO submitted a plan in April 2009. STUK also required TVO to submit a report concerning the risks associated with the current startup and shutdown procedures with regard to reactor water level swelling and entry of water into the steam pipes. In addition, STUK required TVO to revise and assess its action plans to implement a limited emergency control room function during the current operating license period. TVO responded with a two-stage plan under which an emergency control room with the functions currently available in the main control room will be completed during 2011-2014. In the second stage of the plan, both the main and emergency control rooms will be upgraded during 2016-2019. TVO must also implement plant modifications for improving safety in a situation where the turbine bypass valves suddenly and inadvertently open. Taking into account the TVO actions noted above, STUK found Olkiluoto to comply with its regulatory requirements.

\section{A.1.4.4 Emergency Response}

Emergency Operating Procedures: STUK states in the report that current best practices require procedure-specific justifying documentation for emergency operating procedures that include the procedure strategy, assumptions used when drawing up the technical features of procedure, references to analyses made when drawing up the procedure, and other background information related to the procedure. Procedure verification and validation must be implemented in a systematic and comprehensive manner. The validation must be documented and assessed to ensure that the procedures are functional. STUK directed TVO to submit by November 30, 2009, a comparison of the emergency operating procedures for Olkiluoto Units 1 , 2 , and 3. The strategy and justification documentation for these procedures, a report on the adequacy of validation, and any plan on validating the procedures are to be submitted to STUK for information by October 31, 2010. STUK further determined that TVO must assess the need to develop other emergency operating procedures (including design extension conditions, severe accidents, and shutdown states) as well as draw up further plans for developing the procedures by the end of 2011. The general emergency operating procedure, the related procedures, the strategy/justification documentation for outage procedures, and validation of the procedures are to be completed by the end of 2012.

Emergency Response Planning and Organization: Olkiluoto's emergency response arrangements and procedures are designed to ensure the safety of personnel by planning on 
how they will be warned and extra personnel will be evacuated from the power plant area, including the Olkiluoto 3 power plant unit construction site, in the event of a severe accident. A person responsible for emergency response arrangements and his deputy have been appointed for Olkiluoto, and the emergency response organization is described in the emergency plan and procedures, updated with regard to personnel changes and contact information approximately once a year.

Emergency Preparedness: Provisions have been made at Olkiluoto for performing the measures required in an emergency and for analyzing its effects and assessing its development. Instrumentation of the weather mast monitoring system was upgraded in the autumn of 2008. The management of the Olkiluoto emergency response organization has facilities in both plant units, and a backup facility is located in the plant's air raid shelter.

Maintenance of Preparedness: Emergency response training and exercises are conducted annually by the Olkiluoto emergency response organization. The emergency response facilities and systems are maintained in operational order by the preventive maintenance system, and the emergency response plan is updated whenever necessary, but at least once per year.

Emergency Actions: The Olkiluoto control rooms are in constant readiness to initiate emergency operations. The shift supervisor serves as the temporary emergency manager until the appointed emergency manager assumes responsibility for managing the situation. The emergency response plan contains a description of the emergency response organization at the initial stage of its operation as well as of the actual emergency organization, along with the related job descriptions. The plant emergency manager's procedures include providing recommendations on rescue measures until STUK assumes this responsibility.

Rescue Operations: Finland's Rescue Act includes planning obligations required for catastrophes for Olkiluoto 1 and 2 and their surroundings. The regional rescue authorities have procedures in place for accidents, and the environmental rescue plan for a radiation accident was updated on July 25, 2007. Emergency operating procedures have been distributed to the population in the emergency planning zone, and iodine tablets were distributed to the population in the protective zone in 2009.

\section{A.1.4.5 Physical Protection}

Responsibility and Control: Under Finnish law, the licensee is unambiguously responsible for the safety of the NPP. However, the police and other authorities providing assistance to the licensee as required also have legal obligations to secure safety in the event of various unlawful circumstances, including acts of terrorism. STUK also acts as the regulatory authority for physical protection of nuclear facilities. STUK's assessment of the Olkiluoto safety plan determined that the plan must show the means by which the licensee will implement the plant's physical protection. In addition, the plan needs to be more comprehensive and detailed. STUK therefore found that Olkiluoto is not fully in compliance with its regulatory requirements that came into force in December 2008. TVO is required to update the safety plan and safety instruction plan and to submit plans on the development of the above-mentioned issues. Furthermore, attention must be paid to the sufficiency of physical protection staff resources. 


\section{A.1.4.6 Nuclear Materials Safeguards}

The Finnish nuclear safeguards are based on the Non-Proliferation Treaty and the subsequent Safeguards Agreement signed by the International Atomic Energy Agency (IAEA), the European Union (EU) Commission and the non-nuclear weapon states of the EU (INFCIRC/193), in addition to the national Nuclear Energy Act and Decree. The EU Commission also has its own safeguards system that is based on the European Atomic Energy Community (Euratom) Treaty. TVO is obligated to comply with the nuclear material accounting and control manual approved by STUK and the applicable EU regulations. Furthermore, TVO is obligated to follow the accounting and monitoring manual for international nuclear material transfers, as approved by STUK. TVO has submitted all reports and announcements required by the EU Council Regulation for Olkiluoto on time. In general, STUK found this program to conform to regulatory requirements.

However, STUK found that the security standing order submitted by TVO in August 2009 must be supplemented. Issues to be included in the security standing order include, for example, management of the physical protection organization and the arrangement of its operations, including staffing, on-call staffing, deputy arrangements, monitoring, and supervision tasks and operational tactics. The security standing order must also include the outfitting of the physical protection organization - monitoring tools and technology, communication tools, and other tools and accessories including the uniforms of those included in the safety organization - and its protective equipment and use-of-force equipment. TVO was directed to submit a supplemented security standing order as well as an updated comprehensive review of its physical protection arrangements and its current implementation of the relevant regulatory requirements.

\section{A.1.4.7 Plant Decommissioning}

Under Finnish law, the decommissioning plan for a nuclear power plant must be updated every 5 years. TVO last updated the decommissioning plan for Olkiluoto in 2008. The plan for Olkiluoto calls for the decommissioning of the plant approximately 30 years after the termination of the monitored storage. All structures and components exceeding the limits for the removal of regulatory control will be disassembled from the plant and packaged for disposal. The waste packages will be disposed of in facilities constructed in the close vicinity of the disposal facility. Reactor pressure vessels will be disposed as such in separate shafts. The interim storage for spent fuel will not be disassembled until the disposal of spent fuel is implemented. STUK found this program to conform to regulatory requirements.

\section{A.1.5 Performance and Feedback of Experience}

\section{A.1.5.1 Operating Experience}

Olkiluoto 1 and 2 experienced 23 International Event Scale (INES) level 1 events during the 1999-2008 licensing period, and no higher level events occurred. In 2008, aging embrittlement was detected in some emergency diesel generator seals. If allowed to continue, this could have prevented the simultaneous startup of several diesel generators. The seals in question were not included in the regular maintenance program; instead, the aging degradation was detected in connection with periodic startup testing. From 1999 to 2008 the load factor was 93.798.3 percent for Olkiluoto 1 and 93.7-96.9 percent for Olkiluoto 2. During the current 10-year operating license period, there have been 12 fast shutdowns for various reasons, six for each 
plant. STUK found that none of the OpE events during the current licensing period impacted plant safety.

\section{A.1.5.2 Comparison of Operating Experience with U.S. Plant of Similar Design}

Olkiluoto Units 1 and 2 are of the BWR 75 design developed by ASEA-Atom and have no counterpart in the U.S.

\section{A.1.6 Management}

Safety Culture: TVO states that "safety culture is that assembly of characteristics and attitudes in organizations and individuals, which establishes that, as an overriding priority, nuclear plant safety issues receive the attention warranted by their significance." TVO plans to retain Olkiluoto 1 and 2 in operation for a minimum of 60 years. They state that to achieve this objective, the plants must be retained in good condition, which requires staff alertness in reacting to signs of aging and any risks observed, as well as in preventing such risks. TVO implemented a safety culture self-assessment in compliance with the IAEA model in 2004 and 2007, and this self-assessment shows that TVO's safety culture is of a good level based on the IAEA scale. STUK found this program to conform to regulatory requirements.

Safety and Quality Management: TVO's management system consists of a general part and an activity part. In the general part, TVO describes the company policies, general business principles, and requirements for safety and quality management. The activity part includes descriptions of activity processes as well as manuals and procedures guiding activities. During the current operating license period, STUK found no deficiencies relating to the fundamentals or structures of quality management that would have an essential significance to safety or operations affecting quality. TVO has appropriately processed and rectified the single deficiencies observed in the implementation of quality management. Overall, STUK found this program to conform to regulatory requirements.

Lines of Management, Responsibilities, and Expertise: The TVO management system specifies lines of management, responsibilities, and important issues related to expertise in the administrative rules, the organization manual, and the training manual. The administrative rules specify tasks, responsibilities, and authorizations important for nuclear and radiation safety. The rest of the organization and its tasks are specified in the organization manual. TVO has approximately 710 permanent employees, of whom approximately 75 percent have a technical or natural sciences educational background, and approximately 20 percent have a Master-level degree. STUK found this program to conform to regulatory requirements.

Plant Operations: The TVO Technical Specifications specify control-room staffing and control-room operating procedures during normal and emergency conditions. TVO has drawn up three new emergency operating procedures since the modernization of Olkiluoto in the late 1990s. Furthermore, an emergency operating procedure for partial scram and its recovery is under preparation. However, STUK noted that, since the power upgrades of the plants, TVO has not implemented any systematic procedure validation. Overall, STUK found that Olkiluoto complied with regulatory requirements, but the justification documentation for emergency operating procedures and an assessment of the adequacy of the validation of procedures were still needed. 
Technical Specifications: Based on past inspections and observations, STUK has stated that the technical specifications need to be updated to ensure document justification, clarity, and unambiguity. As a part of its periodic safety review, TVO submitted a Technical Specifications development plan to STUK in which it committed to review, supplement, and harmonize all of the technical specifications requirement and justification chapters by the end of 2009. With this commitment, STUK found the Olkiluoto Technical Specifications process to be acceptable.

\section{A.1.7 Environment}

Environmental considerations related to radiation releases are discussed in Section A.1.4.2 under "Radiation Safety." In addition, STUK noted that TVO has not submitted quantitative reviews on the risk caused by oil leaking into the sea from nearby shipping and the adequacy of the plant preparedness for such oil releases. STUK directed TVO to submit a plan for supplementing the PRA with a risk assessment for oil releases.

\section{A.1.8 Conclusions}

STUK's overall evaluation resulting from the periodic safety review is that the regulatory requirements for the continued licensing of Olkiluoto Units 1 and 2 have been met. Several issues were identified, and STUK has imposed requirements related to compliance with government decrees that were revised in 2008 on nuclear plant safety and physical protection. STUK has provided defined time periods for the licensee to respond to these updated requirements. STUK also noted that qualification information still needs to be developed for certain electrical and instrumentation and control components, as well as for special components like pneumatic actuators, that have unique operational requirements under conditions, such as during or after transients and accidents. Several other follow-up items requiring licensee responses were also noted by STUK related to plant safety for various accident scenarios. STUK concluded that aging management at Olkiluoto Units 1 and 2 has been implemented in general conformance with regulatory requirements. However, in recent years certain OpE events have become known in which the aging of equipment or structures has been the cause or a contributing factor. STUK will continue to monitor the factors behind these events during the remaining term of the operating license.

\section{A.1.8.1 Summary of Technical Issues that Merit Further Consideration}

- $\quad$ TVO elected to follow the guidance of NRC Regulatory Guide 1.207 in taking environmental effects into account for the main feedwater piping and certain associated auxiliary systems, even though this guidance is applicable to only new plants in the U.S. (Section A.1.3.2).

- A project was initiated to replace the main steam line inner isolation valves in response to the increased flow rate brought about by the recent power uprates. One of the valves currently in use closed in 2006 because of a higher than normal flow rate after the other isolation valve had closed by itself because the permanent magnet keeping it open had grown weaker (Section A.1.3.2).

- Olkiluoto has taken measures to prevent the formation of frazil ice because of super cooled seawater suddenly freezing by channeling warm condensate water into the seawater intake opening (Section A.1.4.1). 
- In 2008, aging embrittlement was detected in some emergency diesel generator seals. The seals in question were not included in the regular maintenance program; instead, the aging degradation was detected in connection with periodic startup testing (Section A.1.5.1).

\section{A.2 France (900-MWe Pressurized Water Reactors, Types CP0, CP1, and CP2)}

The French nuclear plant fleet consists of 58 pressurized water reactors (PWRs), of which the oldest are the thirty-four 900-MWe reactors commissioned between 1978 and 1988. The 900-MWe standardized series can be split into two main types, as follows:

1. Type CP0, comprising the 6 plants (Fessenheim Units 1 and 2 and Bugey Units 1-4), and

2. Series CPY (subdivided into Types CP1 and CP2), comprising the 28 plants (Blayais Units 1-4, Chinon Units 1-4, Cruas Units 1-4, Dampierre Units 1-4, Gravelines Units 1-6, Saint-Laurent Units 1 and 2, and Tricastin Units 1-4).

Since all of the reactors in a given series have the same design, the French Nuclear Safety Authority (Autorité de Sûreté Nucléaire or ASN) decided to conduct unified PSR studies for the plants in these series. The Type CP0 reactors, with Fessenheim Unit 1 as the lead plant, were covered under one PSR, and the Series CPY Types CP1 and CP2 reactors, with Tricastin Unit 1 as the lead plant, were covered jointly under a second PSR. However, some aspects relating to reactor siting or other specific local characteristics are dealt with on a case-by-case basis.

The present section deals with the two PSRs for all of the above plants. These plants were designed by Framatome; the Type CP0 reactors were commissioned between December 1977 and January 1980 and the Types CP1 and CP2 between March 1979 and April 1988. The PSR observations being reviewed are those resulting from the third decennial review (VD3 900) for the period 2002-2008, conducted under the direction of the ASN with technical support from the Institute for Radiological Protection and Nuclear Safety (Institut de Radioprotection et de Sûreté Nucléaire or IRSN).

The DSR Report No. 285 provides an assessment of and conclusions resulting from the investigation performed by the IRSN over 6 years during which Electricité de France (EdF) carried out the necessary PSR studies for the three reactor types and determined the subsequent modifications to be made to the reactors. The safety review focused on three areas: (1) a comparison of the current safety level of the installation with the level expected today, (2) a consideration of improvements in the technical knowledge base and increased OpE, and (3) a consideration of various aging-related phenomena that can limit the operating lifetime of the plant.

The IRSN DSR review and assessment of the PSR is divided into three sections based on six of the 14 IAEA elements. These three sections are (1) plant design (element 1); (2) aging degradation and management, which include elements 2 (actual condition of SSCs), 3 (equipment qualification), and 4 (aging); and (3) performance and feedback of experience, which includes elements 8 (safety performance) and 9 (use of experience from other plants and research). The results of the two PSRs for three reactor types are largely identical and are for 
the most part combined in DSR Report No. 285. The summary provided here also combines the results of the two PSRs, making distinctions only where the PSR findings differed between the plant types.

\section{A.2.1 Plant Modifications}

The PSR found that debris produced in containment during a severe accident could reach the sump strainers, which are designed to protect downstream equipment such as pumps. The potential blocking of these strainers would cause an increased pressure drop on the suction side of the pumps, increasing the risk of malfunctions in the safeguard systems. Based on the review of sump design basis with regard to the risk of clogging and as a part of the VD3 900 safety review process, EdF decided to modify the sump filter design. This modification was to be applied to all reactors by 2009.

\section{A.2.2 Plant Design}

The principal modifications to the Type CPO plants resulting from the third PSR outage include the following:

- Enhanced seismic resistance (primarily at Bugey).

- Improved consideration of risks associated with explosive gases (principally hydrogen).

- Installation of hydrogen detectors and/or explosion-proof equipment at sites at which there is a risk of an explosive atmosphere.

- Improved robustness of sites with respect to natural external hazards, mainly by enhancing the long-term reliability of emergency diesel generators.

- Consideration of the risk of rapid draindown of spent fuel storage pools. The modifications to be implemented are aimed at increasing the time available for operators to return fuel assemblies in the process of being handled to a safe configuration (automatic shutdown of fuel pool pumps at low-low level, and measurement of draindown rate).

- Improved management of severe accidents, notably by enhancing the reliability of the system for depressurizing the primary system using the pressuriser relief valves, even in the event of severe accidents caused by a loss of electrical power.

- Modifications aimed at reducing personnel radiation dose.

- Improving reactor performance and resolving issues of obsolescence of instrumentation and control equipment by upgrading equipment items that are unable to continue service for 40 years.

The IRSN had previously highlighted the need to improve measures to avoid sudden rupture of the reactor vessel in the case of low-temperature overpressure (LTOP) of the primary system, specifically when the primary cooling system is below $90^{\circ} \mathrm{C}$. During the VD3 $900 \mathrm{PSR}$, the IRSN assessed the adequacy of a modification proposed by EdF, consisting of lowering the 
set-point for pressurizer relief valves when the primary system is closed and the reactor is cooled by the residual heat removal (RHR) system. The IRSN determiend that this proposed modification, along other operating improvements already implemented, will substantially reduce the risk of LTOP-related breaks requiring the use of safety injection. However, IRSN determined that EdF's decision not to apply this modification in certain operating ranges, where the risk of overpressure remains, was not satisfactory. The IRSN found that the modification must be available in all operating ranges in which the primary system is closed and the water temperature in the vessel is below $90^{\circ} \mathrm{C}$.

The current PSR included a review of seismic protection measures, taking into account the following considerations relative to the situation at the time of the previous PSR outage:

- Evolution of state-of-the-art engineering practices, mainly in relation to the considerable advances in the computational power of computers.

- Update of the standards regulating seismic protection. EdF has been relying primarily on IAEA Safety Report 28, "Seismic Evaluation of Existing Nuclear Power Plants" (IAEA $2003 \mathrm{~b}$ ) and the safety review of seismic hazards on site resulting from the enforcement of the new Basic Safety Rule on that issue.

- EdF is pursuing its research and development (R\&D) efforts on seismic risks in two areas: one to control uncertainties relating to the identification of seismic risks and the other to quantify design margins.

Regarding the safety of spent-fuel storage, the evolution over time in operating practices tends to increase the residual power of fuel stored in deactivation tanks and, consequently, to reduce the intervention lead times in case of a total loss of coolant. This concern led EdF and ASN to question the safety of fuel storage in fuel buildings. The design-correction case covers the various issues associated with an incidental loss of coolant or of water inventory. It will allow for the following:

- Unloading of fuel assemblies and transfer to the spent fuel pool (SFP) to be based on a limit of the SFP water temperature, instead of the initial core residual power.

- Improvement of monitoring and detection means.

- Implementation of water-make-up measures to the SFP against total and extended loss of the coolant system of the pools.

The execution of these modifications is underway on all 900-MWe reactors in France.

Clogging of steam generator (SG) tube support plates due to oxide deposits, leading to the gradual obstruction of clearances and flow paths, has occurred in some 900 - and 1,300-MWe reactors in France. This phenomenon was observed for the first time by EdF during autumn of 2006 at the Cruas NPP. Based on the analyses conducted by EdF in 2007, it was confirmed that it extended to 15 reactors (eight 1,300-MWe and seven 900-MWe reactors) out of a total of nuclear fleet of 58 reactors and required that the SGs involved undergo a chemical cleaning 
procedure. By the end of 2008, the SGs of nine reactors had been cleaned (four in 2007, five in 2008) and the six remaining reactors were scheduled for cleaning over the next 2 or 3 years.

Based on its review of the severe accident risk analysis and related plant modifications IRSN determined that EdF should consolidate the reliability and "representativeness" of the instrumentation. This allows real-time assessment of the development of the "hydrogen risk" in containment and detecting the presence of corium at the bottom of the reactor pit to improve the ability to monitor the progress of a severe accident.

With regard to containment safety, IRSN found that the containments of the 900-MWe units show no abnormal behavior due to design, provided the modifications defined by EdF are implemented to improve the integrity of certain air locks and isolating valves. However, in the IRSN's view, some additional investigations, particularly on containment concrete, and the concrete cover of prestressing bars, were needed to demonstrate the suitability for continued operation. For the containment in post-accident situations, IRSN considered that its performance would be satisfactory after a significant modification of the reinforcement of the equipment hatch closing system to guarantee sufficient mechanical strength to withstand pressure peaks that can reach 8 atmospheres in the event of a severe accident.

Based on its review of the level 1 probabilistic safety assessment (PSA), IRSN recommended implementing a modification aimed at reducing the risk of core meltdown. This modification consists of containment bypass in the event of a thermal barrier cooling system rupture of one of the reactor coolant pump sets. Concerning its analysis of the level 2 PSA, IRSN considered that the methods and assumptions adopted by EdF in its PSA analysis demonstrate that the overall goals are met. Nevertheless, certain assumptions must be strengthened, and the EdF must continue to develop level 2 PSAs in order to improve severe accidents management by ranking the different scenarios.

The IRSN report also noted that the consequences of a single or multiple tube rupture event in a SG remains a significant concern, and modifications proposed by EdF will give more time for appropriate operator actions to deal with such an event. These include a modification to the operating conditions of the auxiliary feedwater system (AFS) that would allow early isolation of the water supply to the affected steam generator. Also included is a modification of the steps taken to stop primary coolant leakage as quickly as possible by equilibrating the pressure in the affected SG and the primary system.

In its Opinion No. 2100-AV-0121, the ASN determined that, subject to the forthcoming conclusions of complementary safety assessments initiated following the Fukushima accident, Fessenheim Unit 1 is capable of being operated safely for an additional 3010 years subsequent to the third period PSR, and subject to the following two requirements:

1. Strengthen the reactor basemat by June 30, 2013 to increase its resistance to corium in the event of a severe accident with reactor vessel failure.

2. Install emergency systems by December 31, 2012 to remove residual heat reliably in the event of loss of ultimate heat sink. 


\section{A.2.3 Aging Degradation and Management}

The IRSN Annual Report for 2010 (IRSN 2010) examined whether the reactor vessels of 900-MWe reactors in France were capable of operating safely for 40 years. At ASN's request, IRSN examined the file submitted by EdF that is intended to demonstrate that there is no risk of failure in the event of cold shock due to water from the safety injection system. IRSN and ASN's Nuclear Pressure Equipment Department presented their conclusions to the relevant advisory committee on June 16 and 30, 2010. The group ruled in favor of continuing operation for the reactor vessels of all 900-MWe reactors until their fourth 10-year inspection, provided the temperature of the water used for safety injection on reactor B1 at the Saint-Laurent plant (a Type CP2 PWR) is increased.

With respect to the possible extension of the service life of reactors in the EdF fleet beyond 40 years, IRSN identified two major subjects for investigation: (1) EdF's management of the aging and obsolescence of safety-related structures, systems, and equipment after 40 years, and (2) its ability to anticipate the best time to replace safety-related components as necessary and to make modifications to significantly reduce the probability or consequences of accidents.

ASN's review of the PSR noted that the maximum irradiation creep design limit for the 900-MWe reactor vessels will not be reached over the next few years, but verification is needed to assure that that limit will not be exceeded before the fourth decennial PSR is conducted. ASN also noted two new generic issues with SG degradation in the 900-MWe installations that are related to the SG chemical cleaning (discussed above) and tube plugging, the consequences of which may lead to revisions in the safety reports for SGs. As a result, ASN requested EdF to review the overall design of the SGs by addressing all aspects related to safety, design, manufacturing, and inservice monitoring, and to increase its efforts to anticipate anomalies due to similar potential degradation in future.

With regard to the management of Alloy 600 primary water stress corrosion cracking (PWSCC) issues prior to the fourth 10-year outage, ASN considered it important to (a) verify the overall integrity of vessel-bottom penetrations in the 900-MWe reactors, if it was not possible to install a leak detection system for these penetrations; and (b) continue in-service monitoring for the integrity of the SG partition plate weld and to address every observed discrepancy on a case-by-case basis.

EdF has also proposed specific maintenance actions for Fessenheim 1 for the next 10 years following VD3 pertaining to the bolting of the screening drum, certain electrical relays, and certain position sensors for the control rods, in order to forestall and monitor the effects of aging.

\section{A.2.4 Performance and Feedback of Experience}

The Convention on Nuclear Safety Fifth National Report for the Peer Group Meeting notes the following modifications to French PWRs, based on OpE:

- In early 2006, modifications were made to all safety injection and containment-spray pumps in order to improve vibration resistance during long-term phases of accidents, and

- Modification programs for the circulation sump strainers (discussed above in Section A.2.1) were completed on all reactors by the end of 2009 . 
Over the past few years, SG inspections during maintenance and reloading outages or following unscheduled events have detected the following issues:

- The clogging of SG tube support plates leading to the gradual obstruction of clearances and flow paths, due to oxide deposits (discussed above in Section A.2.2). This resulted in leaks in three SG tubes between 2004 and 2006. EdF therefore implemented a chemical-cleanup strategy for SGs, which was monitored by ASN.

- SG tube-support anomalies, including the vibration fatigue of unsupported tubes. In February 2008, a leak developed in an unsupported SG tube in the Fessenheim-2 reactor, even though that tube had not been identified as sensitive to vibration fatigue. Following that event and at ASN's request, EdF plugged all unsupported tubes in their $900-\mathrm{MWe}$ reactors, as well as those considered at risk in their 1,300-MWe reactors. EdF also revised its vibration fatigue guidelines.

- Some SGs have tubing alloys that are susceptible to corrosion, and are monitored more closely. During inspections of SG No. 1 in Bugey 3 in May 2009, EdF detected small cracks with new features and a significant defect that was only identified during the extraction of the tube for assessment purposes. After several months of assessment and review, EdF decided to replace all SGs in the Bugey 3 earlier than anticipated. This was attributed to the corrosion of the tube at the tube support plate. Assessments carried out on the same type of SG at several other installations revealed the presence of corrosion that had not been properly detected by the inspection processes. Therefore, additional inspections are scheduled on all SGs likely to be of concern.

- Recently, EdF decided to replace the SGs in all 34 of its $900-M W e$ plants. As of February 2012, replacement had been completed at 22 units, and replacement is currently proceeding at a rate of two units per year, with plans to increase this to three units per year in 2016. In 2011, EdF ordered 44 steam generators for 11 of its 201300 -MWe units, with plans to also proceed with the other nine (World Nuclear Association 2012).

While chemical cleaning is a potential remedy against the clogging of steam generators at tube to support intersections, ASN is of the opinion that the cleaning is not without undesired consequences, since the internal structures of steam generators or the tubes are subject to corrosion during this treatment. In addition, deposits on the tubes, whose origin is not readily identifiable, may also be observed after cleaning.

\section{A.2.5 Comparison of Operating Experience with U.S. Plant of Similar Design}

\section{A.2.5.1 Fessenheim Unit 1}

The U.S. plant similar in design to the Fessenheim Unit 1 PWR NPP is the Beaver Valley Power Station (BVPS). The License Renewal Application (LRA) (First Energy Nuclear Operating Company 2007) and resulting Safety Evaluation Report (SER) (NRC 2009b) for BVPS were reviewed to identify common areas of concern and to note similarities and differences in OpE. A caution in making this comparison is that a possibility exists that component equipment manufacturers and the manufacturing process may vary from plant to plant, thus limiting the value of such direct comparison. The findings resulting from this review are summarized below. 
Safety Injection and Containment-spray Pumps: Vibration-related issues in accident situations were identified by EdF based on its review of fleet-wide events, which resulted in modifications on all safety injection and containment-spray pumps to improve their vibration resistance. This issue has not been identified in the BVPS OpE or in the aging management review (AMR) of its LRA.

Recirculation Sumps: The modification program for the strainers of circulation sumps was completed on all reactors by EdF by the end of 2009. At BVPS, the sump strainers in the safety injection and recirculation spray systems are monitored for loss of material under the appropriate AMR item in its LRA. The sump strainer performance with respect to debris accumulation has been reviewed in response to Generic Letter 2004-02 (NRC 2004a) in the BVPS LRA with the determination that it is not an issue related to aging management and it will be addressed separately as needed.

SG Supports: Significant and unanticipated degradation issues were identified for the French reactors at the tube support locations, including clogging due to oxides leading to tube leakage, vibration fatigue because of inadequate support from anti-vibration bars also leading to leakage events, and tube cracking due to corrosion at supports. These locations are included in the Steam Generator Tube Integrity aging management program (AMP) (B.2.38 of LRA) at BVPS and no similar problems have been identified in the OpE at BVPS.

Reactor Pressure Vessel: ASN's review of PSRs considered it important that an upper limit on the neutron flux be guaranteed to manage the irradiation creep in their 900-MWe RPVs, which is an aging effect not considered in the AMR of BVPS.

Alloy 600 PWSCC: ASN considered it important to (a) verify the overall integrity of the lower head penetrations in their 900-MWe reactor pressure vessels, if it was not possible to install a leak detection system; and, (b) continue in-service monitoring for the integrity of SG partition plate weld and to address every observed discrepancy on a case-by-case basis. While these are not noted as specific issues in the BVPS LRA, the current updated industry-wide programs and related augmented inspection programs cover the related Alloy 600 PWSCC management. Accordingly, the BVPS LRA includes in its Appendix A, a commitment to develop a plant-specific AMP that will implement applicable NRC Orders, Bulletins and Generic Letters, and staff-accepted industry guidelines.

\section{A.2.5.2 Tricastin Unit 1}

The U.S. plant similar in design to the Tricastin Unit 1 NPP is the North Anna Power Station (NAPS), and the LRA (Virginia Electric and Power Company 2001) and resulting SER (NRC 2002c) for NAPS were reviewed to identify common areas of concern and to note similarities and differences in OpE. However, the component equipment manufacturers and the manufacturing process may vary from plant to plant, thus limiting the value of such direct comparison. Therefore, caution should be exercised while making this comparison.

Safety Injection and Containment-spray Pumps: Potential vibration problems in the safety injection system during long-term accident scenarios were identified by EdF based on a fleet-wide review, and this resulted in modifications to all safety injection and containment-spray 
pumps to improve their vibration resistance. This potential problem has not been identified at NAPS from OpE or in the AMR of its LRA.

Recirculation Sumps: The modification program for recirculation sumps strainers was completed on all reactors by EdF by the end of 2009. At NAPS, the containment sump strainers have likewise been replaced to provide a greatly increased surface area, and the response of its emergency recirculation system under severe accident conditions has been analyzed in detail, in response to Generic Letter (GL) 2004-02 (NRC 2004a; Virginia Electric and Power Company 2008.

Steam Generator Supports: Significant and unanticipated degradation issues were identified at the tube support locations. These include clogging due to oxides leading to tube leakages, vibration fatigue as a result of inadequate support from anti-vibration bars leading to tube leakage, and tube cracking due to corrosion at supports. These locations are included in the steam generator inspections AMP at NAPS and no similar degradation has been identified in the OpE at NAPS.

Reactor Pressure Vessel: ASN's review of PSRs considered it important that an upper limit on the neutron flux be guaranteed to manage irradiation creep for their 900-MWe RPVs. This aging effect is not considered in the AMR of NAPS.

Alloy 600 PWSCC: ASN considered it important to (a) verify the overall integrity of lower head penetrations of the 900-MWe RPVs, if it was not possible to install a leak detection system for these penetrations; and (b) continue inservice monitoring for the integrity of SG partition plate welds and address observed discrepancies on a case-by-case basis. The NAPS LRA was prepared prior to the publication of NUREG-1801 (NRC 2001a, 2005b, 2010c) and does not include an AMP corresponding to GALL AMP XI.M11B that specifically addresses PWSCC of nickel-base alloys. However, the NAPS LRA states that the cracking of reactor vessel head penetrations is managed through its Augmented Inspection Activities and Boric Acid Corrosion Surveillance programs. In addition, the licensee has participated in the industry response to GL 97-01 (NRC 1997), and current updated industry-wide programs and related augmented inspection programs cover the related Alloy 600 PWSCC management.

Underclad Cracking: According to the ASN, a total of 33 underclad defects have been reported in nine pressure vessels, including 20 in the Tricastin 1 RPV. These defects are regularly inspected to ensure that they do not evolve during operation. The NAPS LRA treats reactor vessel underclad cracking as a time-limited aging analysis (TLAA), and a fracture mechanics analysis has determined that any existing cracks are not expected to grow significantly over a 60 -year analysis period. Neither the NAPS LRA nor the associated SER report the presence of any known underclad cracks in the North Anna 1 and 2 reactor vessels.

\section{A.2.6 Conclusions}

Based on its assessment, as supported by that of the IRSN, ASN found that the generic portion of the PSR applicable to the Types CP0, CP1, and CP2 900-MWe PWRs is capable of maintaining and improving their overall safety level. The results of the level 1 PSA were helpful in determining appropriate design or operational changes, which, once integrated in the reactors, will reduce even further any potential core meltdown. In addition, the ASN found that, at this stage of the review, none of the safety re-assessment studies has detected any element 
that would raise safety-related or generic issues concerning the capability of $900-\mathrm{MWe}$ reactors to remain in service. Beyond the present safety re-assessment, the ASN determined that extending the operating lifetime of reactors may only be envisaged for a nuclear fleet that is correctly maintained and operated responsibly with a view to anticipating any potential anomalies.

With particular reference to the Fessenheim Unit 1 PSR, ASN determined that (a) the licensee $(E d F)$ had demonstrated that the diverse aging phenomena will be under control for a minimum period of 10 years following its third 10-yearly outage, (b) the RPV of the Fessenheim Unit 1 is fit for the 10-year period, and (c) maintenance activities during the third 10-yearly outage confirmed that the aging of the reactor's components are in accordance with what was projected and do not present any special concerns.

\section{A.2.6.1 Summary of Technical Issues that Merit Further Consideration}

- The maximum irradiation creep design limit for the 900-MWe reactor vessels will not be reached over the next few years, but verification is needed to assure that that limit will not be exceeded before the fourth decennial PSR is conducted (Section A.2.3).

In February 2008, a leak developed in an unsupported steam-generator tube in Fessenheim 2, even though that tube had not been identified as sensitive to vibration fatigue. EdF subsequently plugged all unsupported tubes in their 900-MWe reactors, as well as those considered at risk in their 1,300-MWe reactors. EdF also revised its vibration fatigue guidelines (Section A.2.4).

\section{A.3 Slovenia (Krško)}

The Slovenian Krško NPP is a two-loop Westinghouse PWR with a generating capacity of 696 MWe. The plant is located near Krško, Slovenia, the licensee is Krško Nuclear Power Plant or Nuklearna elektrarna Krško (NEK), and the plant was commissioned in 1981. The responsible regulatory agency is the Slovenian Nuclear Safety Administration (SNSA), and the PSR period reviewed is 1990-2000. The results of the PSR are presented in the report PSR-NEK-8.0, Rev. 0 (NEK 2004).

The SNSA report focuses primarily on two areas. The first of these is a review of a set of safety factors defined by the SNSA and loosely based on the 14 IAEA elements previously described in Section 1.1. The seven SNSA safety factors considered were operational experience, safety assessment, equipment qualification and aging management, safety culture, emergency planning, environmental impact and radioactive waste, and compliance with license requirements and prioritization. The second focus area of the SNSA report was a summary of the results of the PSR, with emphasis on the identification of plant weaknesses and issues, suggestions for corrective measures, and actions for the resolution of these issues.

\section{A.3.1 Plant Modifications and Improvements}

The SNSA report does not provide any specific information on plant modifications and improvements related to plant safety. However, the following major safety-related plant modifications and improvement measurements in Krsko plant are reported in the Krško Nuclear Plant 2011 Annual Report (Nuklearna Elektrarna Krško 2012): 
AC Power Supply Upgrade: This activity involved the upgrade of the plant's AC power supply by the provision of an alternative source in the event of Station Blackout (SBO). The upgrading of the existing supply system includes the installation of a 4-MW diesel generator set that will be connected through a new 6.3-kV busbar.

Reactor Head Replacement: The need for this replacement was based on industry OpE with corrosion problems at reactor head penetrations associated with the use of Alloy 600 material and Alloy 82/182 welds, and on the desire to ensure safe operation through the end of the plant's extended operating life. The replacement reactor head utilized Alloy 690 with Alloy 52/152 welds and better manufacturing procedures to ensure safe and reliable operation (Sipro Inzeniring 2012).

Steam Generators: In the fall of 2005, because of extensive tube cracking and plugging, the two original Westinghouse Model D-4 SGs at Krško were replaced with AREVA steam generators with Alloy 690 thermally treated tubes. Along with the replacement, the plant's net power output increased from 632 to $676 \mathrm{MWe}$.

Other significant plant modifications included main generator replacement, modernization of the fire alarming system, plant improvements related to flood safety, replacement of the portal crane, and the addition of mobile AC power equipment to ensure alternate core cooling in response to events at Fukushima.

\section{A.3.2 Aging Degradation and Management}

The SNSA report noted that, while Krško has some aging management activities in place, it does not presently have an integrated AMP. The need to develop such a program was noted, and the SNSA recommended that such a program be modeled on the U.S. approach, following the guidance of 10 CFR 54 and NEI-95-10 (Nuclear Energy Institute 2005). As a first step subsequent to the PSR, a total of 9,251 candidate mechanical components were identified as potentially subject to an AMR, and 6,385 of these were retained within the scope after the application of screening criteria. In addition, 882 electrical components and 673 civil and structural components were included in the database after screening.

The SNSA concluded the NEK organization, information management systems, working practices, and procedures provide the necessary infrastructure and information required to support the development of an integrated AMP. The existing NEK programs, which are in place to manage the aging of certain SSCs, appear to follow internationally recognized codes and standards and apply state-of-the-art methods and techniques. Based on the results of subsequent AMP development activity, the SNSA concluded that NEK has AMPs in place that support the safe operation of the plant over the next 10 years (until the next PSR). Furthermore, NEK must begin with second phase of the AMP "Aging Management Review," which involves the review of all screened SSCs and TLAAs. The review process will result in needed corrective actions in other plant programs and practices and will lead to the development of new programs and organizational aspects to cover required issues and tasks.

\section{A.3.2.1 Nuclear Fuels}

No specific items identified for aging management. 


\section{A.3.2.2 Mechanical Systems}

The PSR identified several specific areas in aging management that the NEK should address, including the following:

Cast Stainless Steel: Determine the degree to which aging affects the structural integrity of cast stainless steel components other than piping and fittings.

Thermal Aging: Demonstrate that the failure probabilities of piping systems are acceptably low when considering the effects of thermal aging.

Fracture Toughness: Obtain a broad database of fracture toughness data (Charpy impact data and J-R curves) adequate for quantitative fracture analysis and develop a method to monitor the loss of fracture toughness in cast austenitic stainless steel components due to thermal aging.

Pressure Locking and Thermal Binding: Develop a work plan to generically address pressure locking and thermal binding (PL/TB) for safety-related operated gate valves. The plan should include the identification of safety-related valves subject to PL/TB. Conduct a literature survey and perform tests and to develop technical bases for generic solutions to PL/TB.

\section{A.3.2.3 Structural Systems}

The following items were identified in the PSR related to aging management of the structural systems:

Frequency of Intake Structure Plugging: NEK should identify the various possible types of plugging causes and evaluate each cause, taking into account Krško OpE and whether near-miss or precursor events to intake fouling have occurred.

Differential Movements: Differential movements (thermal, loss of coolant accident, and seismic) impacting safety-related piping located at building interfaces should be reviewed, updated, and reconciled as necessary.

\section{A.3.2.4 Electrical Systems}

The following aging management issues were identified during the PSR related to electrical systems:

Degraded Voltage: NEK should implement the requirements of NRC Branch Technical Position BTP-PSB-1 from the Standard Review Plan (NRC 2002b), Appendix 8-A ("Adequacy of Station Electric Distribution System Voltages"), with respect to degraded voltage conditions.

Hermetic Seals: NEK should assure the long-term capability of hermetic seals on instrumentation and electrical equipment. The aging-related degradation of these seals does not appear to be specifically mentioned in GALL.

Regulations, Generic Letters, and Bulletins: NEK should consider incorporating the following guidance: 
1. 10 CFR 50.49, Environmental Qualification of Electrical Equipment

2. GL 80-010, Issuance of NUREG-0588, "Interim Staff Position on Equipment Qualifications of Safety-Related Electrical Equipment" (NRC 1980a)

3. GL 80-013, Qualification of Safety Related Electrical Equipment (NRC 1980b)

4. GL 80-104, Orders on Environmental Qualification of Safety Related Electrical Equipment (NRC 1980c)

5. GL 81-05, Information Regarding the Program for Environmental Qualification of Safety-Related Electrical Equipment (NRC 1981)

6. GL 82-09, Environmental Qualification of Safety Related Electrical Equipment (NRC 1982a)

7. GL 84-24, Certification of Compliance to 10 CFR 50.49, Environmental Qualification of Electrical Equipment Important to Safety for Nuclear Power Plants (NRC 1984)

8. GL 88-07, Modified Enforcement Policy Relating to 10 CFR 50.49, "Environmental Qualification of Electrical Equipment Important to Safety for Nuclear Power Plants" (NRC 1988b)

9. GL 89-10, Safety-Related Motor-Operated Valve Testing and Surveillance (NRC 1989)

10. GL 95-07, Pressure Locking and Thermal Binding of Safety-Related Power-Operated Gate Valves (NRC 1995)

11. NRC Bulletin (BL) 77-05, Electrical Connector Assemblies (NRC 1977a)

12. BL 77-06, Potential Problems with Containment Electrical Penetration Assemblies (NRC 1977b)

13. BL 78-02, Terminal Block Qualification (NRC 1978)

14. BL 79-01, Environmental Qualification of Class IE Equipment (NRC 1979)

15. BL 82-04, Deficiencies in Primary Containment Electrical Penetration Assemblies (NRC 1982b)

\section{A.3.2.5 Auxiliary Systems}

No specific items identified for aging management.

\section{A.3.2.6 Equipment Qualification}

NEK developed an Environmental Qualification (EQ) program to ensure that safety-related equipment is capable of functioning under such environmental or operational conditions as 
vibration, temperature, pressure, jet impingement, radiation, humidity, and earthquakes. The objective of the EQ program is to develop requirements for multiple levels and methods of protection (defense in depth) of the equipment. The PSR assessment concluded that the present EQ Program at NEK meets most of the necessary requirements.

\section{A.3.3 Performance and Feedback of Experience}

Section 3.1 of the SNSA report addresses OpE and covers a broad range of topics, including baseline/pre-operational data for SSCs important to safety, data and records of plant modifications, inservice inspection/examination and maintenance, component failures, component repair and replacement, trending analysis, analyses of plant/components life influences, feedback of $\mathrm{OpE}$, and research findings. The OpE and current physical condition at the plant were evaluated against criteria based on the current international standards, guidelines, and good practices developed by the IAEA.

The assessment found that the evaluation of on-site operating events is conducted as a part of a dedicated program. Related plant processes and assignment of responsibilities are well defined in the procedures, and the organizational arrangements and related plant practices are considered satisfactory. The assessment also found that that the activities for collecting and maintaining baseline and the pre-operational data for SSCs important to safety at NEK are well defined and organized on sound principles. The baseline data from plant commissioning have been archived and are easily retrievable. Good performance of NEK is demonstrated based on World Association of Nuclear Operators indicators. The majority of the indicators meet (or essentially meet) the Institute of Nuclear Power Operations (INPO) goals, and no statistically significant adverse trends were observed.

The assessment found that procedures for carrying out systematic trending analysis are in place. However, these procedures are limited to the preparation of high-level plant performance indicators. No explicit requirements in support of the trending analysis at a lower plant level are articulated in the procedures.

The assessment also found there are no specific procedures for monitoring the parameters that can impact plant/component lifetime. The SNSA found that a list of factors that potentially impact plant or component life should be established within the framework of a Plant Aging Program, and suitable arrangements should be made for monitoring these parameters.

The assessment of OpE concluded that, in general, the nature and extent of NEK programs for the effective use of $\mathrm{OpE}$ are satisfactory and reflect adherence to current international requirements and good practices. No major concerns other than those noted above were identified in the review.

\section{A.3.4 Comparison of Operating Experience with U.S. Plant of Similar Design}

The U.S. counterpart plant similar in design to the Krsko Nuclear Power Plant is Callaway. Callaway submitted its LRA in December of 2011 and no resulting SER is currently available. The Callaway LRA was reviewed to identify common areas of concern and to note similarities and differences in OpE. A caution in making this comparison is that that component equipment manufacturers and the manufacturing process may vary from plant to plant, thus limiting the value of such direct comparison. The findings resulting from this review are summarized below. 
Groundwater Monitoring: The SNSA report makes no mention of groundwater monitoring near the plant. However, the Krško Nuclear Plant 2011 Annual Report states that the groundwater level and temperature are monitored on a weekly basis in three boreholes at each of two locations on the Sava River and in 10 boreholes in the Krško-Brežice fields. Similarly, the groundwater in Callaway has been sampled monthly since November 2009 for key water chemistry parameters, including $\mathrm{pH}$, at two wells located north of the turbine building and adjacent to plant roads.

Settlement Monitoring: At Krško, the SNSA report pointed out a need for monitoring and reviewing differential movement of safety-related piping at building interfaces. Callaway maintains benchmarks for monitoring the settlement of all Category 1 structures, including the Ultimate Heat Sink cooling tower.

Cathodic Protection System: Cathodic protection systems at several locations in the Callaway fire water system, as well as for the emergency fuel oil storage tanks, condensate storage tank piping, and one quadrant of the fire water storage tank, were found to be out of specifications in recent years, and corrective actions were taken. The SNSA report makes no mention of cathodic protection systems at Krško.

Steam Generator Replacements: In the fall of 2005, because of extensive tube cracking and plugging, the two original Westinghouse Model D-4 SGs at Krško were replaced with AREVA SGs, which contained Alloy 690 thermally treated tubes. Similarly, in the fall of 2005, Callaway replaced its four original Westinghouse Model F steam generators with AREVA Model 73/19T units.

\section{A.3.5 Conclusions}

The PSR concluded that the plant is as safe as was intended in its original design, and the review did not reveal any major safety issues. As a result, SNSA found that the Krško NPP could safely operate, as a minimum, up to completion of the next PSR. However, the review identified a number of recommendations to further enhance the plant safety.

\section{A.3.5.1 Summary of Technical Issues that Merit Further Consideration}

- The Slovenian regulators stated that the long-term capability of hermetic seals on instrumentation and electrical equipment needs to be assured. The aging-related degradation of these seals does not appear to be specifically mentioned in GALL (Section A.3.2.4).

The PSR noted that differential movements (thermal, loss of coolant accident, and seismic) impacting safety-related piping located at building interfaces should be reviewed, updated, and reconciled as necessary (Section A.3.2.3).

\section{A.4 South Korea (Kori Units 3 and 4)}

The South Korea Kori Units 3 and 4 NPPs are PWRs of the Westinghouse three-loop design, and each is rated at 1,033.1 MWe. Unit 3 was commissioned in September 1985 and Unit 4 in April 1986. The plants are located in Gori (suburban Busan) and are operated by Korea Hydro 
\& Nuclear Power (KHNP). The Korea Institute of Nuclear Safety (KINS) conducted an initial PSR assessment of these plants for the period from startup through 2004, which represents the first and second decades of operation. The results of the KINS review are presented in their March 2006 report, referenced in Section 2.1 above.

The KINS March 2006 report is an evaluation performed by the KINS to (1) determine the soundness of the PSR report prepared by KHNP, and (2) review the safety of the Kori NPP Units 3 and 4 and related facilities. The PSR performed by KHNP evaluated the two reactors with respect to 11 areas, namely physical condition of SSCs, nuclear safety analysis; equipment qualification; aging management; safety performance; use of $\mathrm{OpE}$ and research findings; procedures and specifications; organization and administration; human factors; emergency planning; and environmental impact. IAEA element 1 ("plant design") was not included in the review, and elements 5, 6, and 7 were combined into the more general category of "safety analysis." This is because KINS followed the guidance of the 1994 version of the IAEA Safety Guide (IAEA 1994), which includes only these 11 safety factors rather than the 14 safety factors described in the 2003 version utilized by the other countries reviewed in this study.

\section{A.4.1 Plant Modifications}

Power Uprate: In September 2002, KHNP initiated power uprates for Kori Units 3 and 4 to increase their electrical output by 3.4 percent. The two plants reached their new rated thermal power (2,900 MWth) in December 2009 and February 2009, respectively, and increased their electrical output by 34.1 MWe from $999 \mathrm{MWe}$ to 1,033.1 MWe (Cheongwadae 2011).

\section{A.4.2 Aging Degradation and Management}

\section{A.4.2.1 Nuclear Fuels}

The KINS made several suggestions concerning performance management and equipment inspection procedure Improvement. One of these, related to nuclear fuels, was to revise the inspection procedure document for the nuclear fuel handling and transfer facility. However, no further details were provided in the report.

\section{A.4.2.2 Mechanical Systems}

KINS assessed the test results provided by the licensee to confirm the adequacy of the design functions of the nuclear reactor vessel and internal structures, manual control rod system, pressurizer, piping supports and pipe rupture arrest system, air cleaning system, emergency diesel generator system, and other SSCs. The repair and maintenance records for these SSCs were also reviewed. The results were found to satisfy regulatory safety requirements.

KINS determined that the licensee has generally performed adequate analyses of the mechanical system components using qualitative and quantitative analysis methods, based on operational experience and recent research results related to the degradation of SSCs. However, the licensee needs to develop a degradation assessment and management plan for safety-related SSCs, including areas that are inaccessible because of high radiation levels or other reasons. This should also include the "nuclear fuel structure upper steel part" (meaning unclear in translated document), which is not included in the candidate list. 
The KINS found no issues in the functional performance of SSCs due to degradation and determined that the licensee has adequate safety margins. However, there needs to be a reliability analysis related to failure rate and mean time between failure (MTBF) rate that reflects the actual repair history for the plant control module.

KINS stated that the licensee needed to evaluate potential degradation of the capability of the "recirculation catchment" (sump drains and strainers?) of the containment building and the appropriateness of the current design, based on the most recent standards. Any deficiencies found must be corrected.

KINS also recommended that the "test tolerance error limit" (meaning unclear in translated document) of the pressurizer and main steam safety valve be increased from the current limit of 1 percent to a higher value for improved safety margin during operation and maintenance.

KINS found that the licensee has properly selected candidate equipment for environmental verification and has met inspection and quality assurance requirements, based on the related verification technical standards. However, the licensee needs to establish supplementary procedures for the maintenance of a list of replaced or modified equipment.

Several suggestions were made related to performance management and equipment inspection procedure improvement. Those suggestions applicable to the mechanical systems were as follows:

1. Strengthen the visual inspection of the reactor internal structure.

2. Establish heat exchanger performance management procedures.

3. Reduce management of "outflow heat exchanger" and "sealed water heat exchanger" (meanings unclear in translated document).

4. Analyze lubrication oil of forced lubrication-type pump.

5. Improve electrical drive valve inspection program.

6. Measure cooling water equipment buffer tank thickness.

\section{A.4.2.3 Structural Systems}

KINS assessed the inspection results related to seismic rating of Class 1 structures and buried concrete piping and found no degradation effects that would impact the integrity of these structures. The soil test results were also analyzed to verify that the acidity and chloride chlorine content are within the allowable limits stated in NUREG-1801 (NRC 2001a, 2005b, 2010c). It was concluded that the structures reviewed satisfy regulatory safety requirements. KINS also confirmed that the Kori 3 and 4 buildings and NPP facilities have the necessary support systems and structures, including Class 1 seismic structures, and have an adequate water supply (apparently for emergency core cooling).

KINS found that the licensee must develop a subsurface environmental monitoring program to evaluate the degradation of subsurface concrete structures and subsurface piping, as well as 
structures near the sea and underwater structures. The licensee also needs to provide detailed information on degradation inspection, functional evaluation and maintenance, and degradation management methods for seismic gap filling material that is designed to prevent mutual structural interference in the event of an earthquake, and for sealing materials for safety-related structures and openings.

The licensee also needs to consistently monitor degradation for concrete structures due to such effects as salt and carbonation, and to develop strength prediction and inspection methods using the core strength versus compressive strength of concrete as determined by NDE.

\section{A.4.2.4 Electrical Systems}

KINS found that the licensee needs to develop a degradation management program for passive electrical systems, including the distribution system and cables.

\section{A.4.2.5 Auxilliary Systems}

The report stated that the "simulation removal team facility" (meaning unclear in translated document) needed to be improved by changing from the present simulation removal team to dedicated Kori Units 3 and 4 teams.

\section{A.4.3 Plant Safety}

KINS confirmed that there is proper control and authority over the restricted area around the plants and that the licensee has provided accurate data on the population density within $50 \mathrm{~km}$ of the plants, as well as the predicted population density over the next 10 years. It was confirmed that there are no chemical storage or transportation facilities nearby that can impact the safety of the NPP in the event of an accident. The potential for an accident related to aircraft was also found to be negligible.

KINS confirmed that the licensee's existing approach to accident analysis and results is appropriate, based on the latest interpretation methods and assumptions and the latest computer model accident analysis results. KINS also compared the accident data log at the time of licensing and approval to the accident data log based on the latest standards and found that there are four accident scenarios, which are potentially problematic. These scenarios are containment building exterior outflow duct rupture accident, "vapor generator heating pipe rupture" (apparently meaning steam generator tube rupture) accident, LOCA long-term cooling capacity, and small post-LOCA boron dilution accident. KINS analyzed the first two scenarios and recommended that the licensee carry out detailed analyses of the last two accident scenarios. The boron dilution accident scenario seems to be of particular concern to KINS, and the licensee was specifically directed to apply NRC's detailed evaluation method for this scenario to Kori Units 3 and 4.

KINS determined that the radioactivity levels and the radiation release limits stated in the existing safety analysis satisfy the latest KINS standards. KINS also confirmed that, using proper interpretation of early accidents, the licensee has properly considered various operational transient conditions expected to occur more than once during the lifetime of the plant. 
Natural and environmental conditions expected to occur at the plant, including typhoons, floods, and earthquakes, were analyzed. KINS evaluated conservative estimates of the atmospheric dispersion factor and wind speed standard using the measured atmospheric data from the operational period to evaluate the particular atmospheric characteristics around the plants. The evaluation results satisfied the related requirements. Soil erosion estimates were also made, based on maximum rainfall estimates, and the potential maximum and minimum water levels caused by typhoons, tsunamis, and earthquakes were analyzed. The results generally satisfied the related requirements. However, for the case of potential maximum water level, KINS found that there is a potential for flooding of the first-stage cooling water system intake structure and recommended that the licensee establish a flood prevention plan as a part of safety improvement.

KINS found that the safety shutdown earthquake $(0.2 \mathrm{~g})$ for Kori Units 3 and 4 matches the results of recently performed terrain analyses for Shin Kori 1 and 2 . In addition, the design response spectrum for the safety shutdown earthquake and the operation standard earthquake value are appropriate to the current technical standard. KINS confirmed that there is minimal possibility of terrain and earthquake phenomena that can impact nuclear power generation around the regions of Kori Units 3 and 4. KINS also found that blasting associated with the construction of additional nuclear plants at this site will not adversely affect Kori Units 3 and 4.

KINS found that the licensee has appropriately performed safety-related accident classification and analysis, as well as the documentation and analysis of safety performance index, and has appropriately managed the collective radiation exposure of the workers. The overall determination was that the licensee was managing the safety performance related items appropriately.

KINS determined that the licensee has an appropriate radiation emergency plan in place, and is executing that plan in accordance with regulatory requirements and related technical standards. In addition, the licensee has established a parallel performance procedure and evaluation plan. The licensee has properly selected candidate equipment for seismic verification and has properly performed these verifications, based on appropriate standards and procedures. In addition, the equipment is properly located and protected to prevent seismic damage. However, KINS found that the licensee does not have a seismic verification summary on file for the nuclear steam supply system (NSSS) equipment and identified a need to develop this summary.

KHNP performed field visual inspections of all seismic equipment and carried out corrective actions on areas where some correction was required. Overall, the licensee was found to be properly maintaining and managing the physical condition and functions of the equipment. However, KINS found that the licensee needed to develop a systematic procedure for field inspection, including certification verification, documentation, and quality assurance.

KINS directed the licensee to carry out radioactivity shielding measurements at an unspecified test shielding location during operation to determine whether the radioactivity shielding function is being properly maintained. KINS also requested that the licensee develop confirmation methods to determine whether the radioactive water within the waste package is less than 0.5 percent, as specified in the regulatory requirements for mid-to-low-level radioactive waste disposal. In addition, KINS found that there was a need to further develop safety improvements based on PSA methods, but no details were given. The report also proposed that the licensee 
reset the monitoring values of the radiation-monitoring device for the plumbing, sewer, and working areas to an unspecified appropriate level.

\section{A.4.4 Performance and Feedback of Experience}

\section{A.4.4.1 Operating Experience}

KINS confirmed that the licensee has established a procedure to collect, analyze, and manage domestic and international OpE and has developed a plan to incorporate lessons learned and this OpE. KINS noted that the licensee had proactively replaced "turning vane cap screws" and "diffuser adapter cap screws" in coolant pumps, based upon international experience. In addition, the licensee had upgraded motor-driven valve systems and improved its response to station blackout scenarios. However, KINS requested actions in the following areas, based on industry OpE:

1. The licensee is to reevaluate the current design of the recirculation water collection tank in the containment building.

2. The licensee is to reevaluate whether it can maintain containment building cooling system function and soundness of the containment building when there is external power loss, in accordance with the guidance of NRC GL 96-06.

3. The licensee is to establish a degradation management program for the stress corrosion cracking (SCC) of welded reactor vessel components and internals fabricated of Alloy 600 and Alloy $82 / 182$ weld metal.

4. The licensee is to establish an inspection plan for the second upper bundle-in-bundle in the steam generator to track and monitor stoppage phenomena (meaning unclear in translated document).

5. The licensee is to establish a long-term AMP for the (radiation-related?) degradation of protective coatings used on the containment steel liner plate, internal concrete, and steel structures.

No significant information related to plant performance was identified.

\section{A.4.4.2 Comparison of Operating Experience with U.S. Plant of Similar Design}

The U.S. plant of similar design to the Kori Units 3 and 4 Nuclear Power Plants is V.C. Summer (Gavrilas et al. 2000). The LRA (South Carolina Electric \& Gas Company 2002) and resulting SER for V.C. Summer (NRC 2004c) were reviewed to identify common areas of concern and to note similarities and differences in OpE. A caution in making this comparison is that component equipment manufacturers and the manufacturing process may vary from plant to plant, thus limiting the value of such direct comparison.

The KINS report does not provide details on specific OpE events at Kori Units 3 and 4, so it is necessary to infer apparent aging management issues from the recommendations contained in the KINS PSR. Jin et al. (2009) reported that the main aging issues at Kori Units 3 and 4 are (a) the establishment of supplemental AMPs for electrical passive components and nuclear 
safety-related structures, including the containment building; (b) the improvement in component examination and performance management procedures; (c) strengthening the visual inspection of reactor internals; and (d) performance management of heat exchangers.

The aging-related degradation management issues inferred for Kori Units 3 and 4, as compared with the findings for V.C. Summer, are summarized as follows:

Stress Corrosion Cracking of Dissimilar Metal Welds: KINS stated that the licensee needs to perform further evaluations of and establish a degradation management program for SCC in dissimilar metal welds involving Alloy 600 base metal and Alloy 82/182 weld metal, presumably in the vessel head penetrations and vessel nozzles. This implies that Kori Units 3 and 4 may be experiencing SCC problems at these welds. The V.C. Summer SER (Section 3.1.2.3.1) states that the licensee performed VT-3 inspections of the interior surface of the reactor vessel head in April 1999 and found no recordable indications. Following a request for additional information, the NRC staff found the Summer Alloy 600 AMP to be acceptable.

Steam Generator Tube Inspection: KINS stated that the licensee needs to develop an inspection plan for the second upper tube bundle-in-bundle for the steam generator, implying that there is an inspection accessibility problem for portions of the steam generators. The V.C. Summer SER (Section 3.1.2.3.5) states that, in 2000, the licensee inspected tubes in all three SGs and performed a 100 percent secondary-side inspection. No accessibility issues were noted.

Inspection of Containment: KINS stated that the licensee should conduct direct inspections to evaluate possible degradation in safety-related structures, including the containment structure, where direct access is not possible due to high radiation levels, subsurface locations, and locations that are near the sea or are underwater. In particular, there was a need to monitor subsurface concrete structures and subsurface plumbing in these structures. V.C. Summer uses a plant-specific inspection program to manage aging-related degradation for inaccessible areas of containment (SER Section 3.5.2). This AMP includes groundwater and reservoir chemistry monitoring, inspection of below-grade concrete when exposed, and the use of periodic inspections of underwater concrete structures as an indicator of potential problems.

Coatings Degradation: KINS cited a need for the licensee to establish a long-term performance-monitoring plan for internal "radiation-hardened" protective coatings based on newly enacted regulations and guidelines. Based on an evaluation of the results for protective coatings for the steel liner plate and internal concrete and steel structures in the containment building, the licensee was to establish a plan to analyze degradation phenomena, evaluate durability, and mitigate degradation. From this, it is inferred that containment coatings degradation is an issue at Kori, though the PSR does not provide any specifics. The V.C. Summer plant manages coating degradation in containment through its Containment Coating Monitoring and Maintenance Program, which is described as being consistent with GALL AMP XI.S8, "Protective Coating Monitoring and Maintenance." The V.C. Summer OpE (LRA Section B.1.15.1) describes some minor incidents of containment liner coating degradation, but does not indicate that this is a major problem area.

Containment Sump Clogging: The KINS SER states that the licensee needs to assess the "potential degradation of capability of recirculation catchment of containment building." Although not an aging issue, this presumably refers to concerns about recirculation sump 
strainer clogging due to debris generation in the event of a major steam line break inside containment. The KINS report states that the licensee must evaluate the appropriateness of the current (sump and strainer?) design and correct any deficiencies. This corresponds to NRC Generic Safety Issue 191 ("Assessment of Debris Accumulation on PWR Sump Performance"), which has been exhaustively studied in the U.S. All PWRs in the U.S., including V.C. Summer, have been required to submit a detailed analysis of their susceptibility to this potential problem in response to NRC GL 2004-02, and almost all plants, again including V.C. Summer, have replaced their original sump strainers with improved designs that have greatly increased strainer surface areas.

\section{A.4.5 Management}

KINS found that the licensee has established an appropriate system for documenting and managing operating, repair, and maintenance procedures and that a symptom-based emergency operating procedure has been developed and is being maintained. The licensee was directed to develop an operating procedure document for loss of coolant during shutdown and to develop a similar procedure for the residual heat removal system during "partial water operation."

Based on the evaluation results of the organization and administration, KINS determined that the licensee has established appropriate safety goals and has well-defined written roles and responsibilities for individuals and groups to attain these safety goals. The licensee was found to have established a good safety culture, to have developed written roles and responsibilities, to have a sound education and training program in place, to be leveraging outside expertise as appropriate, and to have a sound organizational structure overall. No follow-up actions were identified.

The KINS review of human factors management determined that the licensee has adequate qualified personnel for plant operation and performs appropriate training for workers. Two items for improvement in the area of man-machine interface (MMI) were noted:

1. The licensee was found to be deficient in evaluating discrepancies between actual MMI condition and the MMI condition reported in documentation written as a of follow-up to the TMl accident.

2. KINS recommended that the licensee apply the latest human engineering design evaluation requirements of NUREG-0700, Rev. 2 (NRC 2002a), and improve its evaluation approach as a part of overall safety improvement.

In addition, it was suggested that the licensee revise the procedure document concerning human engineering to correct errors and ambiguous wording with the goal of decreasing the occurrences of human error.

\section{A.4.6 Environment}

KINS determined that the licensee has an appropriate environmental monitoring system in place and manages environmental impacts appropriately. KINS also determined that the licensee has evaluated all potential radiation release paths and that its environmental program, including civilian radiation exposure, satisfies the related standard. 


\section{A.4.7 Conclusions}

The KINS evaluation of the Kori Units 3 and 4 PSR confirmed that Kori Units 3 and 4 are being maintained and operated according to applicable technical standards and regulatory requirements. A total of 22 follow-up safety improvement items were identified and are summarized in the KINS summary report. These safety improvement items are in the areas of facility improvements (2), operational improvements (12), and safety evaluations (8). KINS requested the licensee to submit an execution plan for the implementation of these recommendations, as well as additional recommendations from the Nuclear Safety Committee Specialization Subcommittee and Nuclear Safety Committee. The licensee is to submit this implementation plan within 3 months after completion of the review of the Nuclear Safety Committee. The Korean Ministry of Science and Technology will review and approve the plan. KINS will review the progress of the implementation process every 6 months until the licensee has completed all of the recommendations. With the implementation of these recommendations, KINS finds that Kori Units 3 and 4 can operate safely until the next periodic safety evaluation.

\section{A.4.7.1 Summary of Technical Issues that Merit Further Consideration}

- The Kori PSR mentions the proactive preventive replacement of coolant pump "turning vane cap screws" and "diffuser adapter cap screws," based upon international industry experience (Section A.4.4.1).

- The Kori PSR appears to refer to a need to develop a long-term plan to monitor the radiation-induced degradation of protective coatings inside containment (Section A.4.4.1).

- The Kori PSR report mentions a need to develop a monitoring program to evaluate the possible degradation of subsurface concrete structures and subsurface concrete piping (Section A.4.2.3).

\section{A.5 South Korea (Ulchin Units 3 and 4)}

The South Korea Ulchin Units 3 and 4 NPPs are two-loop PWRs of the Korean Standard Nuclear Power Plant (KSNP) OPR1000 design. Unit 3 was commissioned in August 1998 and is rated at $994 \mathrm{MWe}$, and Unit 4 was commissioned in December 1999 and is rated at $998 \mathrm{MWe}$. The plants are located in Buk-myeon, Ulchin-gun, North Gyeongsang Province, and are operated by KHNP. KINS conducted an initial PSR assessment of these plants for the period from startup through 2007, and the results of that review are presented in their April 2010 report, referenced in Section 2.1 above.

The KINS April 2010 assessment of Ulchin 3 and 4 utilized Korean and international technical standards related to the plant's physical location, design, facilities, operation, quality assurance, and aging and degradation management. The goal of the assessment was to determine the adequacy of the technical standards and to confirm the ability of the plants to continue safe operation until the next PSR. The assessment took into account domestic and international $\mathrm{OpE}$ and recent research results and technical advances. The PSR performed by KHNP evaluated the two reactors with respect to 11 areas, namely physical condition of SSCs, nuclear safety analysis, equipment qualification, aging management, safety performance, use of OpE and research findings, procedures and specifications, organization and administration, human 
factors, emergency planning, and environmental impact. IAEA element 1 ("plant design") was not included in the review, and elements 5, 6, and 7 were combined into the more general category of "safety analysis." This is because KINS followed the guidance of the 1994 version of the IAEA Safety Guide (IAEA 1994), which includes only these 11 safety factors rather than the 14 safety factors described in the 2003 version that was utilized by the other countries reviewed in this study.

\section{A.5.1 Plant Modifications}

The PSR assessment did not provide any specific information on plant modifications.

\section{A.5.2 Aging Degradation and Management}

KINS determined from the PSR that KHNP performed an adequate degradation assessment of the required SSCs using qualitative and quantitative analysis methods, based on the related OpE and recent research results. This assessment included the degradations and SSCs referenced in the American Society of Mechanical Engineers (ASME) Code Section III, Appendix W (ASME 2004a), and the GALL Report (NUREG-1801).

The occurrence of degradation due to the corrosion of protective coatings and pump and valve bodies, wear, and fatigue was found to be adequately managed through periodic inspection, testing, and maintenance programs as planned and with preventive maintenance, confirming that the SSCs at Ulchin Units 3 and 4 were in good physical condition.

The KHNP PSR assessment stated one safety improvement item related to the equipment qualification, namely "Establish and supplement seismic verification maintenance and management procedure." KINS agreed with this recommendation. It noted that the seismic qualification equipment list and maintenance procedure should reflect that (a) even when safety-related equipment is replaced with new equipment in total or part, the seismic verification document should be managed appropriately; and (b) a system (procedure) is established to evaluate and analyze the impact of seismic equipment replacement responding with proper measures.

\section{A.5.2.1 Mechanical Systems}

A review of inservice testing of safety-related pumps and valves was found to meet the ASME Operation and Maintenance Code standards, and the performance of reactor coolant pumps was found to be without any issue, based on KINS's review of the maintenance and inspection results.

KINS reviewed the performance test record of heat exchangers required for shutdown cooling, determined that it met the allowable standards, and confirmed that the heat exchanger was operating appropriately, based on the review results of maintenance history and field inspection.

The KINS evaluation of the degradation record due to fouling in representative heat exchangers confirmed that their performance was within the allowed tolerance limits and that the utility had established enough margins to maintain the performance level until the next PSR. However, KINS also determined that the utility needed to develop similar procedures and documentation 
for other safety-related heat exchangers not currently under its performance testing/inspection plan, in an effort to improve the safety margin. This resulted in the safety improvement recommendation stated as "Establishment of heat exchanger performance management plan."

\section{A.5.2.2 Structural Systems}

KINS confirmed that the seismic category class type 1 structures were being inspected according to the required procedures, there were no significant deficiencies that would impact their soundness, and the necessary repairs and maintenance were performed as appropriate. KINS also confirmed that the liner plate and MC-rated parts (metal containment components) of the reactor containment building were being managed for aging degradation according to the in-service inspection (ISI) requirements of ASME Section XI, Subsection IWE (ASME 2004b), and the inspection records indicated the thickness of liner plate to be within the allowed limit to maintain the containment pressure limits. In addition, the utility has an ongoing maintenance management program to perform repairs on any confirmed deficiencies. Based on the review of ISI results on the post-tensioning system of the container building over the last 10 years, KINS did not find any degradation phenomena impacting the containment structure and confirmed that the effective tensile strength was within the required limit.

However, KINS recommended supplemental actions as a collective safety improvement item, namely "Establishment of management plan and reliability increase on structural degradation evaluation." These actions included (a) a direct inspection of areas that are difficult to approach, such as structures near seawater, underwater structures, and subsurface locations; (b) collecting additional data and improved assessment so as to increase the reliability of its compression strength estimation method using the Schmidt Hammer; (c) increasing reliability of data and procedures for structural soundness evaluation choosing consistent degradation measurement locations; and (d) removing deficiencies in documentation of the inspection record and repair history on the physical condition of the "radiation protective" coatings on steel structures, plumbing, and equipment inside the containment building.

KINS noted that the PSR did not provide results on the degradation condition of the containment penetration duct sealants and fillers of safety-related structures. This resulted in the safety improvement item "Establishment of degradation management plan for sealant and seismic gap filler." Under this item, KHNP was required to provide (a) an execution plan to inspect for the degradation of sealants of penetrator ducts and openings of safety-related structures constructed for the diverse purposes of radiation shielding and flood protection, including a performance verification and maintenance management plan; and (b) an evaluation showing satisfactory performance of the filler design requirement, based on field measurements, and physical condition of seismic gap filler material necessary for the prevention of mutual interference of structures in the event of an earthquake.

KINS did not find in the PSR any assessment of the physical condition of radiation shielding within the containment. KINS requested that KHNP perform a shielding probe test at the identical location where the initial shielding probe test was performed during initial operation in order to compare the present physical condition to the physical condition at initial operation. However, KHNP was not able to provide the shielding probe test results during the assessment period. As a result, KINS recommended the following items for safety improvement: in order to confirm whether the radiation shielding function is properly maintained, the licensee should perform a shielding exploration test at the same location where the initial shielding exploration 
test was performed on Ulchin Units 3 and 4 during the trial operations and submit the test results for review. This safety improvement item was labeled "Radiation shielding function evaluation."

The PSR report also noted a need to establish a plan for the inspection and maintenance of concrete structures that are difficult to access, including subsurface concrete and the underwater parts of structures near the sea.

\section{A.5.2.3 Electrical Systems}

KINS confirmed the soundness of physical condition of SSCs related to electrical facilities and noted that the plant has two physically independent emergency electrical circuits for the external electrical power system. In addition, for internal safety-related electrical systems, the plant facility continues to maintain and manage adequate capacity, independence, diversity, testability, and reliability, and maintains these electrical systems in good physical condition. KINS reviewed cable, electrical lines, and trays, and found them to be in good physical condition. However, KINS is also planning further inspections by developing an improved inspection procedure before the second PSR.

KINS reviewed KHNP's documentation and confirmed that the design and functional characteristics of the generator protection system and instrument control system satisfied all related technical standards and regulation requirements. KINS also evaluated KHNP's test results, confirming the functionality of electrical system facilities, including the emergency diesel generator system and satisfaction of related requirements.

\section{A.5.2.4 Auxilliary Systems}

Based on their review of the design and manufacturing characteristics, inservice operation history, test records, maintenance records, design change history, and field inspection of the auxiliary and power converter systems, KINS determined that these systems were operating appropriately.

KINS reviewed the testing, inspection, and repairs records of the radiation protection facility and equipment and confirmed that the radiation protection facility and equipment, including the radiation management area, entry and exit management area, radiation measurement equipment, protection equipment, area radiation monitoring system, and worker radiation exposure evaluation equipment, were all in good physical condition. However, KINS noted a deficiency in the inspection system for the active carbon filter and high-efficiency particulate air (HEPA) filter for the breathing air protection system (mask) necessary for reduction of worker exposure. This resulted in KINS's recommendation for KHNP to appropriately correct and improve the system functionality as a safety improvement item labeled "Capability verification of breathing protection system and operational system improvement."

\section{A.5.3 Safety Analysis}

KINS performed an assessment of the key aspects of plant safety analysis required and documented by the licensee for Ulchin Units 3 and 4. The assessment took into consideration various current and updated regulatory requirements and standards, technical standards and guides (including IAEA guidance and NRC Regulatory Guides and GLs). Based on these and 
KINS's review of results of applying the latest interpretation methods, computer codes, and major assumptions, KINS concluded that the licensee's existing approach to accident analysis and results were appropriate and that the approval for operational changes to "PLUS7" fuel usage and for the main steam safety valve open setting reflected the latest technical standard. KINS also requested the addition of an evaluation of a loss of power and loss of normal water supply and confirmation that the pressurizer overfill from the "Condition II" accident (not defined in the report) would not lead to serious power plant conditions.

Based on a review of results related to the loss of decay heat removal function during partially filled water operation, as required by GL 88-17 (NRC 1988c) and related Korean regulations, KINS stated that the licensee should set the minimum flow to prevent exposure of the core and ensure openings to prevent water loss if over-pressure occurs inside the reactor due to boiling. KINS determined that the licensee can perform natural circulation cooling and that it considered the LTOP protection appropriate with the updated requirements and standards. KINS also determined that the licensee has reflected the results of safety interpretation in design changes, operation technical guidelines, and related procedures. KINS also determined that the licensee intends to fully and comprehensively evaluate safety and to make improvements through the coordination of PSR and PSA activities and results.

With regard to assessment of the radioactivity levels and radiation release limits in the event of an accident, although the licensee satisfied the allowed limits applying NRC Regulatory Guide 1.183 (NRC 2000b), KINS determined that the alternate source term did not fit the domestic regulation requirement and requested reevaluation by the licensee. The licensee's reevaluation, based on updated technical information and guidance, was found to be acceptable to KINS for satisfying the allowed limits. However, KINS also determined that the margin for the allowed standard is generally decreased compared to the present Final Safety Analysis Report (FSAR) and that the licensee should keep a record of the safety evaluation results for the present condition of the power plant and incorporate accident interpretation results based on the latest atmospheric dispersion data into its FSAR.

The KINS review determined that the licensee conforms to appropriate regulatory guidance on operator responses, common cause effects, standards for single failure, multiplicity, diversity, and independence in the safety analysis and carried out the appropriate accident analysis, including consideration of various operational transient conditions expected to occur more than once during the lifetime of the power plant.

KINS reviewed the licensee evaluations for natural and environmental conditions expected to occur around the nuclear power facility, including typhoons, floods, and earthquakes, as well as weather conditions and population distribution. KINS determined that the licensee used appropriate conservative estimates of atmospheric dispersion factors and weather conditions and took into consideration soil erosion based on the maximum rainfall estimate, as well as the potential maximum and minimum water levels caused by typhoons, tsunamis, and earthquakes.

A review of the functional maintenance of the ultimate heat sink was also conducted, considering seawater temperature around the Ulchin Unit 3 and 4 NPPs and water intake opening and assuming an increase in seawater temperature during the next 10 years. KINS determined that the licensee safety analysis satisfied the necessary requirements. However, in a case where seawater is flowing back into the power plant due to topography and geologic media effects, the underground water distribution characteristics are likely to be impacted, and 
liquid radioactive material may leak to the environment. KINS requested, as a safety improvement item, that the licensee provide radionuclide distribution characteristics for the underground water around the power plant and evaluate the dispersion impact.

KINS confirmed that Ulchin Units 3 and 4 are well within the conservative design limit of $0.2 \mathrm{~g}$ for seismic activity. However, in response to the requirements for the new Shin Ulchin Unit 1 and 2 NPPs currently being constructed near the Ulchin Units 3 and 4 sites, a precise geological survey (including the marine sea floor) is being performed, and KINS requested that the licensee update its safety analysis report based upon the results.

In summary, KINS determined the appropriateness of the licensee's safety analysis in light of current analysis methods, safety standards, and knowledge, taking into account physical conditions at the time of evaluation as well as those expected 10 years from the reference assessment date. Based on its review of the safety analysis elements, KINS determined that the licensee satisfied the relevant standards. However, KINS also recommended the following for safety improvements: (1) update the FSAR to reflect the atmospheric dispersion factor based on latest standards, and (2) evaluate the dispersion impact in case of an accident scenario resulting in liquid radioactive material leakage to the underground water, with provisions for water quality monitoring.

\section{A.5.4 Performance and Feedback of Experience}

\section{A.5.4.1 Performance}

No significant information related to plant performance was identified in the report.

\section{A.5.4.2 Operating Experience}

KINS confirmed that KHNP has established a procedure to collect, analyze, and manage domestic and international operational experience and to utilize the results, including root cause analysis and lessons learned, in the improvement plan at Ulchin Units 3 and 4. In particular, KHNP has incorporated the significant lessons learned for the reactor pressure vessel (upper head penetrations, coolant nozzles, etc.), control rod drive systems welded parts (for stress corrosion), reactor internals, steam generators, pressurizer nozzles, and primary and secondary coolant systems. KINS noted that KHNP used relevant NRC Regulatory Guides to improve reliability of operation for the emergency diesel generators (EDGs), and has appropriately reflected domestic and international operational experience, including the U.S.'s Licensee Event Reports (LERs) and GLs on maintenance, replacement, and improvement of testing procedures for valves and valve drive systems. In addition, KHNP has incorporated research results into the inspection of seismic category 1 concrete structures and maintenance procedures.

In April 2002, Ulchin 4 experienced an SG tube rupture that was attributed to a manufacturing defect. An inspection of the same location in other tubes did not reveal the presence of any similar defects. KHNP performed the required SG inspections and incorporated the U.S.-based SG management program.

KINS noted a recent instance of PWSCC in the upper head penetration of the Yonggwang Unit 3 NPP reactor vessel. Since the Ulchin Units 3 and 4 reactor vessel upper head penetration areas are made of the same PWSCC-sensitive material (Alloy 82/182), KINS 
recommended that KHNP enhance the degradation management program to prevent or mitigate PWSCC at the penetration welds of the Ulchin Units 3 and 4 reactor vessels.

KINS reviewed the inspection results of radiation effluents released through the rad-waste gas treatment system and found the conditions to be satisfactory. KINS also noted an incident at Yonggwang Unit 3, where defects in the nuclear fuel resulted in an accidental release of traceable amounts of inert gases through the rad-waste gas treatment system. As a result, KINS recommended that KHNP revise the plant procedure document to reflect post treatment and identification of causes for unidentifiable radionuclides, including $\mathrm{Br}-82$.

The containment sump (also known as emergency or recirculation sump) in a PWR is part of the emergency core cooling system (ECCS) that is required to be functional to mitigate a design basis accident. The NRC identified a generic issue with the sump strainers and associated debris blockage of flow paths that might impede the long-term operation of the ECCS or containment spray system, and requested all operating PWR licensees in the U.S. through GL 2004-02 to perform analyses to ensure system functionality. Based on its review of Ulchin Units 3 and 4 PSRs, KINS noted that KHNP had not addressed this issue and recommended it do so as a safety improvement item. KINS also recommended similar actions for the containment building.

\section{A.5.4.3 Comparison of Operating Experience with U.S. Plant of Similar Design}

Ulchin Units 3 and 4 are two-loop PWRs of the KSNP design, and there are no similar plants in the U.S.

\section{A.5.4.4 Management}

No significant information related to plant management was provided in the report.

\section{A.5.4.5 Environment}

Information related to environmental effects was not reviewed.

\section{A.5.5 Conclusions}

The assessment of the PSR performed by the KINS for KHNP's Ulchin Unit 3 and 4 NPPs concluded that the PSR was appropriately completed according to the requirements of Korean Nuclear Power Act 23-2 (Periodic Safety Assessment). It also concluded that the two NPPs were being operated appropriately according to the latest technical standards in effect at the time of the assessment. Based on its assessment, KINS also identified 15 items as recommendations for safety improvement, of which two were related to plant physical condition, one to equipment qualification, four to aging, and three to safety performance and OpE. The remaining items included two for safety analysis, one for human factors, and two for environmental impact. KINS requested KHNP submit an execution plan responding to these safety improvement items to the Ministry of Education, Science, and Technology (MEST) within 3 months, with semi-annual progress reports to be confirmed by MEST until plan completion. KINS indicated that if KHNP executes the approved plan for safety improvement items, then KINS expects the Ulchin Unit 3 and 4 NPPs to continue to operate with improved safety conditions for the next 10 years from the reference evaluation date (November 8, 2007). 


\section{A.5.5.1 Summary of Technical Issues that Merit Further Consideration}

- The Ulchin PSR noted a need to establish a plan for the inspection and maintenance of concrete structures that are difficult to access, including subsurface concrete and the underwater parts of structures near the sea (Section A.5.2.2).

- The Ulchin PSR notes a need to improve the reliability of the Schmidt Hammer method for estimating the compressive strength of concrete (Section A.5.2.2).

\section{A.6 South Korea (Yonggwang Units 3 and 4)}

The South Korea Yonggwang Unit 3 and 4 NPPs are two-loop PWRs of the Combustion Engineering System 80 design. Unit 3 was commissioned in March 1995 and Unit 4 in January 1996, and each unit is rated at $1000 \mathrm{MWe}$. The plants are located in Yonggwang, South Korea and are operated by KHNP. KINS conducted an initial PSR assessment of these plants for the period from startup through 2006, and the results of that review are presented in their June 2007 report referenced in Section 2.1 above.

The KINS June 2007 report is an evaluation performed by KINS to verify that the Yonggwang Units 3 and 4 PSR Assessment Report conforms to Korean regulatory requirements and that safe operation of the plants is ensured until the next review. The PSR performed by KHNP evaluated the two reactors with respect to 11 areas, namely physical condition of SSCs, nuclear safety analysis, equipment qualification, aging management, safety performance, use of OpE and research findings, procedures and specifications, organization and administration, human factors, emergency planning, and environmental impact. IAEA element 1 ("plant design") was not included in the review, and elements 5, 6, and 7 were combined into the more general category of "safety analysis." This is because KINS followed the guidance of the 1994 version of the IAEA Safety Guide (IAEA 1994), which includes only these 11 safety factors rather than the 14 safety factors described in the 2003 version that was utilized by the other countries reviewed in this study.

\section{A.6.1 Plant Design}

\section{A.6.1.1 Actual Conditions of SSCs}

The PSR confirmed that the current physical condition of the pumps, valves, heat exchangers, and fire protection system were good, based on the results of a review of test and inspection records. A review of testing conducted before and during operation and the repair records of the metallic components such as reactor coolant system confirmed that they were in accordance with relevant requirements, including Korean Ministry of Science and Technology Notice 2004-13, ASME Code Sections III and XI, and similar standards. The physical condition of the instrumentation and control facilities was good, based on a review of quality assurance inspection, visual inspection, and site inspection records.

The PSR confirmed that the seismic class 1 structures were appropriately maintained and managed, and periodic checks found no severe defects that could affect the integrity of the facilities. Any defects detected were appropriately repaired. The physical condition of the off-limit areas and radiation management areas, radiation measurement and protection 
equipment, local radiation monitoring system, and exposed radiation dose evaluation system were also good. The results of a review of the licensee's inspection results and repair records for the supplementary systems and power conversion systems confirmed that these inspections were appropriately conducted, and that necessary repairs and changes were made during the planned preventive maintenance.

The PSR concluded that the physical condition of the systems, equipment, and structures at the time of the safety assessment was generally good and that testing and repairs were appropriately conducted. The safety of the nuclear facilities was also found to be appropriately maintained, although three areas of safety improvement related to long-term cooling following a LOCA, atmospheric dispersion factors associated with a radioactive release, and evaluation of the effects of sea level flooding on safety related structures were noted.

\section{A.6.1.2 Equipment Qualification}

Equipment Qualification is divided into earthquake-qualification and environmental qualification. The PSR cited a number of U.S. standards and NRC regulatory guides as being applicable to equipment qualification at Yonggwang.

\section{Earthquake Qualification}

The PSR identified several improvements for Yonggwang Units 3 and 4 related to earthquake-resistance qualification. KINS found that it was difficult to manage the quake-resistance verification of the NSSS and balance of plant (BOP) equipment due to a lack of summarized data on quake-resistance verification. KINS therefore requested the licensee to prepare a summary table on the earthquake resistance of this equipment. Because the equipment list submitted documenting the maintenance and management of earthquake resistance does not include all the equipment to be verified, the licensee was requested to check the current status of this documentation and prepare an inventory list to ensure that all applicable equipment is included in the current plan to establish procedures for maintaining and managing quake-resistance verification. A list of equipment to be verified for earthquake resistance that has not yet been inspected must also be prepared, and appropriate corrective measures must be taken, if necessary.

\section{Environmental Qualification}

With respect to environmental qualification, the PSR confirmed that the locations of the equipment to be qualified were divided into favorable and harsh environments, and the environmental conditions (such as temperature, humidity, and radiation) were monitored and managed in accordance with design requirements. For the replaced equipment, the PSR found that the management of verification documents for some replaced equipment whose design was changed was not sufficient. The licensee developed a safety improvement item on this, and KINS reviewed its contents and found them to be appropriate.

\section{A.6.2 Aging Degradation and Management}

\section{A.6.2.1 Aging Management Review}

The AMR covers the following five areas: 
- Classifying and selecting the systems, equipment, and structures, and evaluating their maintenance;

- Analyzing the aging of the systems, equipment, and structures, and evaluating their maintenance;

- Classifying the functions and safety allowances of the systems, equipment, and structures according to the applicable aging phenomena;

- Developing measures and management plans to mitigate aging of the systems, equipment, and structures; and

- Predicting the time the systems, equipment, and structures will fail to perform satisfactorily, and their future conditions.

The details of these five areas are described below.

\section{Classifying and Selecting the Systems, Equipment, and Structures, and Evaluating their Maintenance}

The PSR confirmed that aging management covers various control systems, the protection systems, the instrumentation systems, the metal debris monitoring system, and the earthquake monitoring system. In addition, aging analysis was conducted on the detectors, recorders, relays, sensors, switches, orifices, nuclear reactor trip breakers, transmitters, power supplies, electronic circuit cards, controllers, indicators, amplifiers, fuses and fuse holders, and panels, and so forth. The PSR found that the selection of the systems and components to be evaluated was appropriate because it was made by considering the characteristics of the instrumentation control facilities and their effect on safety.

The PSR also found that the classification of the equipment to be evaluated for aging was appropriate, as this equipment was classified in accordance with ASME Section III, Appendix W (ASME 2004a), including active and passive equipment as well as equipment for which the electronic characteristics were considered.

\section{Analyzing the Aging of the Systems, Equipment, and Structures, and Evaluating their Maintenance}

The PSR stated that aging of components in contact with the coolant and cooling water systems was managed in part by maintaining appropriate water chemistry in accordance with water quality management procedures. The PSR also stated that if the current aging management program is appropriately implemented, the aging of most seismic class 1 structures could be properly managed. However, an analysis of the aging phenomena based on the physical conditions of these structures and an evaluation of their durability has not been submitted by the licensee. Therefore, plans for monitoring the performance of protective coatings and applying new technical standards must be developed and their contents must be implemented, and a plan for managing and mitigating aging must be prepared in such a way as to conform to the guidance in the revised Regulatory Guide 1.54 (NRC 2000a).

Jin et al. (2009) states that the main aging issues at Yonggwang Units 3 and 4 were related to condition monitoring and preventive maintenance improvement, performance management of 
heat exchangers, and assessments of nuclear safety-related structures, including the containment building. All aging issues have been identified as follow-up measures in the resulting implementation schedule.

\section{Classifying the Functions and Safety Allowances of the Systems, Equipment, and Structures According to the Applicable Aging Phenomena}

The PSR confirmed that the performance of the components in instrumentation-control facilities were appropriately maintained based upon an aging analysis that considered stress corrosion, conductor failure, changes in characteristics, insulation degradation, and corrosion. It also determined that the function and performance of the instrumentation control facilities related to safety were appropriately maintained and they were in proper condition for carrying out their safety-related functions.

The observed wall thinning of the containment liner plate due to corrosion was $0.13-0.19 \mathrm{~mm}$, which is below the range (>10 percent) that requires a response under ASME Section $\mathrm{XI}$, Subsection IWE (ASME 2004b). The surfaces in question was treated and repaired by recoating. The safety margin of the prestressing tendons was found to be properly maintained and the effective tension of the tendons was within the acceptable range.

\section{Developing Measures and Management Plans to Mitigate Aging of the Systems, Equipment, and Structures}

The PSR confirmed the aging phenomena for the main parts of the nuclear RPV, the steam generators, and the primary and secondary system piping was appropriately analyzed using qualitative and quantitative evaluation methods and the latest research results and OpE. The PSR states that, for the instrumentation and control systems equipment, five aging effects/mechanisms (e.g., stress corrosion, conductor failure, changes in characteristics, insulation degradation, and corrosion) were analyzed, and the results confirmed satisfactory performance.

The thickness of the containment liner plates was within the specification, and no aging phenomena were found that could affect the pressure threshold of the reactor building. In addition, no aging phenomenon was found to be severe enough to affect the prestressed containment, and the effective tension of the tendons was within the range of expected values.

For the heat exchangers, the PSR confirmed that the overall heat transfer coefficients and fouling factors were within acceptable limits. The likelihood of performance degradation caused by fouling before the next PSR was found to be low. However, the PSR noted that it is necessary to reevaluate the possibility of PWSCC at dissimilar metal welds from the perspective of the LBB (leak before break) screening criteria.

For the class 1 structures, the PSR identified several follow-up improvement items:

- No inspection was carried out for areas that were difficult to access, such as underground structures and those near seawater. This requires corrective measures.

- A revised inspection plan for the water intake structures for cooling the primary equipment needs to be established due to the corrosive nature of the seawater environment. 
- Additional data are needed to increase the reliability of the estimation of concrete compressive strength using the Schmidt Hammer.

- The procedure documents for determining the degradation factors for structures need to be revised and made more consistent to improve the reliability of the data for evaluating structural integrity.

- The repair and inspection records for the physical condition of the radiation-resistant protective coatings applied to the liner plates in the containment buildings, concrete, equipment, pipes, and steel structures were not adequate and need to be supplemented.

The PSR found no abnormal phenomena such as cracking on the foundation slopes, and it was determined that the slopes and the foundation were stable. KINS also reviewed the fillers and sealants used at structural penetrations and found that, while the materials selected and their performance at the time of the facility construction were satisfactory, the potential aging of these sealants has not been addressed. The PSR identified the following improvement items:

- An AMP must be submitted that includes verifying the performance and maintenance of the fillers used at penetrations and openings in safety-related structures constructed for various purposes such as radiation shielding and flood protection.

- A plan must be developed for checking the condition of the seismic gap fillers used to prevent structures from interfering each other in an earthquake. The plan is to include assessing filler performance by collecting samples from the site, evaluating whether the design conditions of the fillers are satisfied, and assessing their maintenance and management.

- A plan to periodically maintain and manage the watertight doors and blast-proof doors, which are considered safety-related structural elements, must be developed.

\section{Predicting the Time the Systems, Equipment, and Structures Will Fail to Perform Satisfactorily, and their Future Conditions}

The PSR states that the items whose performance was found to be below requirements as identified through inservice testing and inspection were repaired or replaced, and a sufficient safety margin exists with respect to aging phenomena over the next 10 years. The PSR confirmed that the failure rates and the MTBF for instrumentation and control components were determined through continuous testing, inspection, and maintenance of the control facilities. This means the instrumentation control facilities have been continuously monitored and evaluated for aging based on the characteristics of the active equipment in the instrumentation control facilities, and it was found that the present AMP is effective for maintaining the integrity of the instrumentation control facilities.

The PSR pointed out that the seismic class 1 structures presently do not have any performance problems, and a sufficient margin exists for aging phenomena over time, in accordance with the requirements of the applicable regulations. However, it is necessary to estimate the strength 
and to verify the core compressive strength of the concrete using non-destructive methods in order to improve the reliability of the aging evaluation.

\section{A.6.3 Safety Improvements Identified}

This section describes the safety improvements identified in the PSR that must be implemented at Yongwang Units 3 and 4 to ensure safe operation through the next PSF, based on a review of aging, equipment qualification, and OpE.

\section{A.6.3.1 Nuclear Fuels}

No items identified.

\section{A.6.3.2 Mechanical Systems}

The PSR cited a need to establish a maintenance and management system for the environmental qualification of mechanical components. This includes establishing procedures for maintaining a list of the equipment subject to environmental-resistance verification, and reviewing and updating the required documents for that equipment.

The PSR also cited a need to establish a maintenance and management system for earthquake-resistant qualification. This includes establishing and applying procedures for maintaining and managing systematic earthquake-resistance verification. The FSAR summary table listing the equipment to be verified needs to be updated, and the equipment that has not gone through site inspections should be identified and inspected.

In addition, the PSR cited a need to perform visual inspections and thickness measurements on carbon steel tanks, including the performance of ultrasonic thickness measurements on the buffer tank for equipment cooling water as well as the safety injection tank. Likewise, a plan was needed for managing heat exchanger performance, to include the preparation of procedures for performance inspections specific to the heat exchanger for the recycled, leaking, and used fuel reservoir.

A consolidated program is also needed to manage the cracking of Alloy 600/82/182 components. The program should build on the Alloy 600 DB (data base?), evaluate the cracking sensitivity, and set up methods for preventive maintenance. In addition, the parameters for the detection of PWSCC by NDE techniques in Ni-alloy base metal and dissimilar metal welds (including the pressurizer) need to be defined, and a plan needs to be established to improve inspection reliability. The possibility of PWSCC in dissimilar metal welds from the perspective of the LBB Screening Criteria should be reevaluated, and a plan should be established to maintain component integrity when SCC is detected.

Finally, a plan needed to be developed for removing sludge from the second steam generator.

\section{A.6.3.3 Structural Systems}

The PSR cited the following needs in this area: 
- Establish a plan to examine difficult-to-access areas such as underground concrete structures and underwater parts of structures near seawater.

- Establish a plan to examine the corrosion status of reinforcing rod in the seawater intake structures for cooling the primary equipment.

- Obtain additional data to increase the reliability of the equation used to estimate the compressive strength of concrete using the Schmidt Hammer, and state the equation used to make the estimation.

- Establish plans to revise procedure documents for consistency in the area of measuring degradation factors, and increase the reliability of the data used for evaluating the integrity of the structures.

- Establish plans to evaluate the potential degradation of sealing materials used in penetrations and openings in safety-related structures. These include materials used for radiation shielding, preventing flooding, and filling seismic gaps. Verify the performance of these materials and develop procedures to maintain and manage them.

- Establish plans to periodically maintain and manage the watertight doors and blast-proof doors.

- Establish a long-term monitoring plan for radiation-resistant protective coatings. This plan should meet the new regulatory guidelines for radiation-resistant protective coatings and should apply the most recent technical standards.

- Establish a plan for analyzing the aging phenomenon, evaluating durability, and mitigating aging, based on inspection results for protection coatings, including coatings on steel liner plates, and concrete and steel structures in the hangar building.

\section{A.6.3.4 Electrical Systems}

The PSR cited a need to establish an AMP for the electrical distribution facility and to prepare a procedure for the periodic visual inspection and maintenance of clean equipment. In addition, a program was needed to manage the aging of cables, including an inspection procedure to maintain the integrity of Class $1 \mathrm{E}$ cables in harsh environments.

\section{A.6.3.5 Auxiliary Systems}

No items identified.

\section{A.6.4 Safety Analyses}

The PSR concluded that the safety of the nuclear facilities was appropriately maintained. The assessment reports on the safety analyses of the reactor core design, thermal hydraulic design, accident interpretation, characteristics of natural phenomena near the plant site, weather conditions, and population distribution determined that the design safety satisfied the latest standards. 


\section{A.6.5 Performance and Feedback of Experience}

\section{A.6.5.1 Performance Assessment}

The PSR concluded that the classification and analysis of safety-related accidents and items related to safety performance were appropriately maintained. The selection and records of operating data, the analysis of operating data trends, and the preparation and review of safety performance indexes were appropriately carried out. The levels of radiation exposure to workers and the release of radioactive material were appropriately managed.

\section{A.6.5.2 Operating Experience}

The PSR had the following major findings and conclusions related to OpE:

- The PSR confirmed that Yonggwang Units 3 and 4 have reflected and implemented international and domestic OpE and research results in heat exchangers, fire protection, aging management, protective coatings, concrete anchor systems, steam generators, and the primary loop.

- Inspections, periodic checks and monitoring of the pressure transmitter, aging of the temperature transmitter, and aging and response time of the pressure sensors were appropriately implemented by Yonggwang, applying domestic and overseas research results on nuclear power plant instrumentation control facilities.

- Items such as replacing the principal components prone to failure and establishing periodic monitoring of facilities, taking into account domestic and overseas experience, were appropriate.

- Analysis of failures in the turbine facilities and pumps and valves of domestic and overseas nuclear power plants determined they were often caused by malfunctions of instruments and control systems, and such failures were determined to be preventable with appropriate inspection and checking.

- Results related the corrosion of valves, including motor operated valves, air operated valves, and non-return valves, were evaluated.

- Overseas concrete aging incidents were reviewed, the process for checking and repairing degradation of concrete structures was established, and research on building a computerized database system were implemented to manage the aging of seismic class 1 concrete structures. The research results were appropriately utilized in the procedures for checking and managing such structures.

- Cracks found in the SG tubes were caused partly by the denting due to sludge buildup. Yonggwang established a plan to remove the sludge in the second SG, depending on the results of the inspection on the tubes. 
- To reflect NPP OpE and research results in the U.S. and the change from Regulatory Guide 1.54 (Rev. 0; NRC 1973) to Regulatory Guide 1.54 (Rev. 1; NRC 2000), Yonggwang must develop a plan to monitor the long-term performance of quake-resistant protective coatings on the interior liner plates, concrete, equipment, pipes, and steel structures of the containment buildings. The plan should include a procedure for monitoring the performance of coating materials, coating workers, coating inspectors, verification of coating companies, and education and training for coating inspectors as a part of an effort to improve the performance of the protective coating.

- For the SGs and associated equipment, necessary measures were taken by appropriately reflecting domestic and overseas $\mathrm{OpE}$ and research results.

- Basic guidelines were established for inspecting and evaluating corrosion caused by boric acid by taking into account overseas incidents, and inspection was implemented by applying the resulting inspection procedure.

- Based on OpE, an evaluation of PWSCC-sensitivity of Ni alloys (Alloy 600/82/182, $690 / 52 / 152)$ in the system must be conducted immediately, and plans need to be made for carrying out NDEs to detect PWSCC and improve inspection reliability and for preventing and repairing PWSCC cracking.

- The licensee should analyze in a more systematic way the root causes of events and the applicability of significant international experience.

\section{A.6.5.3 Comparison of Operating Experience with U.S. Plant of Similar Design}

The U.S. plant similar in design to the Yonggwang is Palo Verde Units 1, 2, and 3. The LRA (Arizona Public Service Company, 2009) and resulting SER for Palo Verde (NRC 2011b) were reviewed to identify common areas of concern and to note similarities and differences in OpE. A caution in making this comparison is that component equipment manufacturers and the manufacturing process may vary from plant to plant, thus limiting the value of such direct comparison. The findings resulting from this review are summarized here.

Steam Generator Tube Cracking: SG tube cracking at Yonggwang was caused partly by denting resulting from sludge buildup. Yonggwang established a plan to remove the sludge on the second SG depending on the results of the inspection of the SG tubes. The SGs at Palo Verde Units 1,2, and 3 were replaced during the fall of 2005, 2003, and 2007, respectively. Wear is presently the only active damage mechanism in the Palo Verde replacement SGs, and this wear specifically results from the interaction of tubes with the tube supports. The SGs of Yonggwang Units 3 and 4 have not yet been replaced, and the damage mechanisms were mainly from cracks due to tube denting.

On February 19, 2004, Palo Verde Unit 2 was operating at full power when radiation monitors indicated of a low-level primary-to-secondary SG leak. The decision was made to shut the unit down to find and repair the leak. Further analysis showed that the leak was due to a tube puncture caused by a wood screw that was used in the construction of the shipping crates for the tubes when the SGs were being manufactured. The tubes were placed in the crate and the crate assembled around them. One of the screws that was used near the outer diameter of the top of the tube bend protruded through the wood and partly penetrated one of the tubes. The 
unit was operated from its post-outage startup up to the time the tube finally began leaking. No similar incident has been reported at Yonggwang 3 and 4.

\section{A.6.6 Management}

The PSR concluded that the items related to organization and administration, were satisfactory. Goals that prioritize safety were established, the roles and responsibilities of organizations and individuals were clearly defined to accomplish work objectives, systematic education and training plans were established and implemented, and independent quality assurance activities were implemented.

\section{A.6.7 Environment}

The PSR concluded that the items related to the effects of the radioactive materials on the environment were satisfactory. The release routes into the environment were appropriately monitored and managed, and monitoring the environment in the areas other than the power plants, assessing the amount of radiation exposures of residents, and environment monitoring met the applicable standards.

\section{A.6.8 Conclusions}

The PSR concluded that the units were operated in accordance with current technical standards. Based on aging, equipment qualification, OpE, research results, and latest technologies, the PSR identified 17 items of safety improvements (nine items of operation improvement and seven items of safety assessment). The PSR concluded that, after these safety improvement items were appropriately implemented, Yonggwang Units 3 and 4 could operate safely until the next PSR.

\section{A.6.8.1 Summary of Technical Issues that Merit Further Consideration}

- The Yonggwang PSR stated the need to develop a plan to examine the corrosion status of reinforcing rod in the seawater intake structures for equipment cooling water (Section A.6.2.1).

- The Yonggwang PSR, like the Ulchin PSR, notes a need to improve the reliability of the Schmidt Hammer test for estimating the compressive strength of concrete (Section A.6.2.1).

- The Yonggwang PSR notes the need to develop a plan to periodically maintain and manage the filler and sealants in safety-related watertight doors and blast-proof doors (Section A.6.2.1).

\section{A.7 Spain (Almarez Units 1 and 2)}

The Spanish Almarez Unit 1 and 2 NPPs are PWRs of the Westinghouse three-loop design and are rated at 980 and $984 \mathrm{MWe}$, respectively. Unit 1 was commissioned in March 1980 and Unit 2 in June 1983. The plants are located in Almaraz (province of Cáceres), Spain and are operated by the utility consortium Endesa-Iberdrola-Unión Fenosa. The Spanish Consejo de Seguridad Nuclear, or Nuclear Security Council (CSN), conducted a PSR assessment of the 
plant for the period from 1998 through 2008, and the results are presented in their report listed in Section 2.1 above.

The PSR report made available for review was extremely brief, consisting of four pages, and contained only Sections 4.2 ("Periodic Safety Review") and 5 ("Opinion of the Nuclear Safety Council"). Section 4.2 summarizes the findings of the PSR and lists the deficiencies noted, and Section 5 describes the corrective actions required by the CSN. Because of the brevity of the available PSR report, an attempt was made to supplement its content, particularly with respect to plant modifications and $\mathrm{OpE}$, with information from other sources.

\section{A.7.1 Plant Modifications}

New Emergency Diesel Generator (EDG): A fifth EDG was placed into service in December 2006 to supplement the two EDGs already in place at each of the two units. The fifth EDG is intended to provide supplemental emergency power in the event of a SBO, and is capable of replacing any of the four already in service (CSN 2013).

Power Uprate: In October 2008, the licensee requested a power uprate of approximately 8 percent for each of the two units. These uprates required the replacement, expansion, or adaptation of a range of equipment and systems, including replacing the alternator and exciter, installing a new high-pressure turbine, and changing the condensate and heater drain pumps, as well as other modifications. Upon completion of these modifications, the Spanish Ministry of Industry and Energy authorized the increase in power at Unit 1 in December 2009 and at Unit 2 in December 2010 (Nuclear Engineering International 2011b).

\section{A.7.2 Operating Experience}

Section 4.2 of the CSN report notes two specific OpE events at Almarez, namely the failure of a diesel generator at Unit 1 in the first trimester of 2007 and reactor coolant leaks at Unit 2 in the "fourth trimester" of 2007. No details are provided on either of these events, but an independent search of other sources located the following information on the coolant leak:

Reactor Coolant Leak: In 2007, At Almaraz II, reactor coolant leakage occurred in Alamaraz II in excess of that allowed in the Operating Technical Specifications. During the cooldown to initiate the refueling outage, a residual heat removal system safety valve was opened, causing a letdown flow to the pressurizer relief tank. The valve did not close on reaching its setpoint and the discharge to the tank continued for approximately 1 minute until the line was isolated. This event is not aging related (CSN 2007).

In the period corresponding to the present PSR, Almarez has reported 93 events (43 in Unit I and 50 in Unit II), of which two (pme in each unit) have been classified as "anomalies" of level 1 (the second lowest on the INES scale). Both of these were due to calibration errors of instrumentation from a reactor trip in 2004. All other events (98 percent) have been INES level 0 and "without security significance."

\section{A.7.2.1 Comparison of Operating Experience with U.S. Plant of Similar Design}

The U.S. plant similar in design to the Almaraz Nuclear Power Plant is V.C. Summer. However, the portion of the Almarez PSR report made available for review was very brief and provided no 
detailed descriptions of problem areas or OpE. Therefore, no common areas of concern and similarities and differences in OpE between the Almaraz plant and the V.C. Summer plant were identified.

\section{A.7.3 Findings Resulting from the PSR}

As a result of the PSR findings, the CSN noted the following deficiencies at Almarez Units 1 and 2:

- In the area of OpE, the licensee should analyze in a more systematic way the root cause of events and the applicability of significant international events.

- With respect to equipment performance, the licensee needs to study life span management, update seismic margin calculations, and develop further information on environmental qualification.

- The PSA results define the requirements necessary for power plant fires.

- New programs need to be instituted in the areas of primary instrumentation, containment sumps, severe accidents, functional technical specifications, and security.

The CSN stated that the licensee needs to correct the deficiencies detected during the evaluation in the next revision of the PSR document.

\section{A.7.4 Required Improvements and Enhancements}

In response to the findings resulting from the PSR, the CSN imposed 13 requirements on the licensee with respect to plant improvements and enhancements. The most significant of these were the following:

- The installation and commissioning for each unit of a new alternative shutdown panel outside the control room to improve guarantees of a safe shutdown of the plant in case of fire in the wiring closet or control room. In addition, the fire protection system must be upgraded to meet seismic requirements in areas related to safe shutdown of the plant.

- In each unit, the installation of ventilation and extra filtrate in the fuel building, as well as further modifications to other systems required for ventilation and filtering in the plant's buildings.

- Changes in the plant's electrical and instrumentation systems to ensure the independence and physical separation of paths, circuits, and electrical cables.

- Changes in the control room to include the automatic selection of external air intake with the least amount of radiation in the case of an emergency.

- Modifications for enhancing the protection and monitoring of the system 125-V power supply and installing additional lightning in some buildings, as well as associated ground connections, to reinforce protection against lightning. 
- Changes arising from the switch in licensing for fire protection (transition from Appendix $R$ of 10 CFR 50 to NFPA 805 [National Fire Protection Association 2010]).

In addition, there were 17 complementary technical instructions associated with license renewal, subject to prior approval by decree of the Ministry of Industry, Tourism, and Trade. These instructions were in the following areas:

- New improvement programs, in regards to location design for instrumentation in the primary circuit, containment sumps, and severe-accident management.

- Improvement actions related to the root cause analyses of events and of the applicability of OpE reports from INPO, information on the environmental qualification of equipment, and upgrade of the seismic margin of the plant.

- Actions in relation to new requirements for meteorological monitoring, cooling of the spent fuel pool, detection and control of combustible gas in containment, sealing of lines penetrating containment, and the treatment system for solid radioactive waste.

- General document revision to include evaluation results.

\section{A.7.5 Conclusions}

The PSR analyzed all the relevant aspects of safety for the period from 1998 to 2008, including $\mathrm{OpE}$, radiological impact, changes in regulation and rules, equipment performance, modifications completed by the power station, the probabilistic analysis of security, and the 18 programs of security improvement completed by the licensee. The evaluation identified several relatively minor deficiencies that are to be addressed. The PSR concluded that the power stations maintain an adequate level of safety to continue operation during the next decade.

\section{A.7.5.1 Summary of Technical Issues that Merit Further Consideration}

None identified.

\section{A.8 Sweden (Oskarshamn Unit 3)}

The Swedish Oskarshamn Unit 3 NPP is a BWR of the ASEA-Atom BWR 75 design and is rated at $1450 \mathrm{MWe}$. The plant was commissioned in August of 1985 and is located in Kalmar Län, Sweden. It is operated by the Oskarshamn Power Plant Group (Oskarshamnsverkets Kraftgrupp, or OKG). The Swedish Nuclear Power Inspectorate (Statens Kärnkraftinspektion, or SKI) conducted a PSR assessment of the plant for the period from March 31, 1995 through December 31, 2005, and the results are presented in their report SKI 2005/40 (SKI 2008), which is listed in Section 2.1 above.

The SKI report reviewed here is an evaluation of the PSR report for Oskarshamn 3 prepared by the operating utility OKG, which was not available for the present review. This main report is supplemented by a series of 13 underlying project reports on various aspects of plant design 
and operations. The purpose of the SKI study was to assess (a) how the facility, at the time of the review, met the applicable safety requirements; (b) whether Oskarshamn 3 had conducted a comprehensive analysis and overall assessment of the facility's safety; and (c) whether there were reasons to conclude that the plant could not be operated safely until the next review. These assessments relied, in part, on inspections carried out by the licensee and SKI, during the period in question. In some cases, inspection results carried out shortly after the review period were included in the review basis.

The SKI report first defines the plant's barriers for containing radioactivity, namely the fuel pin, the fuel capsule, the reactor's pressure-bearing primary system, and the reactor containment. It then considers the defense-in-depth concept as it applies to the plant. Following this, the SKI report evaluates the safety of the plant and its compliance with regulatory requirements in the following 15 areas:

1. Construction and design of facilities (including changes)

2. Management, control, and organization of nuclear operations

3. Competence and staffing of nuclear operations

4. Operations, including the handling of defects in barriers and defense in depth

5. Reactor core and fuel issues, and criticality issues

6. Emergency preparedness

7. Maintenance, material, and control issues, including obsolescence

8. Primary and independent safety reviews

9. Investigation of incidents, operations-experience feedback, and external reporting

10. Physical protection

11. Safety analyses and safety reporting

12. Safety program

13. Storage of plant documentation

14. Handling of nuclear materials and nuclear waste

15. Nuclear materials control, export controls, and transport safety

\section{A.8.1 Plant Modifications}

Power Uprates: An initial power uprate that increased the maximum generating capacity from the initial design value of $1050 \mathrm{MWe}$ to $1200 \mathrm{MWe}$ was completed in 1989. A second power uprate completed in 2009 further increased the maximum output to $1450 \mathrm{MWe}$. This second uprate included upgrades of the turbines, the reactor safety systems, and other critical SSCs, with the additional objective of extending the plant's life to 60 years. Numerous problems were encountered, and the reactor was on and off the grid with prolonged maintenance outages during 2010. The plant finally reached full-power operation at $1450 \mathrm{MWe}$ net on September 23, 2011. On November 30, 2011, the remaining testing program associated with the uprate was suspended and the power level was reduced to approximately $1300 \mathrm{MWe}$. This was accomplished to avoid any possible operational disruptions during the high-load winter period. The remaining tests will resume as soon as weather conditions and power demand permit (SKI 2008, Section 6.1).

Piping Replacement: The SKI report states that, to make the testing program more efficient, OKG has replaced some material, which was susceptible to stress-corrosion cracking with a low-carbon content material. Presumably, this refers to the replacement of recirculation cooling loop piping. However, no further details are provided (SKI 2008, Section 6.7). 


\section{A.8.2 Improvements and Enhancements}

In addition to the above plant modifications, the SKI report identifies the following plant improvements or enhancement measures carried out by the licensee:

(a) Control room modifications (details not provided)

(b) Replacement of $8 \times 8$ fuel rod grids with a $10 \times 10$ design for improved fuel usage efficiency, shutdown margin, and core stability

(c) Upgrading of the computer code used for core monitoring and simulation

(d) Replacement of the power range monitor system

(e) Revised management system for plant operations

(f) Establishment of a new joint command center for emergency preparedness

The SKI report states that aging-related degradation at Oskarshamn 3 is currently handled through its ongoing preventive and remedial maintenance activities. A program has been initiated for identifying ongoing aging mechanisms, and a comprehensive program for managing the aging of materials has been devised; there are plans to implement it in 2010 . The program covers aging effects in passive long-lifetime equipment, and is based on the guidance given in NUREG-1801 (NRC 2001a, 2005b, 2010c). Revision 0 of the GALL Report, dated July 2001, is referenced, but presumably the Oskarshamn AMP will follow updated GALL guidance. The licensee also stated that it plans to expand the AMP to include active as well as passive components. However, no further details of the program are provided, and the SKI report does not discuss aging management in any depth.

\section{A.8.2.1 Nuclear Fuels}

Fuel Cladding Failures: During the period from 1995 through 2005, Oskarshamn 3 (OKG) has had more than 20 fuel element failures, considerably more than any other reactor in Sweden. These failures involved the cladding being perforated; in one isolated case this was due to $\mathrm{PCl}$, but the main cause was abrasion by small metal fragments in the coolant. No specific information was provided as to the source of these fragments. Mitigation measures taken to date included the installation of filters in fuel assembly inlets to prevent debris from reaching the fuel rods and a program to reduce the amount of harmful debris that entered the system during maintenance work. Feed-water cleaning was also under consideration, but the problem continues. The reactor is shut down for the removal of leaking fuel if the uranium release is above a threshold limit value, and measures that are more stringent are being considered. The SKI deems the consequences of this damage insignificant for safety, but the leaking fuel elements do contribute to increased background radiation levels. The SKI regulations also require the detection of any new serious cladding damage, which could be difficult in the current situation (SKI 2008, Section 6.5). 


\section{A.8.2.2 Mechanical Systems}

Inspection of Mechanical Components: The licensee utilizes a computerized system to manage the periodic inspections of the reactor vessel, piping, and related components. The program is reexamined after audits, and when there are new findings or new experience it is updated as necessary. The licensee reports that major efforts have been made on the qualification of the testing system since the mid-1990s, and they indicate that their knowledge of the condition of the facility's mechanical components is very good.

When degradation is detected in a mechanical component, a "damage group" is convened to assess the damage and direct the response. The group gathers data concerning the cause of the damage, estimates the damage-tolerance ability, monitors trends, and analyzes the statistics in the facility. The group not only monitors damage in mechanical components, but also in building structures, including the reactor containment. In the electrical components area, however, response to the degradation and damage is handled by remedial maintenance operations.

The SKI found that the licensee's maintenance program is well equipped to handle damage in the mechanical area, and that a group assigned to analyze the damage conducts analyses and investigations when damage occurs in mechanical components. The licensee stated that its maintenance program also effectively manages aging using an approach similar to that described in the GALL Report, and SKI did not challenge this claim in its report. However, the SKI report provided no detailed information on the degradation of specific components and systems (pressure vessel, piping, etc.) in the mechanical components area. The licensee has indicated that its present system could be developed further with regard to analysis and investigations of damage and failure in electric components. The SKI concurred and stated that this area is important and needs further work. The licensee also stated that a strategy for handling flow-accelerated corrosion (FAC) should be developed, based on OpE and R\&D results, in order to conduct more effective periodic inspections and implement mitigation measures.

\section{A.8.2.3 Structural Systems}

Structural Integrity of the Primary Containment: In Oskarshamn 3, damage was found in 2002 in the containment basin walls in the concrete surfaces above the plate lining. This PSR investigation also expressed concerns about possible corrosion at the containment grommets, based on problems observed at the Barsebäck reactor in Sweden. The licensee analyzed this and reported that the manufacturing method for the grommets at Oskarshamn is different from that used in Barsebäck, and the risk of corrosion damage was small in Oskarshamn 3. The licensee also joined the European research project "CONMOD," where, in addition to other research, methods of checking and testing containment have been studied and developed. The SKI found that OKG is handling the containment structural degradation issues satisfactorily, but noted that the area is important and that it intends to review its regulatory requirements regarding containment inspection. Overall, the SKI determined that no defects with significance for safety or deviations from regulatory requirements were identified with respect to reactor containment. The licensee was found to be carrying out periodic checks and leak testing according to the prescribed program. 
Degradation of Structural Components: As stated in Section A.8.2.2 above, when degradation is detected in a mechanical or structural component, a group is convened to assess the damage, and then directs the response. The group gathers data concerning the cause of the damage, determines the ability for damage tolerance, monitors trends, and analyzes the statistics in the facility. The group assesses not only damage in mechanical components, but also that in building structures, including the reactor containment. The SKI found this system to be satisfactory, and no significant structural issues were noted in the SKI report, outside of the containment concrete cracking problem discussed in the previous paragraph.

\section{A.8.2.4 Electrical Systems}

Maintenance of Electrical Equipment: The licensee noted that only limited information was available on environmental conditions that could impact the safe functioning of various types of equipment when the plant was built. Detailed requirements for electrical equipment were subsequently added to the technical specifications, based on international standards. The licensee stated that these new technical specification requirements are only partially met at present, and that a common methodology needs to be used in assessing both electrical and mechanical equipment safety functions. The licensee is carrying out a review of environmental qualifications for equipment in containment as well as for other equipment in the plant.

The SKI identified the need to develop maintenance procedures to improve the handling of malfunctions in, and damage to, electrical equipment, as well as functional testing of electrical components and systems during facility renewal (apparently referring to the upgrades being performed as a part of the second power uprate described in Section A.8.1 above). The licensee's program for electrical equipment maintenance was otherwise found to be satisfactory.

\section{A.8.2.5 Auxiliary Systems}

Fire Protection System: The licensee stated that further development of maintenance plans for building components, physical protection, and fire-protection systems is planned. The fire protection systems at OKG are handled by an internal resources group, which establishes requirements and communicates them to the Oskarshamn municipal emergency services. In the maintenance area, the fire protection section, like other sections, is divided into system levels and distributed throughout the resource areas. The licensee stated there are currently shortcomings in some of the checks that the Oskarshamn municipal emergency services carry out. These are being updated. The SKI did not note any deficiencies in the OKG fire protection system in the report.

Nuclear Waste Handling: The SKI found that redundancies in qualified personnel working in the waste facility were not completely satisfactory. There was also uncertainty about the current qualifications of processing operators and the requirements with which they had to comply before being authorized. The SKI stated that it has no basis to assess whether the radionuclide inventories meet regulatory requirements. Otherwise, the nuclear waste handling operation was found to be satisfactory.

Nuclear Materials Controls and Transport: The SKI found that Oskarshamn 3 complied with the regulatory requirements for nuclear-materials control, export control, and transport safety during the review period. 


\section{A.8.3 Safety Analyses}

Information related to plant safety analysis was not reviewed.

\section{A.8.4 Performance and Feedback of Experience}

\section{A.8.4.1 Performance}

No significant information related to plant performance was identified.

\section{A.8.4.2 Operating Experience}

The SKI PSR report did not specifically address OpE as a separate item. However, the following OpE events were described in the report, and an independent search of other sources identified a number of items related to OpE. These are included here to provide additional background for the current review.

Power Instability Event: A power instability event occurred in Oskarshamn 3 during February 1998. After a restart, following reactor charging at 60 percent mean power, the reactor core started oscillating between 40 percent and 90 percent reactor power. Power oscillations mean a major increase in reactivity, and the characteristics of the oscillations showed that the reactor was fluctuating outside the linear range, which led to an increase in mean power. This instability was not detected by the operators and lasted for approximately 8 minutes. An additional increase in reactivity was brought about by drawing control rods, and the reactor stopped suddenly and automatically at 96 percent reactor power. This instability led to deterioration in the margins in regulator function of the turbine valves. A significant safety issue is a hypothetical course of events involving an incident where the turbine valves close during ongoing instability. The International Nuclear Event Scale (INES) rating for this event was not reported.

A basic issue was that the instrumentation was not providing the operators adequate information on the core's instability. Immediately after the incident in 1998, the licensee added instrumentation to provide better indications, restrictions on power operation with low coolant flow, and later, a number of additional measures to reduce the risk of instability. In 2000, an advanced stability monitor was installed in order to provide detailed information to operators. In 2005 , automatic monitoring of stability was established, and a diagnosis tool, "detect and suppress," which warns of instability, was instituted. A contributing cause of the instability was the replacement of the original $8 \times 8$ fuel rod grids with $10 \times 10$ grids in 1995, resulting in higher cartridge power levels (SKI 2008, Section 6.5; Kruners 1998).

Containment Cracking: The SKI report states that, during 2002, damage was found in the concrete of the 316 basin walls in the surfaces above the plate lining in containment, but no further details are provided (SKI 2008, Section 6.7).

HTG Event: On September 23, 2003, Oskarshamn 3 experienced a so-called HTG ("Högsta Tillåtna Gränsvärde," or maximum allowed temperature limit) in which cold water was introduced near the bottom of the reactor pressure vessel while the main coolant pumps were switched off. The natural circulation from the decay power did not provide sufficient mixing, and when the main coolant pumps were restarted, a rapid temperature increase occurred near the 
lower plenum. The maximum allowed change in RPV water temperature is $70^{\circ} \mathrm{C}$ in 2 minutes, and temperature sensors at the lower plenum indicated a higher rate of change that triggered the HTG alarm. A subsequent analysis followed by inspections carried out during the 2004 outage determined that no harmful thermal stresses occurred during this event, and the incident was classified as an INES level 1 event (see Westin et al. 2009).

Control Rod Failures: An inspection conducted at Oskarshamn 3 during October of 2008 found a broken control rod and cracks in several other control rods. The affected control rods were replaced, and inspections were ordered for the remaining Swedish BWRs (see World Information Service on Energy 2008).

Containment Nitrogen Pressure: On January 5, 2011, Oskarshamn 3 was manually shut down because of reduced nitrogen pressure in the containment. After correcting the problem, the unit was restarted on January 8 (see OKG 2007).

Valve and Turbine Problems: On June 28, 2011, Oskarshamn 3 restarted following the completion of the annual maintenance outage. During the outage, three of the eight turbine bearings were replaced with an improved design. Restart was originally scheduled for June 19 but was delayed because of problems with two valves as well as turbine vibrations after the new bearings were installed (see OKG 2008).

Feedwater Pump Fault: On August 25, 2011, Oskarshamn 3 was shut down because of a failure in a feedwater pump circuit breaker that resulted in increased water levels in the reactor vessel. The problem was corrected and the reactor was restarted on September 1, 2011 (see OKG 2011).

\section{A.8.4.3 Comparison of Operating Experience with U.S. Plant of Similar Design}

Oskarshamn 3 is BWR 75 design developed by ASEA-Atom. There is no U.S. nuclear power plant with a similar reactor design.

\section{A.8.5 Management}

Information related to plant management was not reviewed.

\section{A.8.6 Environment}

Information related to plant environment was not reviewed.

\section{A.8.7 Conclusions}

The SKI's overall assessment was that the construction of Oskarshamn 3, along with its systems and processes, assures sufficiently high quality of performance, operations, and maintenance, and that the plant meets the requirements for the first level of defense in depth. On the other hand, SKI concluded that the licensee OKG did not currently meet all of the regulatory requirements for physical protection of nuclear facilities. The SKI found that Oskarshamn 3 has a management system that provides control over operational disturbances and the detection of malfunctions through supervision and plant monitoring so that plant safety is maintained. The plant's safety systems and operating procedures assure adequate response 
to accident scenarios, although clarification of staffing requirements and verification of safety systems is required. The SKI also found that the STF (Technical Specifications, Operational Limits and Conditions) testing program does not fully verify the safe functioning of the tested systems under realistic design basis accident conditions. Furthermore, there have been no studies on the scope and frequency of testing, and there seemed to be no plans to perform such studies. The SKI's inspection did not identify any defects in OKG's handling of the fifth level of defense in depth (mitigating the consequences of any accidental radiation releases into the environment). However, the SKI stated that the licensee did not adequately describe how the scenarios for emergency preparedness are designed or the analyses on which they are based, and that it did not adequately consider certain events, including access to the plant by terrorists. The licensee's handling of spent nuclear fuel and nuclear waste was found to be satisfactory, but the personnel resources in this area need to be strengthened to provide increased redundancy.

At the time of the review, aging-related degradation was being handled within the context of the licensee's preventive and remedial maintenance programs. However, a new program had been initiated for identifying and managing ongoing aging mechanisms, and there were plans to implement it in 2010. This new program covers aging effects in passive long-lifetime equipment and follows the recommendation of NUREG-1801 (NRC 2001a, 2005b, 2010c). The SKI did not identify any specific significant deficiencies with respect to aging management in the report.

\section{A.8.7.1 Summary of Technical Issues that Merit Further Consideration}

- Oskarshamn 3 has identified several areas for improvement in order to ensure continuing compliance with regulatory requirements. One of these areas is to expand their AMP to include the management of active components (Section A.8.2).

- Oskarshamn 3 utilizes a computerized system to manage the periodic inspections of the reactor vessel, piping, and related components. The program is reexamined after audits, and when there are new findings or new experience, it is updated as necessary (Section A.8.2.2).

\section{A.9 Switzerland (Leibstadt)}

The Swiss Leibstadt NPP is a BWR of the General Electric BWR/6, Mark III Containment design and is rated at $1220 \mathrm{MWe}$. The plant was commissioned in May of 1984 and is located in Leibstadt, Canton Aargau, Switzerland. It is operated by the Leibstadt Nuclear Power Station, or Kernkraftwerk Leibstadt (KKL). The responsible government regulatory agency at the time of the PSR was the Swiss Principle Nuclear Safety Division (Hauptabteiling für die Sicherheit der Kernanlagen, or HSK), which was replaced by the Swiss Federal Nuclear Safety Inspectorate (Eidgenössisches Nuklearsicherheits-inspektorat, or ENSI) effective January 1, 2009. ENSI conducted a PSR assessment of the plant for the period from January 1, 1995 through December 31, 2005, and the results are presented in their report ENSI 12/1300 (ENSI 2009), which is listed in Section 2.1 above.

In 2006, KKL, the operator of the Leibstadt Nuclear Power Plant, submitted a series of five safety review documents to HSK, which has since been superseded by ENSI. These documents presented the results of a PSR of the Leibstadt Plant for the period from January 1 , 1995, through December 31, 2005. The current report, prepared by ENSI, provides a detailed 
summary of the results and findings of that PSR, as well as the resulting recommendations and required actions mandated by ENSI.

Section 1 of the ENSI report provides background information, the bases for the HSK evaluation of the PSR documents submitted by KKL, and describes the extent to which the legal bases for that evaluation have changed or been updated since KKL's last safety review. Section 2 summarizes the completion status of the conditions from the Swiss Federal Council's decision of October 28, 1998, to approve KKL's request for a power uprate. It also discusses the status of requirements specified in an HSK opinion from March 1996 pertaining to the power uprate. Section 3 describes the key plant features and the installation modifications undertaken during the period of evaluation. Sections 4 through 9 cover HSK's evaluation of the PSR documents in the following areas, respectively: organization and personnel, operational behavior and monitoring, safety-relevant parts of the installation, protecting the installation against design-based accidents, protecting the installation against accidents caused by exceeding design rating, and emergency protection. Of these five middle sections, only subsections 5.3 ("Reportable events during the evaluation period"), 5.5 ("Maintenance and aging monitoring"), and 6.3 ("Nuclear steam generation system") were available for review. Section 10 presents a cumulative assessment of whether the fundamental goals of protection as specified in HSK guidelines for guaranteeing nuclear safety are fulfilled. It also includes a detailed listing of all 50 requirements for follow-up actions resulting from the PSR.

\section{A.9.1 Plant Modifications}

Power Uprate: On July 31, 1992 KKL Aktiengesellschaft (known as AG), submitted a request to modify the operating license for KKL and applied for an increase of thermal reactor power output from $3138 \mathrm{MW}$ to $3600 \mathrm{MW}$. The Swiss Federal Council approved the request for increased power output with its ruling dated October 28, 1998, and issued the operating license contingent on six conditions, all of which were met by the utility (ENSI 2009, Section 2).

Noble Metal Chemical Additions: KKL installed a noble metal chemical addition system in the feedwater system and initiated trial operation in late 2008. This system, in combination with the plant's existing hydrogen water chemistry system, was introduced to reduce the susceptibility of piping and reactor internals to SCC. No SCC of these components has been confirmed at KKL to date, but ultrasonic testing (UT) has detected possible indications at recirculation piping welds (ENSI 2009, Section 3.4).

Other Modifications (Section 3.3):

- Commissioning of the new repair shop (1995)

- Supplementation of the reactor protection system with additional select rod insertion criteria (1995)

- Replacement of feedwater check valves (1996)

- Expansion of instruments in emergency control centers (1996)

- Modifications in the secondary part of the installation (1996) 
- Modification of main control room ventilation (1996)

- Modifications in the secondary part of the installation (1997)

- Modification of safety-relevant motor-driven fittings (1998)

- Modifications in reactor protection and regulation (1998)

- Modification of safety-relevant motor-driven fittings (1999)

- Modification in the triggering of the automatic pressure relief system (1999)

- Modification of safety-relevant motor-driven fittings (2000)

- Increasing the suction capacity of the high-pressure turbine (2000)

- Modification of the emergency power and emergency coolant systems (2000)

- Modification of the recirculation air cooling units of the emergency system (2000)

- Modification of the dampened check valves of the feedwater pipes (2001)

- Modification of the emergency power and emergency coolant systems (2001)

- Increase in the suction capacity of the high-pressure turbine (2002)

- Changes in fire protection (2002)

- Modification of the emergency power and emergency coolant systems (2003)

- Modification of the dampened check valves of the feedwater pipes (2003)

- Changes in fire protection (2003)

- Installation of recombiner inserts at the discharge pipes of the safety valves (2004) Planned Plant Modifications (Section 3.4):

- Replacement of fire detection systems and security systems

- Replacement of multiple major components in the condensate and feedwater circuit

- Replacement of major electrical components

- Strengthening the cooling tower

- Renovating and optimizing the reactor recirculation system 
- Lightning protection retrofits to bring previous protection measures up to date

Requirements for Follow-Up Action Related to Plant Design (Section 10.6)

- KKL was to submit the results of the detailed review of the design of the 130-ton fuel element warehouse crane and the 115/5-ton polar crane to HSK for review by June 30 , 2010.

- The design of the overfeed protection was to be reviewed by KKL by December 31, 2009, taking into consideration possible consequences of an outage and the design of the overfeed protection in other BWRs.

- The fire protection in the decontamination building and the preparation building was to be retrofitted by KKL by December 31,2010, such that in the event of a fire, the guide values specified in the guideline HSK-R-50 for the release of activity are not exceeded.

- $\mathrm{KKL}$ was to conclude the lightning protection retrofitting and demonstrate its effectiveness by December 31, 2010.

- KKL was to investigate how the automatic containment closure (shutoff device of the water removal lines) can be improved in the event of earthquakes by October 31, 2009.

\section{A.9.2 Aging Degradation and Management}

\section{A.9.2.1 Maintenance and Aging Surveillance (Section 5.5)}

The long-term maintenance program for the plant's annual inspection involves a varying sequence of brief inspections ( 14 days) and standard inspections (20 days), with a prolonged inspection (30 days) every 10 years. The second 10-year inspection was carried out in 2005. The configuration of the plant's safety systems also permits limited maintenance during power operation, according to the KKL Technical Specifications. Findings from the PSAs were included in the maintenance and aging surveillance. The plant subsystems subject to maintenance and aging surveillance are listed below, along with specific findings and resulting remedial requirements of HSK.

\section{A.9.2.2 Mechanical Engineering Maintenance (Section 5.5.2)}

- KKL lacked a complete and up-to-date list of all components that contain safety-related mechanical equipment parts. KKL must submit a complete list to HSK by December 31, 2009.

- Deficiencies were found in the periodic mandatory testing of components in safety classes 2 through 4. KKL has until December 31, 2009, to complete the required periodic testing of components in safety classes 2 through 4 , especially "containers" (pressure vessels and tanks?), and connected piping of safety classes 3 and 4. 
- $\mathrm{KKL}$ has until December 31, 2009, to identify the underlying causes that necessitated significant shortening of the test intervals for the functional testing of safety-related valves in various pressurized systems and to submit a report to HSK.

- Upgrades in NDE testing have been required by the HSK since 1996. However, because of a lack of detailed guidelines, the Swiss nuclear power plants carried out these quality upgrades as pilot projects. The pilot projects carried out by KKL represent an important basis for the evaluation of the already existing quality upgrades before their next application.

\section{A.9.2.3 Mechanical Engineering Aging Surveillance (Section 5.5.3)}

- The great majority of the fact sheets for the components managed by this program have been prepared, and the KKL goal of submitting all fact sheets for the essential mechanical equipment by the end of 2008 is largely fulfilled.

- The current program permits potential aging mechanisms for mechanical components in $\mathrm{KKL}$ to be recognized and evaluated in a timely manner. During the reporting period, numerous clarification requests have been completed and others are still being processed. HSK has requested all Swiss nuclear power plants revise AMP documentation annually, considering internal and external OpE, as well as the state of science and technology.

- During aging surveillance of the mechanical equipment of the primary cycle and safety systems, KKL has identified the fatigue-relevant SSCs for safety class 1 for which transient monitoring and tracking, and updated fatigue analyses based on the current state of the art are required. However, based on fatigue monitoring experience in other Swiss nuclear power plants, the HSK has concluded that the limitation of fatigue monitoring to only safety class 1 SSCs is not justified. Rather, all fatigue-relevant areas, as well as thermal-hydraulic problem zones, in KKL must be included in the monitoring program, taking into consideration in-house and international $\mathrm{OpE}$. The identification of the fatigue-relevant zones was to be justified technically and the methods of monitoring fully explained. The areas that needed to be monitored with the fatigue-monitoring program FatiguePro were to be specified. HSK was to provide recommendation on this issue in the 2009 annual report on fatigue wear. In addition, the licensee was directed to evaluate whether the fatigue analyses are to be updated to include environmental effects.

\section{A.9.2.4 Maintenance of the Electrical and Control Systems (Section 5.5.4)}

- In KKL, all maintenance tasks and activities involving the electrical, measurement, control and regulating systems and equipment, as well as process and simulation computer systems, are assigned to the electrical and process control department.

- KKL considers assurance of a high degree of safety and availability of the safety electrical and control equipment an important prior condition for long-lasting continuous operation of the plant in the future. KKL recognized that the aging monitoring program is a supporting pillar for the usage duration management of the electrical and control engineering equipment. Knowledge of the aging behavior and the useful service life duration of components and structural parts derived from it represent important safety-related and 
economical boundary conditions for preventive maintenance. A striking feature during the evaluation period was the increased number of switching errors in the medium- and low-voltage power switches, which resulted in the establishment of new maintenance intervals, as well as general reviews of and improvements in the maintenance tasks. Through these measures, the occurrence of switching errors could be practically eliminated.

- HSK found that, overall, KKL has a well-developed maintenance plan for electrical and control engineering devices. The results of the periodic tests performed during the evaluation period confirm the good status of the electrical and control engineering devices. HSK further stated that the quality of the maintenance has improved substantially through preventive replacement of individual parts susceptible to malfunctioning within the scope of the large-scale inspection of switches carried out every 5 years.

- The expansion of the aging surveillance program to include components that were recognized as risk-relevant based on the results of probabilistic safety analyses and component of safety-related systems has resulted, from the current standpoint, in the creation of 18 new fact sheets and the revision of 22 existing fact sheets.

\section{A.9.2.5 Aging Surveillance of the Electrical and Control Systems (Section 5.5.5)}

All the fact sheets to be prepared in KKL for aging surveillance of electrical and control engineering equipment with accident resistance requirements have been submitted, and the individual fact sheets conform to HSK requirements. For $1 \mathrm{E}$-classified equipment without accident-resistance requirements (e.g., medium-voltage cables), complete implementation of the HSK requirements has not yet been achieved. The expansion of the aging surveillance program to include components that were recognized as risk-relevant based on the results of probabilistic safety analyses and components of safety-related systems requires the creation of 18 new and 22 revised existing fact sheets.

\section{A.9.2.6 Civil Engineering Aging Surveillance (Section 5.5.6)}

- HSK has reviewed and essentially accepted the fact sheets submitted by KKL in 1996 and 1997 for the reactor building and the other buildings. HSK included instructions for future revisions of the fact sheets in the evaluations (e.g., paints and coatings should also be included in the inspection program). HSK also finds that a significant portion of the required basic inspections is still incomplete and that no inspection results have yet been included in the fact sheets. The scheduled delivery of the still-outstanding fact sheets for class 1 structures was not achieved by the end of 2007 (24 completed and 28 still in preparation).

- By December 31, 2009, a plan must be submitted for the entire inspection program of the civil engineering aging surveillance program. For all class 1 structures and for all secondary components (reinforced and prestressed concrete, steel construction, intersections, fixations, fire seals, jointing bands, gaskets, coatings), it must specify the outstanding basic inspections as well as the subsequent intermediate and main inspections. 
- The still-outstanding fact sheets on the structures of structural class 1 were to be submitted by December 31, 2009.

- The results of the still-outstanding basic inspections of the structures of structure class 1 were to be supplemented in the fact sheets. The supplemented fact sheets were to be turned in stepwise by December 31, 2011, one-third of the supplemented fact sheets by December 31, 2009, and one-third by December 31, 2010.

\section{A.9.2.7 Reactor Pressure Vessel and Internals (Section 6.3.1)}

- The RPV and core internals were exposed to stresses due to sudden reactor shutdowns associated with two additional incidents. HSK found the effects on the RPV of the resulting temperature transients to be minor in terms of safety relevance.

- HSK accepts the amended testing strategy for the inspection of connecting welds in the control rod drive and the core instrumentation housing penetration nozzles. KKL will inspect these areas annually for leaks using modern visual tests. If new international findings should emerge or if leaks should occur at KKL, HSK reserves the right to again require a special testing program.

- Some of the RPV internals are considered by KKL to be replaceable parts with a limited service life, and they are replaced as part of regular or as-required replacement programs. These components include the control rods, the core instrumentation nozzles, the control rod drives, and the orifice fuel support (fuel element support). As of 2007, a total of 32 core instrumentation nozzles had been replaced. The remaining 13 core instrumentation nozzles were to be replaced in 2010. Although the recommended 15-year service life of the remaining core instrumentation nozzles has been exceeded, HSK accepts this procedure since adequate monitoring of the lances in question is assured.

- Limited tests on unirradiated notch impact reactor vessel surveillance specimens have been conducted. However, when the resulting data are compared to the ductile-brittle transition curve obtained from the first round of tests on irradiated specimens, the data indicated that the ductility increased with radiation. Additional tests on unirradiated material are needed to clarify this unlikely finding, which is contradictory to expected behavior. Therefore, KKL has until December 31, 2010, to determine the ductile-brittle fracture transition curves for the unirradiated weld material in the RPV longitudinal and circumferential welds from additional tests on material identical to the original and then to re-evaluate the results of the first irradiation set.

- KKL has until December 31, 2010, to examine the fracture mechanics samples from the unirradiated sample sets and from the second irradiation set using the standardized master curve concept (ASTM E 1921) and to determine the brittle fracture reference temperature RTTo of the RPV.

- KKL has until December 31, 2009, to clarify according to the current state of the art whether the effect of water chemistry was to be considered for the transients used as the basis for calculating the fatigue usage factor for the fatigue-relevant areas of the nuclear SG system. The fatigue analyses were to be updated if necessary. 
- $\mathrm{KKL}$ is required to introduce the monitoring and recording of the transients by electronic data processing corresponding to the current state of the art for the fatigue-relevant areas of the nuclear SG system. The results of the fatigue analysis were to be submitted to HSK annually, beginning with the 2009 annual fatigue report.

- As long as no cracking has been observed in the core barrel, HSK considers the current testing program to be appropriate. Under this program, a 40-degree segment of the core barrel is tested by visual techniques every 2 years. The occurrence of cracking would necessitate a change in the testing strategy.

\section{A.9.2.8 Reactor Recirculation System (Section 6.3.2)}

- In 2000, NDE detected indications in two recirculation piping weld seams. These regions were tested again in 2001 and 2004 and the periodic test program was expanded to include additional weld seams. By the end of the evaluation period, indications were found on total six weld seams. These discrepancies occurred exclusively on weld seams that were welded by the manufacturer. Of these weld regions, four were subjected to one re-test and two to two re-tests. These additional examinations do not appear to indicate any flaw growth, and fracture mechanics analyses do not indicate any negative effects on plant safety. At the current time, $\mathrm{KKL}$ is proceeding on the assumption that the welds in question can be monitored in the long term by periodic tests. HSK has imposed a requirement that these welds must continue to be monitored every 2 to 5 years, depending on observed behavior.

- For the mechanical equipment in the circulation system, HSK finds that the licensee has properly identified and documented the potentially relevant aging mechanisms. For the piping, these are SCC, thermal embrittlement, "contact" (galvanic or general) corrosion and "fission" (crevice or pitting) corrosion. Additional aging mechanisms include fatigue and wear for the pumps and gate valves, and for the supports, shock absorbers, and other equipment not in contact with the medium. In addition, there is the aging of elastomers and hydraulic fluids, as well as the creep and relaxation of springs.

\section{A.9.2.9 Other HSK Requirements Related to Aging (ENSI 2009, Section 10.6)}

- KKL must perform studies of the vibrations of the pipeline systems and the steam dryer, taking into consideration the recommendations of the Boiling Water Reactor Owner's Group (BWROG) and of the manufacturer, and submit the results, including planned corrective measures, to HSK by December 31, 2009.

- KKL must document in detail the aging mechanisms for the coatings used in the primary containment. In addition, specifications for the evaluation of the status of coating shall be prepared that can also be used for water seals, and suitable inspection methods shall be proposed for evaluation of the status of the coating. These documents shall be submitted to the HSK by December 31, 2010.

- By March 31, 2010, KKL must examine and report to HSK whether the portions of containment penetrations below water, particularly the parts categorized under testing category 2.2 in accordance with Regulation NE-14 and penetrations with high fatigue 
utilization (Ueff > 0.7), are adequately covered in the repeated testing program. If necessary, the repeated testing program shall be revised.

- $\mathrm{KKL}$ must check whether the repeated testing programs for the mechanical components of the reactor core isolation cooling system must be expanded beyond the basic requirements of current specifications to be able to detect the appearance of damage (e.g., due to erosion, fatigue) earlier and to initiate repair/maintenance measures in a timely manner. The test results must be included in the next annual verification documentation (June 30, 2010).

- KKL shall check by December 31, 2009, to what extent the classification of the components of the containment fuel element storage pool cooling system specified in the component list corresponds to the system specifications. If necessary, KKL must supplement the component list and submit it to HSK.

- By June 30, 2011, KKL must subject the entire stationary wet extinguishing installation to a general overhaul and submit the corresponding first inspection records to HSK.

- KKL must review the damage detected on mechanical equipment in the reactor water purification system in the 2005 annual inspection for relevance to aging monitoring by December 31, 2009.

- The description of the fire protection system was to be adapted by KKL to the current status of the fire protection provisions by October 31, 2009.

\section{A.9.3 Safety Analyses}

The Swiss Federal Nuclear Safety Inspectorate identifies four levels of safety measures. These are, in order of increasing severity: (1) those that prevent deviations from normal operation, (2) those that avoid the activation of safety systems, (3) those that return the plant to a safe state after safety systems are activated, and (4) those that prevent core damage or limit the consequences of core damage in the event of a severe accident.

The relevant sections of the report (Sections 7-9) were not available for review. However, Section 10.6 of the report summarized the following requirements pertaining to safety analyses:

- The Severe Accident Management Guidance (SAMG) was to be improved by KKL as follows:

- A superordinate management plan for regular determination of the status of the plant and for the corresponding establishment of priorities was to be supplemented by December 31, 2009.

- $\quad$ The SAMG was to be expanded to cover shutdown operation by December 31, 2009.

- $\quad$ The full-load SAMG was to be revised by December 31, 2010. 
- By December 31, 2010, KKL was to update the analysis for the limiting transients "Closing of all live steam isolation valves under anticipated transients without SCRAM" conditions in terms of the effect of fuel elements with partial length fuel rods, as well as the feedwater runbacks.

- $\mathrm{KKL}$ was to determine the frequency of accidental reactor water cleanup (RWCU) line fracture, taking into consideration the plant-specific pipeline lengths and sizes in the building areas in question on the basis of international OpE, by June 30, 2010.

- KKL was to check to what extent the parts of the plant with a safety-engineering classification withstand the effects of earthquakes. The draft plan was to be submitted to HSK for approval by December 31, 2009.

- KKL must submit the minimal scope of the electrical devices that are to be protected against a lightning strike, and are necessary for maintaining the fundamental protection goals, to the HSK by December 31, 2009.

- KKL must demonstrate the effects of the new source term specification ANS-18.1-1999 (American Nuclear Society 1999) on the activity inventory used as the basis in the radiological accident analysis by June 30, 2010.

- KKL must demonstrate by June 30, 2010, that the dynamic flow processes occurring in the case of a feedwater pipeline rupture are covered by the activity inventory on which the radiological analyses are based.

- The classification of certain fuel element management accidents were to be justified by KKL through detailed analysis by June 30, 2010.

- The analysis of the radiological effects of coolant loss accidents inside the drywell was to be revised by KKL by June 30, 2010.

- The radiological analysis for accidents in the exhaust gas filter building was to be supplemented by KKL by June 30, 2010.

- The radiological effects of a rupture of the steam jet suction line in the turbine building were to be analyzed by KKL by June 30, 2010.

- $\mathrm{KKL}$ was to determine the frequency of occurrence of a failure of the evaporator in the processing building and reproducibly present the assumptions and model theorems for the analysis of the radiological effects. In addition, the measures for limiting the effects of accidents and the maintenance of the corresponding dose limits must be reproducibly demonstrated by June 30, 2010.

- By June 30, 2010, KKL was to conduct a reproducible analysis for the radiological effects of a rupture in the reactor water-purification system, factoring in different variants of the accident depending on the location of the break. 
- KKL was to determine the activity inventory of the components and systems that do not withstand the effect of earthquakes at a frequency of 10-4 per year with adequate safety. Based on this, the anticipated total dose was to be determined with realistic assumptions of damage and the observance of the dose limit by December 31, 2009.

- The Post-LOCA studies were to be reviewed by $\mathrm{KKL}$ and updated if necessary by June 30 , 2011, factoring in the plant modifications completed and the expansion of the emergency management plan in terms of its current status.

- The previous earthquake probabalistic safety analysis of 2006 was to be revised to conform to the state of the art and current plant configuration. Any seismic weak points in the plant were to be systematically identified and potential retrofits evaluated in terms of risk.

- The core damage states of the probabalistic safety analysis of 2006 were to be updated after the revision, and the entire analysis updated by June 30, 2012.

- A series of required improvements to the the PSA specified in an HSK action list were to be implemented.

- KKL was to develop a step 2 PSA for the non-power operation by June 30, 2012.

- The frequency of occurrence of a fire in the active carbon filters in the exhaust gas system in the exhaust gas filter building was to be determined by KKL by June 30, 2010.

\section{A.9.4 Performance and Feedback of Experience}

\section{A.9.4.1 Performance}

No significant information related to plant performance was identified.

\section{A.9.4.2 Operating Experience}

This area was not discussed separately in the report, but was instead included under Subsection 5.2 ("Aging Degradation and Management") above. The following summary of reportable incidents during the 10-year period of the PSR was identified in Section 5.3 of the ENSI report:

Reportable Incidents during the Reporting Period: During the reporting period (1995-2005), KKL identified a total of 127 incidents or events that were determined to be "reportable." These incidents were classified as follows, in order of increasing severity:

- 13 Class Ö incidents (of public interest)

- 72 Class $U$ incidents (of significance for governmental supervision)

- 42 Class B incidents (of minor safety-engineering importance) 
- 0 Class A incidents (of safety-engineering relevance but with no or only minor radiological effects on the environment)

- 0 Class $S$ incidents (represent a risk for the plant or the personnel or have major radiological effects on the environment)

Detailed descriptions were not provided for any of the incidents listed above.

An independent search of other sources also identified the following items related to OpE:

Main Generator Failure: In 2005, the Leibstadt nuclear power plant was shut down for 5 months because of a ground in the main generator that necessitated its complete replacement. The cause of the damage to the generator was attributed, among other factors, to the increase in power output carried out during the evaluation period immediately following startup (ENSI 2009, Section 10.1; swissnuclear 2005).

Planned Shutdown: In September of 2011, the Swiss Parliament approved a plan for a phased shutdown of all of the country's nuclear power plants in reaction to the accident at Fukushima. Under this plan, Leibstadt would be the last of the five plants to be shut down, in 2034 (Tip News 2011).

\section{A.9.4.3 Comparison of Operating Experience with U.S. Plant with Similar Reactor Design}

The U.S. plant with similar design to the Leibstadt Nuclear Power Plant is the Perry Nuclear Plant. Perry plans to apply for license renewal in December 2014 (ADAMS ML102110085), and the LRA and associated SER have not yet been prepared. Instead, information available on the NRC web site was reviewed to identify common areas of concern and to note similarities and differences in OpE. A caution in making this comparison is that component equipment manufacturer and the manufacturing process may vary from plant to plant, thus limiting the value of such direct comparison. The findings resulting from this review are summarized below.

Control Rod Degradation: Beginning in 1997, elevated boron concentrations detected in the coolant at Leibstadt were attributed to control rod damage and dissolution of the boron absorber material. Since then, more than 80 control rods have been replaced, returning the boron concentration in the reactor water to its original value. No similar problems have been reported at Perry, but IN 2011-13 (NRC 2011e) notes that the control rod blade design at Perry is susceptible to cracking.

Core Shroud Cracking: The ENSI report states that core shroud cracking has not been observed at Leibstadt, and the licensee attributes this to good water chemistry control and the use of crack-resistant materials of contruction. Nonetheless, the licensee has instittuted hydrogen water chemistry and noble metal additions to mitigate SCC throughout the coolant system. However, core shroud cracking has occurred at Perry, and it has been addressed using the standard General Electric tie rod repair approach (NRC 2006a). Hydrogen water chemistry and noble metal additions have not been used at Perry (General Electric Advanced Technology Manual, Chapter 4.9; NRC 2010a).

Nozzle Safe End Welds: In 2008, three flaw indications that exceed the flaw acceptance standards of ASME Code Section XI IWB-3514-2 criteria have been identified in safe end welds 
at Perry (Structural Integrity Associates 2008). These are Alloy 82/182 dissimilar metal welds, which connect low-alloy steel nozzle forgings to the Alloy 600 safe ends. An analysis determined these indications were subsurface fabrication defects that did not reduce the capacity of the welds below Code allowable, and that all Code margins were maintained. In contrast, the ENSI PSR report does not identify any dissimilar weld metal problems at Leibstadt.

Steam Dryer Vibration: At Leibstadt, the nuclear steam dryer system is exposed to elevated vibrations, due to the higher flow velocities related to the increased power output associated with power uprate. As a consequence, an expanded surveillance program was introduced for the steam dryer, and the replacement times for supporting components were shortened or engineering improvements implemented. Flow-induced vibration and cracking problems in steam dryers have also been reported for several U.S. plants after power uprates, including Quad Cities 1 and 2 and Dresden 2 and 3 (NRC 2002d, 2003, 2004b, 2005a). However, this problem has apparently not been reported at Perry, even though a 5 percent power uprate was implemented there in June of 2000 (Wood 2001).

\section{A.9.5 Management}

The relevant section of report (Section 4) was not available for review.

\section{A.9.6 Environment}

The relevant section of report (Section 5.8) was not available for review.

\section{A.9.7 Conclusions}

Overall, the Leibstadt plant was found to be in general compliance with regulatory requirements, and it was determined that the plant was maintained and operated in a safe manner. However, HSK imposed a significant number of follow-up requirements on KKL, the operator of Leibstadt, because of the safety review. These requirements emphasized aging management, safety analysis and accident management, seismic analysis, and the updating of existing designs and analyses to current codes and standards.

\section{A.9.7.1 Summary of Technical Issues that Merit Further Consideration}

- The Leibstadt PSR reported that limited tests on reactor vessel surveillance specimens have indicated that the ductility appeared to increase with radiation. The Swiss regulatory agency has determined that additional tests on unirradiated material are needed to clarify this unlikely finding (Section A.9.2.7).

- The nuclear steam dryer system is exposed to elevated vibrations due to the higher flow velocities related to the increased power output associated with power uprate. As a consequence, an expanded surveillance program was introduced for the steam dryer, and the replacement times for supporting components were shortened or engineering improvements implemented (Section A.9.4.3).

- Since 1997, an elevated boron concentration has been detected in the Leibstadt plant that could be attributed to control rod damage due to washing out of the boron absorber material. Since then, more than 80 control rods have been replaced, returning the boron concentration in the reactor water to its original value (Section A.9.4.3). 
- In several places, the PSR document requires that specific SSCs in the Leibstadt plant originally designed under earlier codes and standards be reevaluated on the basis of current codes and standards. For example, Requirements 6.3.1-3 and 6.3.1-4 require that the plant reevaluate environmental effects on the fatigue life of coolant system components and introduce the monitoring and recording of fatigue transients according to "the current state of the art" (Section A.9.2.3).

\section{A.10 Switzerland (Mühleberg)}

The Swiss Mühleberg NPP is a BWR of the General Electric BWR-4, Mark-I Containment design and is rated at $1097 \mathrm{MWe}$. The plant was commissioned in November of 1972 and is located in Mühleberg, Canton Berne, Switzerland. It is operated by BKW FMB Energie AG (BKW FMB Energy Ltd.). The responsible government regulatory agency at the time of the PSR was HSK, which was replaced by ENSI effective January 1, 2009. ENSI conducted a PSR assessment of the plant for the period from September 8, 1990 through December 31, 2005, and the results are presented in their report HSK 11/1100 (HSK 2007) listed in Section 2.1 above.

On November 9, 1990, the operator of the Mühleberg NPP, BKW, applied for an unrestricted operating license and a power uprate. On December 14, 1992, the Federal Council of Switzerland instead granted a 10-year license extension to 2002 and ruled that BKW must submit a comprehensive safety evaluation of the plant every 10 years to the Swiss nuclear regulatory agency HSK. In 1998, another request for an unlimited license extension was turned down, and the operating license was extended for another 10 years to 2012. Additional safety reviews and updates of safety documentation were also required. Because of these two rulings, BKW conducted an initial PSR in 2001 for the 10-year period from September 1990 through September 2000, and supplemented it with an updated review for the ensuing period extending through the end of 2005. The current report, prepared by HSK, provides a detailed summary of the results and findings of the combined 15-year PSR, as well as the resulting recommendations and required actions mandated by HSK.

Section 1 of the HSK report provides background information on the initial and supplemental $\mathrm{BKW}$ periodic safety reviews of the Mühleberg plant, lists the documentation submitted by BKW in 2000 and 2005 as a part of its PSR, describes the bases for the HSK evaluation of these documents, and summarizes the HSK nuclear plant inspection process. Section 2 reviews the licensing history of the plant, summarizes the status of requirements and open issues from past licensing and safety reviews, and describes the status of current plant activities related to safety and aging management. Section 3 provides an overview of the facility with respect to design and safety features and summarizes organizational and technical changes made since 1990. Sections 4 through 10, respectively, evaluate the following aspects of the plant with respect to safety: organization and personnel; operational history of the facility; important buildings, systems, and components; performance in design-basis accidents; performance in accidents beyond design basis; emergency management organization; and evaluation of key components for operation beyond 40 years. Section 11 provides an overall evaluation of the plant's PSR and lists the 16 resulting HSK requirements, almost all of which entail multiple follow-up activities and analyses. Only Sections 1, 2, 3, 6.4 ("Nuclear Steam Production System"), 10, and 11 were available for this review. 


\section{A.10.1 Plant Modifications}

The following plant modifications were reported in the PSR report or in the literature:

Pipe Cracking: During the 1986 annual outage, much of the recirculation piping was replaced because of the observance of IGSCC. No details are available on the alloy used for the replacement piping. It is noted, however, that the recirculation piping in the Leibstadt nuclear power plant is Type 316NG stainless steel.

SUSAN: In 1989, the SUSAN ("Selbstständiges, unabhängiges System zur Abfuhr der Nachzerfallswärme," or Free-standing Independent System for the Removal of Decay Heat) emergency core cooling system began operation. A detailed description of the system is apparently provided in Section 6.6.7 of the report, which was not available for review. However, it appears to include a separate control room, pumps, and emergency diesel generators in a partly underground facility designed to withstand, among other hazards, airplane crashes and major seismic events. The purpose of the facility is to provide emergency cooling water from the Aare River in the event of a LOCA and to provide backup capabilities for a reactor SCRAM (an emergency shutdown of a nuclear reactor).

Core Shroud Cracking: Cracking in the core shroud was first detected in 1990. At the time of the current safety review, the condition of the core shroud was characterized being "slightly cracked," and a clamping assembly consisting of four anchor bolts had been installed as a precaution. The cracking continues to be monitored through annual inspections by the licensee, but HSK has determined that the current configuration is only a temporary fix and the licensee must develop a final solution for long-term operation (HSK 2007, Section 10.2).

Coolant Water Chemistry: Hydrogen water chemistry and noble metal additions were first instituted in 2000 to mitigate SCC in components in contact with the coolant. However, the original procedure did not appear to be effective. Mühleberg has used an altered procedure since the 2005 annual audit (OnLine-NobleChem) in order to achieve this goal, and its effectiveness is currently being evaluated (HSK 2007, Section 2.2.3).

Safe End Cracking: In 2003, a visual inspection of the safe end of the N9 connector revealed the presence of connected cracks. A subsequent analysis determined that the cracks were caused by thermal fatigue associated with thermal striping. Modifications to the coolant circulation paths eliminated the thermal striping problem, and the cracking was brought under control (HSK 2007, Sections 2.2.4 and 6.4.1.2).

Pump Bearing Modification: Based on favorable international experience with fiber ceramic bearings without grease lubrication, the bearings of the main coolant pump A and auxiliary coolant pump B were converted to this type of bearing. Through this conversion and optimization of the lubrication intervals for remaining pumps, the amount of grease introduced into the Aare River was reduced by 85 percent. The remaining pumps were to be converted in stages by 2008 (HSK 2007, Section 2.2.4).

Power Uprate: The power output of the plant was increased by a total of 10 percent in two stages in 1993 to the current level of 1097 MWe. HSK found that this power uprate had no 
detrimental effect on plant reliability, fuel rod integrity, annual collective radiation dose, or the Aare river heat sink (HSK 2007, Section 11.1.6).

Other Modifications: Other plant modifications mentioned in the HSK report include the following: (a) installation of a seismic qualified field instrument and replacement of the entire seismic instrumentation in 1992 and 1993; (b) strengthening of fasteners and support structures related to seismic requalification of mechanical equipment in the reactor building that could affect the functioning of the SUSAN system in 1993; (c) retrofitting of the polar crane in the reactor building in 1994; and (d) modifications to the high-pressure turbines and bypass valves in 1992 and 1993 (HSK 2007, Sections 3.4.2 and 6.8.2).

The sections of the HSK report related to plant design were not provided for review. However, Section 11.3 summarized the following two requirements for follow-up action by BKW pertaining to plant design:

- By the end of 2009, the plant must refurbish the 17MR010A measuring system so that it is suitable for the ambient conditions occurring during a containment pressure relief (HSK Requirement PSÜ-6.13-1). (No further details were given in the portions of the report available for review.)

- By mid-2008, the plant must provide an anchoring plan for the movable frames in which the sensors for monitoring the exhaust air radioactive aerosols are installed so that these frames satisfy earthquake stability requirements (HSK requirement PSÜ 6.13-2).

In addition, the HSK report listed the following previous requirements related to plant design that had been completed prior to the current PSR:

- Requirement 4.5 included the installation of an exhaust hood for smoke and heat and for the limitation of fire load. This requirement was completed in 1997 (HSK 2007, Section 2.2.1).

- Requirement 4.8 demanded annual review and possible updating of the safety report. The safety report was periodically revised during the reporting period (HSK 2007, Section 2.2.1).

- Requirement 4.9 demanded periodic updating of the risk analysis related to changes in the facility and regulations. This requirement was completed (HSK 2007, Section 2.2.1).

- A current and complete documentation by KKM of the fasteners used in the plant, including the design bases for existing and new fasteners, was to be prepared by the end of 2003. This requirement was completed in 2006 (HSK 2007, Section 2.2.3).

- As a result of concerns raised at the Barsebäck plant in Sweden, the suction strainers for the emergency core cooling systems in the torus were enlarged to avoid possible plugging during a loss of coolant accident (HSK 2007, Section 11.2.2).

\section{A.10.2 Aging Degradation and Management}




\section{A.10.2.1 Maintenance and Aging Surveillance}

The details of the maintenance and surveillance programs at Mühleberg were not described in sections of the HSK report available for review. However, the plant subsystems subject to maintenance and aging surveillance are listed below, along with specific findings and resulting remedial requirements of HSK.

\section{A.10.2.2 Mechanical Engineering Maintenance (HSK 2007, Section 11.3)}

- HSK found that the licensee has identified the essential aging mechanisms for the safety-related vessels and piping. However, the licensee must also document the appropriateness and effectiveness of the methods, processes, and techniques used for aging monitoring. The licensee is requested to complete this documentation by the end of 2012 (HSK requirement PSÜ-5.5-1).

- The component lists for the mechanical systems did not include the RPV internals or the control air system components. The licensee has been requested to submit these component lists by the end of 2008 (HSK requirement PSÜ 5.5-2).

\section{A.10.2.3 Maintenance and Aging Surveillance of the Electrical and Control Systems}

The relevant sections of the HSK report (Sections 5.5.2, 6.6.2, 6.7.2, and 6.8.1) were not available for review. However, the following item was noted:

- As a part of the 10-year license extension granted in December of 1992, the licensee was required to develop and implement a systematic program for monitoring the aging of safety-related buildings and electrical and mechanical equipment with significance for safety. The plan was presented on time and approved by HSK, and its implementation will continue to be tracked by HSK.

\section{A.10.2.4 Civil Engineering Structures Aging Surveillance}

Primary Containment: The main degradation processes for the primary containment are considered to be various corrosive aging mechanisms, embrittlement of elastomers in seals, and damage to painted coatings. The difficult-to-reach outer portions of the steel pressure shell of the primary containment are exposed to a slow corrosion process due to periodic contact with water leaking from the reactor pool. So far, no deviation from the nominal minimum wall thickness has been observed. The licensee has introduced measures to test the condition of the steel pressure shell on a regular basis and to mitigate further leakage. HSK has determined that it may be necessary in the future to reconsider the integrity of the primary containment based on the results of aging monitoring activities, particularly with reference to the wall thickness for those parts of the steel shell affected by corrosion. For the present, the condition of the primary containment does not represent a limitation on the lifetime of the plant (HSK 2007, Section 10.3).

In addition, HSK required that aging of the primary containment must be periodically checked and updated to the current state of the art, taking into account plant OpE and information from comparable facilities (international exchange of experience). The first check and adjustment was to be carried out by the end of 2003 (HSK 2007, Section 6.5.1). 
Buildings Important to Safety: The licensee has summarized the state of earthquake design in the document "Buildings Important for Safety and Cross-system Aspects, Earthquake Design" for the entire facility. However, no mention is made of possible operation for more than 40 years. Based on the evaluation of the condition of these buildings, the licensee has determined that aging of the buildings does not limit the lifetime of the Mühleberg nuclear power station and has recorded this information in various documents. In its overall evaluation, the licensee judges the buildings durable. This determination was based on inspection and monitoring results that found no new aging phenomena or serious damage was detected, damaged components were repaired quickly, preventive maintenance was practiced, and additional surface protection systems were placed on important components. The licensee considers the useful life of the buildings to be 80 years. HSK agrees with the licensee's assessment that building aging does not limit the expected lifetime of the plant, based on the current state of knowledge (HSK 2007, Section 10.4).

However, for long-term operation past 40 years, HSK noted the absence of an overall evaluation of earthquake safety for long-term operation. HSK believes that structural earthquake safety is defined as the relationship of the load-bearing capacity to the stress in critical components. While the load-bearing capacity can be maintained through the monitoring and maintenance measures of aging management, stresses expected in an earthquake may change due to new knowledge and/or new methods of calculation. Such information may be derived from the updated local earthquake hazard analysis by the PEGASOS project (Probabilistic Earthquake Risk Analysis for the NPP sites in Switzerland), and continued further development of methods of calculation and computer programs for dynamic earthquake analysis. HSK required the licensee to perform an in-depth seismic requalification and PSA based on the new knowledge of updated local earthquake hazards from PEGASOS for long-term operation beyond 40 years (HSK 2007, Section 10.4).

HSK requirement related to earthquake analysis stated that the earthquake analysis of 2005 was to be revised by December 31, 2008, to correspond to the state of the art and the current plant configuration. In particular: (a) the decisions for selection of the components and buildings are to be made on the basis of a modern procedure based on a comprehensive walk-through of the plant; (b) all the previous fragility analyses are to be updated; (c) the earthquake PSA is to be included in the PSA model as an integral component; and (d) the earthquake analysis is to be documented comprehensively and reproducibly. With the revised PSA model, all possible seismic weak points in the plant are to be systematically identified, and potential refurbishments are to be evaluated from a risk-engineering aspect. The masonry walls in the operations building are also to be analyzed (HSK requirement PSÜ 8.3-1h).

\section{A.10.2.5 Reactor Pressure Vessel and Internals}

Reactor Pressure Vessel: All three surveillance capsules initially installed for monitoring the neutron embrittlement of the pressure vessel have been removed and tested. Based on the test results, HSK has determined that operation up to 60 years is possible. A reconstituted fourth surveillance capsule was placed in the reactor in 2004 to provide additional verification and was positioned to receive a neutron dose equivalent to 50 years of operation by 2015 and 60 years by 2012. Weld seam V2, which has a high copper content, remains a concern with respect to neutron embrittlement, and the licensee is reevaluating previously withdrawn specimens fabricated of this weld material using the master curve concept (American Society for Testing 
and Materials 1995). HSK has endorsed the approach proposed by the licensee for monitoring neutron embrittlement of the RPV, but with the following two requirements (HSK 2007, Sections 6.4.1 and 10.1):

- The licensee should submit a plan by the end of 2010 that describes the test plan and indicates by what methods the fracture-mechanics characteristics are determined for reactor vessel surveillance samples 1-4 and how these values are to be used when evaluating the vessel embrittlement (HSK requirement PSÜ 6.4-1).

- The licensee is to develop an improved procedure for detecting defects in the weld seams of the RPV control rod and instrument penetrations of the by the end of 2008 (HSK requirement PSÜ 6.4-2).

Core Shroud: Cracking was first observed in the core shroud in 1990, and a clamping assembly consisting of four anchor bolts was installed in 1996. The licensee has submitted a long-term operation safety evaluation of the modified core shroud with the clamping assembly. This evaluation includes design verification according to Boiling Water Reactor Vessels and Internals Project- (BWRVIP-) 02-A (EPRI 2005) and inspection verification according to BWRVIP-76 (EPRI 1999). Annual inspections through 2003 and biannual inspections from 2005 have monitored the propagation of cracks in the welding seams, and a sufficient remaining cross section (without cracking damage) has been found to be present to permit continued safe operation. The clamp assembly, which is considered by the licensee to be a final repair, is viewed as a backup security measure against the unexpected failure of the welding seams. HSK has not accepted the argument by the licensee that the clamps represent a final repair of the cracked core shroud and has imposed the following requirements (HSK 2007, Sections 6.4.2 and 10.2):

- The model used by the licensee to calculate permissible crack length in the core shroud requires the following clarifications by the end of 2009: (a) the licensee must demonstrate that the core shroud can be treated as a very long cylinder with respect to the cracks on circumferential weld seams 4 and 11, taking into account the stiffness of its rings and seals; and (b) the permissible crack sizes for circumferential weld seams 4 and 11 are to be reviewed in terms of the effect of neighboring cracks on the stress intensity factor and of the application of the crack length combination criterion (linear elastic fracture mechanics) and the crack length distribution criterion (limiting load analysis) (HSK requirement PSÜ 6.4-3).

- In order to assure safe operation of the crack-damaged core shroud for long-term operation (beyond 40 years), new safety concepts are necessary that conform to national and international regulations. The licensee should submit a revised maintenance plan for the crack-damaged core shroud by December 31, 2010 (HSK requirement PSÜ 10.2-1).

Fatigue Analyses of RPV Components: Though not a part of the analysis for extended operation, the licensee performed an evaluation of the condition of various RPV components and internals with respect to fatigue as a part of its 2002 safety review. These components included the feedwater nozzle "heat shielding jackets" (thermal sleeves) and safe ends, the RPV bolts, and weld seams for the instrument passages in the housing and supports of the poisoning system. The overall conclusion was that fatigue degradation was being managed and was not a problem. HSK endorsed this position. In a supplemental review of the 2005 safety evaluation, 
HSK noted the discovery in May 2003 of visible cracks in Safe End N9. The measures taken by the licensee to modify the configuration of this safe end to eliminate thermal striping were deemed satisfactory by HSK (HSK 2007, Sections 2.2.4 and 6.4.1.2).

\section{A.10.2.6 Reactor Recirculation System}

No items identified.

\section{A.10.2.7 Other HSK Requirements Related to Aging}

Fatigue Analyses: For the various locations in the reactor coolant pressure boundary system, with the exception of the feedwater connectors, the fatigue usage is quite low. A continuous monitoring of the actually occurring transients by electronic data processing (EDP) corresponds to the state of the art and it is being used at KKM for a quick comparison of actual transients with the design transients. HSK noted that this practice was to be continued and supplemented with a report to HSK every 5 years (PSU Open Issue P16/2002). The open issue was resolved by KKL by establishing reporting every 5 years.

\section{A.10.3 Safety Analyses}

The Swiss Federal Nuclear Safety Inspectorate identifies four levels of safety measures. These are, in order of increasing severity: (1) those that prevent deviations from normal operation; (2) those that avoid the activation of safety systems; (3) those that return the plant to a safe state after safety systems are activated; and (4) those that prevent core damage or limit the consequences of core damage in the event of a severe accident.

The relevant sections of the report (Sections 6-8) were not available for review. However, Section 11.3 of the report summarized the following requirements pertaining to safety analyses:

- The licensee should provide an analysis of feedwater and live steam system piping ruptures outside of the containment without assuming a single-fault condition. If the accident dose cannot be maintained at the regulatory requirement of $1 \mathrm{mSv}$ for accidents of incident category 2 (not defined), proposals for refurbishing should be devised and evaluated. The analysis and evaluation of the results should be submitted to HSK by the end of 2008 (HSK requirement PSÜ 7.4-1).

- The licensee should provide a "safety earthquake" analysis without assuming a single-fault condition. If the accident dose cannot be maintained to regulatory requirements of $1 \mathrm{mSv}$ for accidents of incident category 2, proposals for refurbishing should be devised and evaluated. The analysis and evaluation of the results should be submitted to HSK by the end of 2008 (HSK requirement PSÜ 7.6-1).

- In the area of deterministic safety analyses, the following requirements were imposed (HSK requirement $\mathrm{PSÜ-8.3-1a):}$

- All component reliability characteristics including CCF (common cause failure) parameters should be updated with consideration of the plant-specific experience. 
- The licensee's data-recording plan should be revised with respect to component reliability.

- The assumptions and bases for the licensee's currently prescribed operator actions under various accident scenarios (loss of coolant, fire, etc.), as well as natural events (earthquakes, tornadoes, etc.), should be revised and updated (HSK requirements PSÜ-8.3-1b-I and PSÜ 8.5-1a-k).

- After revision of the licensee's stage 1 accident scenario model, the core damage states should be quantified again with a consideration of the entire spectrum of triggering incidents, and the stage 2 model should be updated accordingly (HSK requirement PSÜ-8.4-1a). If no stable or clearly defined end state is reached in the stage 2 PSA within 48 hours after the accident occurs, then this end state should be discussed with respect to its further development and the countermeasures that are available. Optionally, an end state should be assumed that appears in the time space after 48 hours (HSK requirement PSÜ 8.4-1b).

- Analogous to the stage 1 PSA analysis, a stage 2 PSA analysis should be developed for non-power operation (HSK requirement PSÜ-8.6-1).

- The analysis of extreme winds and tornadoes should be revised in accordance with the current state of art (HSK requirement PSÜ-8.3-1i).

- The various failure mechanisms of the Wohlensee dam should be analyzed by modern methods (HSK requirement PSÜ-8.3-1j).

\section{A.10.4 Performance and Feedback of Experience}

\section{A.10.4.1 Performance}

No significant information related to plant performance was identified.

\section{A.10.4.2 Operating Experience}

The relevant section of the HSK report (Section 5) was not available for review. The report noted that the PSR documentation submitted to HSK by the licensee included a section entitled "Operating Experience in the Entire Facility," but details of the contents of this section were not provided in the HSK report.

The HSK report states in the summary Section 11.2.1 that the licensee's OpE over the past 15 years has been good. They noted a high utilization of labor and time availability, and they further stated that the very small number of fuel element damage incidents (a cladding damage incident occurred in 2002), as well as the small number of incident-related shutdowns, were clear evidence of a good plant and good operational management.

An independent search of other sources identified a number of items related to OpE. These are included here to provide additional background for the current review. 
Turbine Hall Fire: On July 21, 1971, a fire in the turbine hall resulted from the ignition of lubricating oil, causing heavy damage to the turbine housing and cables connected to safety systems. The fire occurred during systems tests prior to full commercial operation and caused the start of commercial operation to be significantly delayed (NRC 2001b).

High Temperature of Cooling Water: The Muhleberg plant uses water of the Aare River as its ultimate heat sink. The high temperature of the Aare River in the summer of 2003 led to KKM having to reduce its output from the beginning of June to the beginning of the shutdown in order to maintain the permitted water temperatures at the cooling water discharge. This was also occasionally necessary for some days in subsequent years (HSK 2007, Section 3.1).

Heat Removal from the Reactor Pressure Vessel: The heat removal from the RPV was accomplished with live steam. Possible problems include the loss of one or both turbo groups, the loss of both condensers, the loss of the last heat sink, and the unintended closing of all live steam isolation valves. Between 1990 and 2005, a total of 15 disturbance-related turbine fast shutdowns occurred, four of which led directly to a reactor shutdown. Since the new turbine control system was installed in 2003 and 2004, erroneous triggerings have not occurred (HSK 2007, Section 11.1.2).

\section{A.10.4.3 Comparison of Operating Experience with U.S. Plant with Reactor of Similar Design}

The U.S. plant with a reactor similar in design to the Mühleberg Nuclear Power Plant is Vermont Yankee (Gavrilas et al. 2000). The LRA (Entergy Nuclear Vermont Yankee, LLC, 2006) and resulting SER for Vermont Yankee (NRC 2008, 2009a, 2011a) were reviewed to identify common areas of concern and to note similarities and differences in OpE. A caution in making this comparison is that component equipment manufacturers and the manufacturing process may vary from plant to plant, thus limiting the value of such direct comparison. The findings resulting from this review are summarized below.

Recirculation Piping Replacement: During the 1986 annual outage, much of the recirculation piping at Mühleberg was replaced with a more resistant alloy because of observations of IGSCC. No details are available on the alloy used for the replacement piping, although the recirculation piping in the Swiss Leibstadt nuclear power plant is Type 316NG stainless steel. Similarly, at Vermont Yankee the SER (Section 3.0.3.2.5) indicates that extensive piping replacement and mitigating treatments were applied throughout the austenitic piping system during the decade from 1977 to 1986, and the result of these actions is that nearly all piping, nozzles, and welds in the austenitic system are composed of resistant materials. Neither plant has reported significant cracking problems subsequent to these replacements.

Core Shroud Cracking: Cracking in the core shroud at Mühleberg was first detected in 1990. At the time of the current safety review, the condition of the core shroud was characterized as being "slightly cracked," and a clamping assembly consisting of four anchor bolts had been installed as a precaution. The cracking continues to be monitored through annual inspections by the licensee, but HSK has determined that the present configuration is only a temporary fix and the licensee must develop a final solution for long-term operation. HSK has also requested that the licensee refine the model used to calculate the maximum acceptable crack length in the core shroud. 
The SER for Vermont Yankee (Section 4.2.6.2) similarly reports that core shroud repair tie rods were installed prior to the 2004 ISI and notes that these rods obstructed the volumetric inspection of two axial welds. The Vermont Yankee SER (Section 4.3.1.2.2) also states that fatigue of the core shroud repair is considered to be a TLAA with a 40-year design life (Section 4.3.1.2.2), thus indicating that it is not regarded as a temporary fix. In addition, the Vermont Yankee SER discusses the fatigue analyses of the core shroud and core shroud support, as well as thermal shock of the core shroud, all of which are treated as TLAAs (SER Sections 4.7.1.2, 4.7.2.3, and 4.7.2.8). The HSK report briefly mentions possible fatigue cracking of the repaired core shroud at Mühleberg, but it provides no details. Both Mühleberg and Vermont Yankee follow BWRVIP-76 (EPRI 1999) core shroud inspection and flaw evaluation guidelines.

Coolant Water Chemistry: Both Mühleberg and Vermont Yankee employ hydrogen water chemistry and noble metal additions to mitigate SCC. However, whereas the initial application of these measures did not appear to be effective at Mühleberg, no such problems with their implementation are reported in the Vermont Yankee LRA and SER.

Safe End Cracking: Cracking of the safe end of the N9 nozzle due to thermal fatigue associated with thermal striping was reported at Mühleberg in 2003. In 2004, the licensee modified the N9 nozzle by cutting and isolating the existing control rod drive (CRD) system return line to nozzle $\mathrm{N} 9$ and rerouting the CRD return line to the CRD cooling water header. The modification also included removing the safe end and thermal sleeve from nozzle N9 in 2006, after some difficulties, and installing a cap (Section 2.2.4). A similar modification was performed at Vermont Yankee to address the same potential thermal fatigue problem. The modified CRD return line nozzles and caps are susceptible to SCC, but liquid penetrant and ultrasonic examinations of nozzle safe end welds performed at Vermont Yankee in May 2001 and October 2002 resulted in no recordable indications (SER Section 3.0.3.2.5). The PSR for Mühleberg does not mention any cracking detected in the modified N9 nozzle.

Reactor Vessel Penetrations: HSK is requiring the licensee to develop an improved procedure for detecting defects in the reactor pressure vessel control rod and instrument penetration welds, suggesting that this is a problem area (HSK requirement PSÜ-6.4-2). The SER for Vermont Yankee (Section 3.0.3.2.4) states that liquid penetrant examination of instrument penetration nozzles in May 2001 resulted in no recordable indications of cracking and finds this to be evidence that the licensee's AMP is effective for managing instrument penetration nozzle cracking.

\section{A.10.5 Management}

The relevant section of report (Section 4) was not available for review. The HSK evaluation of the licensee's safety culture and personnel development in Sections 11.1.4 and 11.1.4 do not note any significant deficiencies. In addition, as stated above, Section 11.2.1 of the HSK report states that the good OpE over the past 15 years is clear evidence of a good plant and good operational management.

\section{A.10.6 Environment}

The relevant section of report (Section 5.7) was not available for review. In the summary Section 11.1.7, HSK states, "in terms of environmental effects, the plant is operated with 
negligible secondary effects." Report Section 11.3 lists the following two HSK requirements related to environmental impact:

- The licensee should submit by December 31, 2008, a written report to HSK describing the results of a review of the implementation of the zone concept relative to possible "unregistered" (non-permissible?) emissions of radioactive substances from the monitored zones of the plant (HSK requirement PSÜ-5.6-1).

- The licensee must implement measures to reduce the emissions of radioactive substances in the wastewater at the end of 2010 , while maintaining the proportionality (?), to a target value of less than $1 \mathrm{GBq}$ per year (without tritium). An annual progress report is to be submitted to HSK (HSK requirement PSÜ-5.7-1).

\section{A.10.7 Conclusions}

Overall, because of the PSR, HSK determined that a high degree of technical and organizational safety awareness exists in the Mühleberg NPP. They state that the plant has reliably operated for the past 15 years and that the pre-conditions for continued safe operation are in place. In order for the licensee to better conform to industry OpE and the current state of science and technology, HSK has imposed a number of required improvement measures. These requirements do not call into question the safe operation of the plant; rather, they are intended to ensure continued safe operation. In addition, non-recurring open issues remaining from the safety-engineering evaluation of 2002 should all be completely taken care of. The licensee has accepted all of the measures for improvement required by HSK, and HSK will follow up on these requirements until they are completed.

\section{A.10.7.1 Summary of Technical Issues that Merit Further Consideration}

- The Mühleberg PSR states that, on the basis of good international experience with fiber ceramic bearings without grease lubrication, the bearings of the main coolant pump $A$ and auxiliary coolant pump B at Mühleberg were converted to this type of bearing. Through this conversion and optimization of the lubrication intervals for the remaining pumps, the amount of grease discharged to the Aare River was reduced by 85 percent. The remaining pumps were to be converted in stages by 2008 (Section A.10.1).

- The Mühleberg PSR states that one open issue is the verification of the effectiveness of hydrogen water chemistry and noble metal additions for protecting RPV components. The goal of hydrogen-noble metal additions, first instituted in 2000 , was to prevent the initiation of new cracks and to reduce the speed of propagation of existing cracks, but the original procedure did not appear to be effective. Mühleberg has used an altered procedure since the 2005 annual audit (OnLine-NobleChem) in order to achieve this goal; its effectiveness is currently being evaluated. Problems with the implementation of HWC and noble metal additions have also been observed at some U.S. plants (Section A.10.1).

\section{A.11 Taiwan (Chin Shan Unit 1)}

The Taiwanese Chin Shan Unit 1 NPP is a BWR of the General Electric BWR-4, Mark-I Containment design and is rated at $604 \mathrm{MWe}$. The plant was commissioned in December of 1978 and is located in Chin Shan, Taiwan. It is operated by Taipower, and the responsible 
government regulatory agency is the Taiwan Atomic Energy Council (AEC). The AEC conducted a PSR assessment of the plant for the period from 1998 through 2007, and the results are presented in their report NRD-SER-98-03 (Taiwan Atomic Energy Council 2009b) listed in Section 2.1 above.

The third 10-year (1998-2007) Safety Assessment Report by the AEC on Chin Shan Unit 1 provides a review and assessment of operations safety, improvement and enhancement measurements implemented at the plant, and overall aging management, seismic safety assessment, and reliability assessment of the electrical equipment. During the preceding 10 years, Unit 1 completed operations more than fuel cycles. The plant availability ranged from 81 percent to 100 percent. Factors affecting plant availability include shutdown (including overhaul), emergency shutdown, load change and restrictions (including restrictions on scheduling, maintenance and load increase), full-function operation capability of the reactor core (including control rod adjustment), and periodic tests. The translated PSR report did not include Chapters 2 ("Review and Assessment of Radiation Safety"), 3 ("Review and Assessment of Operation of the Radioactive Wastes"), 6 ("Seismic Safety Assessment"), or 7 ("Related Improvements of 3A Accidents of Nuclear Power Plants").

\section{A.11.1 Plant Modifications}

\section{A.11.1.1 Completed Plant Modifications}

The following plant modifications have been completed and are described in the PSR report or in the literature:

Monitoring and Control System Upgrade: In February of 2005, General Electric Nuclear was awarded a multi-million dollar contract to upgrade monitoring and control systems at the Chin Shan Nuclear Power Station in northern Taiwan. The package included design, hardware and software, engineering, licensing support, installation and training. The system improved reliability and accuracy of the Power Range Monitoring System while reducing maintenance costs and addressing an equipment obsolescence concern (GE Energy 2005).

Main Transformer Replacement: Because of aging in the existing main transformer and the lack of a standby transformer, Unit 1 replaced the main transformer with a new one in 2008.

Power Uprate: Unit 1 of the Chin Shan plant completed a power uprate on February 24, 2009, increasing its output by $6 \mathrm{MW}$. Under this uprate, the maximum thermal power output of a nuclear reactor is set at 102 percent of the rated thermal power. This 2 percent margin takes into consideration the possible inaccuracy of feedwater flow measurement in the calculation of power (Taiwan Atomic Energy Council 2009a).

Review of Major Safety-related Design Modification Projects Already Completed: This task keeps track of and assesses performance after improvement projects are completed to confirm their effectiveness in achieving the original design objectives. During the past 10 years, Unit 1 had three "major safety-related design modification projects," namely, (1) the feedwater hydrogenation improvement project; (2) the power range neutron monitoring system improvement project; and (3) automatic emergency shutdown system of the reactor in the event of a strong earthquake. 


\section{A.11.1.2 Planned Plant Modifications}

The following plant modifications have planned, as reported in the PSR report or in the literature:

Generator Rotor Replacement and Rewinding: The main generator rotor has been in operation for more than 25 years. Unit 1 plans to replace it in 2013 and re-wind the new one to extend the service life of the generator. After the generator rotor is re-wound, its rated capacity will increase by more than 10 percent so as to meet the future requirements for power uprates. Because the generator has entered the aging and frequent fault stage, the AEC required Taipower to develop appropriate measures to deal with this aging prior to replacement or re-winding in the future.

Replacing the Existing Analog Generator AVR with New Digital Equipment: Unit 1 stated that the existing analog generator AVR (auto voltage regulator) has been in operation for more than 20 years, and many of its components require replacement. Unit 1 will replace the existing AVRs with digital AVRs to avoid the possibility of potential unexpected faults due to aging; however, digital equipment can also age. The AEC recommended that Unit 1 draw upon the $\mathrm{OpE}$ of other plants and collect related information to review and formulate plans to meet the requirements for design improvement in the replacement project.

In addition, the AEC reviewed and assessed the following major improvements or enhancements that either have been implemented in the last 10 years or are to be implemented at the Chin Shan Unit 1.

- Main transformer replacement.

- Addition of the ultrasonic feedwater flow measuring system.

- Reduce the idle voltage of the high-pressure cooling injection (HPCl) control system.

- Change the existing 345-KV start/standby transformer to two units.

- Flow adjustment from the critical seawater system to the RHR/CSCW (combined service \& cooling water system) heat exchanger seawater side.

- Review major safety-related design modification projects that have already been completed.

- Description of critical safety analysis of the new fuel storage vault.

The AEC noted that after nearly 30 years of operation, the plant is experiencing problems related to gradual aging of the parts and components of the various systems. Since nuclear-grade items are becoming more difficult to obtain, nuclear plants are replacing the old system equipment successively by means of the DCR (design change request) process to maintain the operation safety of the unit. However, an application must be submitted to the AEC for approval before construction if a DCR involves operational specification modifications, new safety issues, safety-related quality equipment, or modification of the safety analysis report, or if there is the possibility of reducing the original design standards. 
Unit 1 verifies drawings for plant modifications against as-built conditions to ensure consistency. The AEC recommended that the verification be extended to modifications of non-safety design modifications.

Based on the assessment, the AEC concluded that the control of major safety-related design modification projects by Unit 1 is good.

\section{A.11.2 Aging Degradation and Management}

Taipower developed an aging management plan in accordance with the U.S. AMP described in NUREG-1800 and NUREG-1801 (NRC 2001a, 2005b, 2010c). The resulting AMP includes 42 AMPs (32 existing programs and 10 new programs). However, in November 2011, it was announced that no life extensions will be granted to Taipower's existing NPPs in a newly announced nuclear energy policy (see Section A.11.4.1, "Operating Experience") (World Nuclear News 2011).

\section{A.11.2.1 Nuclear Fuels}

The report noted an ongoing problem with the "bending of fuel boxes" (fuel channel deformation) that could adversely impact control rod insertion and removal, and 19 "fuel boxes" have been replaced due to significant deformation. In addition, Taipower is taking the following measures: (1) re-designing the reactor core in accordance with the latest design standards, (2) adopting Zircaloy-4 as the material for the fuel boxes; (3) performing periodic inspections and testing in accordance with the recommendations of the fuel manufacturer.

The AEC concluded that that the nuclear fuels at Unit 1 have remained in good condition during the past 10 years. In the future, Taipower will move toward high fuel utilization efficiency, high fuel operational performance, and a lowered fuel damage rate.

\section{A.11.2.2 Mechanical Systems}

Reactor Vessel and Internal Components of the Reactor Core: During the nearly 30 years of operation, similar to other plants, cracking occurred in a number of Unit 1 reactor core components. In addition to making improvements in terms of material, water quality, and stress, reactor core components are inspected in accordance with appropriate BWRVIP guidelines. Unit 1 initiated its feedwater hydrogenation project in 2006 and its 0.5 ppm hydrogenation in 2007 to mitigate IGSCC. During the third 10-year operating period, the RPV and associated components in Unit 1 have undergone NDE six times. In the future fourth 10-year "Inspection Schedule during the Operating Period," Unit 1 will adopt a stricter Performance Demonstration Initiative to inspect the reactor pressure vessel components to identify the defects early and take remedial measures more effectively.

The AEC concluded that the continued implementation of the inspection plan in accordance with ASME and BWRVIP specifications provides reasonable assurance of proper management of cracking of the components during the fourth 10-year operating period.

Austenitic Stainless Steel Components in the Recirculation and Safety Systems: Unit 1 implemented 0.5 ppm HWC in 2007 to mitigate IGSCC in the recirculation and safety systems. 
Only the inspection of Type $E$ welds is performed in accordance with the inspection cycle in NRC GL 88-01 (NRC 1988a), while the inspection frequency of other types of welds is more conservative than those requirements. Based on comparisons with 33 BWR units performing NRC GL 88-01 (NRC 1988a) inspections, the number of inspection times performed at Chin Shan Unit 1 is nearly twice that of BWRs in the U.S.

Based on inspection results, IGSCC occurred on only three welds in the recirculation system piping in the third 10-year operation period. After assessment, these cracks have been repaired by weld overlay using the technology recommended by Institute of Nuclear Energy Research, and the IGSCC rate has decreased significantly.

Chin Shan Unit 1 took following enhancement measurements to improve their IGSCC inspection technologies:

- Request the Institute of Nuclear Energy Research to verify and test its inspection capabilities, including dissimilar metal welds, to help improve the overall UT inspection technology.

- Keep track of the development of new technologies, assess their practicality, and introduce these technologies as appropriate.

- Check for leakage during shutdown or startup for early identification of pipeline degradation and take preventive measures in a timely manner to ensure the integrity of the primary pressure boundary.

- Keep track of the effects of adjustments in hydrogen concentrations in HWC on the prevention of IGSCC.

The AEC concluded that the results of the third overall safety assessment of Unit 1 indicate that proper inspection plan enhancement, water quality improvement, and existing maintenance, monitoring, inspection and, surveillance properly manage aging and degradation of the relevant SSCs to ensure safe operation of the unit.

Performance Assessment of the Safety System: The RHR and EDG systems have performed well over last 10 years. The performance indicators of the $\mathrm{HPCl} /$ reactor core isolation cooling $(\mathrm{RCIC})$ systems did not meet target values due to problems that included valve malfunctions and turbine speed adjustment problems. Unit 1 determined the root causes of these problems and implemented the required remedial actions.

The AEC concluded that the comparison of performance data for Unit 1 with mean values for BWRs around the world indicates that the performance of most of the systems at Unit 1 is not inferior to similar plants in other countries.

Water Chemistry Analysis and Assessment: Unit 1 implemented a feedwater nitrogen improvement project in May 1996. The normal water chemistry (NWC) was changed to HWC in 2006 to inhibit the occurrence of IGSCC initiation and growth, thereby maintaining the safety margins of the components in the bottom assemblies of the reactor. 
In the 10-year period from 1998 to 2007 , Unit 1 took several measures to improve the water chemistry quality treatment and technologies, including (1) installing an electrolyzed seawater chlorination system; (2) protecting the integrity of reactor components through HWC; and (3) reducing the radiation dose of plant personnel through chemical decontamination. Planned future improvements include (1) implementation of moderate hydrogen water chemistry (HWC-M); and (2) addition of depleted zinc oxide to the feedwater. Unit 1 will determine the feasibility and timing of depleted zinc oxide additions to the feedwater based on overseas experience.

AEC found that the water quality at Unit 1 showed an overall trend toward gradual improvement during the past 10 years. The AEC recommended that, in view of equipment aging and extended fuel cycles, Unit 1 should continue to strive to improve the water quality to prevent the buildup of radiation fields and equipment corrosion and to track the specific results of feedwater hydrogenation.

The feedwater hydrogenation system failed frequently due to equipment malfunctions, indicating low system reliability. The AEC recommended that system reliability be improved, drawing upon the OpE of overseas plants.

\section{A.11.2.3 Structural Systems}

Structural Integrity of the Primary Containment: Unit 1 applied ASME Section XI, Subsections IWL and IWE (ASME 2004b), requirements in its containment inspections. Both IWL and IWE inspections were completed in 2001 within the specified 5-year timeframe, and the inspection results have been submitted to regulators for approval and reference. The second IWL ISI was completed in 2006.

In addition to IWE and IWL inspections, other major activities in containment inspection include primary containment surface coating inspection, ultrasonic inspection of the lining in the sand cushion area, local leak-rate testing, and integrated leak-rate testing. Their approach is consistent with aging management in U.S. BWRs. The inspection results and thickness measurements performed in the third 10-year period did not reveal any major defects. The AEC concluded that, overall, the primary containment integrity program at Unit 1 meets regulatory requirements.

\section{A.11.2.4 Electrical Systems}

Main Transformer Replacement: Because of aging in the existing main transformer and no standby transformer, Unit 1 replaced the main transformer with a new one in 2008.

Thermal Aging of Cables: Cables in the high-temperature areas of the buildings experienced accelerated aging at Unit 1 due to, for example, high temperature at the reactor drywell and main steam tunnel. Embrittlement was found in most of the cables in the main steam tunnels. Unit 1 took several measures to reduce the temperatures in the high-temperature areas to prevent cable aging. After the improvements, the temperature in the dry well and main steam tunnels decreased from $55^{\circ} \mathrm{C}$ to approximately $45^{\circ} \mathrm{C}$. The project also involved replacement of the cables in the drywell and main steam tunnels with high-temperature-resistant silicone cables. 
The AEC concluded that, in recent years, Unit 1 has made multiple improvements in ventilation in high-temperature regions, and these improvements have resulted in obvious improvements in the temperature in these regions. After the temperature in the high-temperature zone decreased, the impact on cable aging also decreased. In the most recent 10-year period, there has been no cable aging based on inspection results.

\section{A.11.2.5 Auxiliary Systems}

Assessment of Fire Protection Functions: There were four fire-related incidents at Unit 1 in the last 10 years. None of these incidents was related to the aging of fire protection SSCs. Unit 1 implemented 18 measures to improve the fire protection system in the last 10 years, including the isolation of fire hydrants, sealing the cable penetrator on the fire pump, and improving the fire protection of the turbine generator, switch room, and outdoor oil-immersed transformer. The AEC concluded that fire protection functions at Unit 1 during the last 10 years were acceptable and recommended that Unit 1 revise FSAR requirements related to fire protection in accordance with NRC RG 1.189 (NRC 2009c).

\section{A.11.3 Safety Analyses}

Operational Safety: The PSR report states that during the last 10 years, Chin Shan 1 has (a) promoted a nuclear safety culture and implemented stable operation of the plant;

(b) improved operation and maintenance practices; (c) gradually reduced personnel operational errors; (d) improved the performance of the equipment; and (e) achieved stable operation of the unit on the whole. The AEC concluded that to achieve the safety performance objectives in the next 10 years, Chin Shan Unit 1 should continue to implement the nuclear safety culture and nuclear operation enhancement measures, and continue to perform assessments of the safety system in accordance with the inspection plan developed by Taipower.

The safety analysis aspects of the various plant systems are included in the discussion of aging management in Section A.11.2 above.

\section{A.11.4 Performance and Feedback of Experience}

\section{A.11.4.1 Operating Experience}

Abnormal Event Assessment: Chin Shan Unit 1 recorded 44 abnormal events during the third 10 -year period, including 35 equipment faults, of which 21 caused equipment failures. Taipower was requested by the AEC to clarify whether it had developed handling measures for the faulty equipment to reduce their failure rate. Taipower provided clarification on the above issue, but no details on the actions taken were given in the report.

The AEC concluded that, based on a statistical analysis performance of Chin Shan Unit 1, there has been a clear decrease in the number of abnormal events during the past 10 years as compared to the previous 10-year period. This indicates that improvements have been made in implementing a safety culture, preventing operational errors by personnel, and equipment maintenance. The AEC also concluded that equipment failures account for a large proportion of the equipment faults that occurred during the past 10 years. Because Unit 1 has been in operation for 30 years, more attention should be given to the aging/deterioration of equipment in 
subsequent equipment maintenance, and equipment replacement should be undertaken where necessary to maintain the plant in good operating condition.

Review of Violations: In the third 10-year period, Chin Shan Unit 1 recorded 18 violations. Among these, 13 violations occurred between 1998 and 2002 and five violations occurred between 2003 and 2007. Most violations were minor, with the most severe one being a fuel hoisting error that resulted in damage to the fuel elements and control rods. This incident was not related to aging.

The AEC requires power plants to share related experience with other plants to prevent the occurrence of similar incidents. Although there have been improvements in the number and level of the violations at Unit 1 during the past 10 years, the AEC stated that the plant should continue to make greater efforts to reduce the occurrence of such violations.

Good Operating Practice: Chin Shan Unit 1 developed 26 Good Operating Practices in such areas as handling of serious deterioration in systems, shortening the pressure suppression tank decontamination time, the effective use of water used for overhaul, creation of a web site to promote the mear miss system, establishment of a safety culture, and creation of the overhaul management information website. The AEC recommended that Unit 1 publish typical examples of good operating practice on the internal web site.

Analysis and Assessment of Equipment Failures in the Safety System: As an indicator of the operational reliability of the equipment of the safety system, Chin Shan Unit 1 counted the number of Request for Repair Forms that were generated in last 10 years. Root cause failure analyses are performed for future improvement. Unit 1 recorded 53 electric faults, 35 instrument faults, and 25 mechanical faults in the last 10 years. Ranking first among these was the emergency diesel generator system, followed by the control rod drive hydraulic system, the neutron detection system, the residual heat removal system, the reactor core isolation cooling system, the high-pressure coolant injection system, the reactor re-circulating water system, and the plant seawater system.

Specific faults that may be related to aging deterioration include the following:

- Occurrence of an alarm due to insulation deterioration in the immersion heater of the emergency diesel generator.

- Air leakage of the outlet valve, safety valve, and pipeline of the startup air storage tank.

- Air leakage of the unloading mechanism and exhaust valve of the startup air compressor and wear of the coupling of the lubricant pump of the \#5 diesel generator.

- Clogging and oil seepage of the sensor pipelines of the Fuel Oil Day Tank.

- Alarms in the wide-range neutron monitoring of the neutron detection system due to noise, sensor degradation and detector aging.

In addition, the following specific OpE incidents were noted: 
Reactor Core Isolation Cooling System Valve Malfunction: During a routine testing procedure conducted on January 5, 2006, the maintenance crew was unable to open the RCIC system discharge valve. The plant entered a "limiting condition for operation" mode, and the operating personnel verified that the HPCl system was operating normally. After restoring the valve to its original position, it was determined that the steam shutoff valve also could not be opened. The backup valve drive motor and temperature overload relay were replaced on January 7 , and the $\mathrm{RCIC}$ system was declared operable. The RCIC discharge valve failure was found to be due to a burned out drive motor associated with poor contact between the carbon brush and the commutator. The steam shutoff valve failure was also caused by a burned-out drive motor, in this case caused by a malfunction of the valve torque switch due to insufficient thrust of the valve operator. The AEC determined this to be an INES Level 0 event with no safety significance (Taiwan Atomic Energy Council 2006a).

Reactor Core Isolation Cooling System Pump Malfunction: During a RCIC pump operability and flow test conducted on February 16, 2006, the operating personnel discovered that the equipment could not smoothly execute a turbine speed adjustment, and it was necessary to manually trip the RCIC system. The RCIC system was declared inoperable, and the plant entered into a "limiting condition for operation" mode. The maintenance crew inspected the governor valve system and discovered that the set screw thread of the lock nut on the connecting rod had been damaged and the governor stem could not be properly positioned. Repairs were made, and the RCIC system was declared operable the same day (Taiwan Atomic Energy Council, 2006b).

With respect to detector aging in the neutron detection system, the AEC raised the concern that the review and improvement measures indicate that the detector itself has a finite life. They asked whether this detector is included in the regular replacement cycle. The Taipower response is not included in the report.

The AEC concluded that Unit 1 has reviewed and improved these faults through (1) replacement of parts and components in the equipment; (2) strengthening maintenance operations and modifying related procedures; (3) installing additional monitoring equipment; and (4) providing experience feedback to other units to prevent re-occurrence of the faults.

\section{A.11.4.2 Comparison of Operating Experience with U.S. Plant of Similar Design}

The U.S. plant similar in design to the Chin Shan Nuclear Power Plant is Vermont Yankee. The LRA (Entergy Nuclear Vermont Yankee, LLC, 2006) and resulting SER for Vermont Yankee (NRC 2008, 2009a, 2011a) were reviewed to identify common areas of concern and to note similarities and differences in OpE. A caution in making this comparison is that component equipment manufacturers and the manufacturing process may vary from plant to plant, thus limiting the value of such direct comparison. The findings resulting from this review are summarized below.

Coolant Water Chemistry: Both Chin Shan and Vermont Yankee employ HWC to mitigate IGSCC. No problems with their implementation are reported in the Vermont Yankee LRA and SER. Based on Chin Shan inspection results, IGSCC occurred in three welds in the recirculation system piping in the third 10-year operation period. After assessment, these cracks have been repaired by weld overlay using the technology recommended by Institute of Nuclear Energy Research, and the IGSCC rate has decreased significantly. 
Core Shroud Cracking: The SER for Vermont Yankee (Section 4.2.6.2) reports that core shroud repair tie rods were installed prior to the $2004 \mathrm{ISI}$ and notes that these rods obstructed the volumetric inspection of two axial welds. The Vermont Yankee SER (Section 4.3.1.2.2) also states that fatigue of the core shroud repair is considered a TLAA with a 40-year design life (Section 4.3.1.2.2), thus indicating that it is not regarded as a temporary fix. In addition, the Vermont Yankee SER discusses the fatigue analyses of the core shroud and core shroud support as well as thermal shock of the core shroud, all of which are treated as TLAAs (Sections 4.7.1.2, 4.7.2.3, and 4.7.2.8). The Chin Shan PSR report indicates that during its nearly 30 years of operation, similar to other plants, cracking occurred in a number of Unit 1 reactor core components. However, no details of the cracking are given in the report.

\section{A.11.5 Management}

Assessment of Personnel Training Results: Training courses at Unit 1 cover several areas. To provide reference documents for training, technical information, DCR, abnormal events, documents of the AEC, INPO documents, World Association of Nuclear Operators (WANO) documents, root cause failure analyses, and experience feedback have been put into the computer-based training management system. The AEC found training at Unit 1 to be acceptable.

\section{A.11.6 Environment}

Related information is not available.

\section{A.11.7 Conclusions}

The AEC concluded that during the last 10 years, Chin Shan Unit 1 has (a) promoted a nuclear safety culture and implemented a stable operation scheme for the unit, (b) improved operation and maintenance practices, (c) gradually reduced operational errors by plant personnel on a yearly basis, (d) improved the performance of the equipment, and (e) overall, achieved stable operation of the unit. The AEC recommended that in the next 10 years, Chin Shan Unit 1 should continue to implement nuclear safety culture and nuclear operation enhancement measures, and continue to perform assessments of the safety system in accordance with the inspection plan developed by Taipower so as to achieve the desired safety performance objectives. Overall, the AEC concluded after their review that there are no safety concerns that would be expected to impact the operation of Chin Shan Unit 1 over the next 10 years.

\section{A.11.7.1 Summary of Technical Issues that Merit Further Consideration}

- Cables in the high-temperature areas of the buildings experienced accelerated aging and embrittlement due to high temperatures at locations such as the reactor drywell and main steam tunnel. Chin Shan Unit 1 took several measures to reduce the temperatures in the high-temperature areas to prevent cable aging. After the improvements, the temperature in the dry well and main steam tunnels decreased from $55^{\circ} \mathrm{C}$ to approximately $45^{\circ} \mathrm{C}$. The project also involved replacement of the cables in the drywell and main steam tunnels with high-temperature-resistant silicone cables (Section 11.2.4). 


\section{A.12 United Kingdom (Sizewell B)}

The British Sizewell B NPP is a PWR of the Westinghouse 4-loop design and is rated at $1195 \mathrm{MWe}$. The plant was commissioned in February of 1995 and is located in Sizewell, Suffolk, England. It is operated by EdF Energy, which acquired British Energy (BE) in 2009. The responsible government regulatory agency is the British Health and Safety Executive (HSE). HSE's Nuclear Installations Inspectorate (NII) conducted a PSR assessment of the plant for the period from 1995 through 2005, and the results are presented in the HSE report listed in Section 2.1 above.

The Sizewell B PWR is a development of the U.S. Standardized Nuclear Unit Power Plant System (SNUPPS) design, which was augmented mainly to accommodate UK siting and safety requirements. Changes to the SNUPPS design include the following:

- two diverse reactor protection systems;

- an emergency boration (diverse shutdown) system;

- four physically segregated trains of protection and safeguards equipment;

- improved emergency core cooling systems.

Since Sizewell B commenced operations in 1995, this PSR covers the first 10-year cycle of the plant. The PSR primarily covers six areas:

1. safety management systems;

2. operations and safety performance;

3. aging, obsolescence, and equipment qualification;

4. safety analysis;

5. SSCs; and

6. technical disciplines

In the report, plant aging and projected life are taken into account in forming judgments on the practicability of making safety improvements. In addition, the report considers the differences between the original standards to which the plant was built and the current safety standards.

\section{A.12.1 Plant Design}

\section{A.12.1.1 Plant Modifications and Improvements}

The PSR does not mention specific plant modifications and improvements in the Sizewell plant. The following plant modifications and improvement measurements are reported in sources other than the PSR:

Replacement of Reactor Vessel Head: NPPs with reactor vessel closure heads containing Alloy 600 base materials and Alloy 182 weld materials are susceptible to PWSCC. The first indications of degradation of Sizewell's reactor vessel head containing Alloy 600 base materials and Alloy 182 weld materials emerged during the plant's seventh refueling outage. In 2006 (eighth refueling outage), Sizewell B installed a new vessel head that uses Alloy 690 and Alloy 152 weld materials because these alloys are less prone to PWSCC (WANO 2008). 


\section{A.12.1.2 Assessment against Current Safety Standards and Methodologies}

In its assessment against changes of design codes, current safety standards and methodologies, and relevant good practice, the PSR identified several differences or changes between the original design and the current safety standards and methodologies, as summarized here.

Structural Integrity: HSE found that it is not clear from the documents referenced for the procedure for assessing the effects of reactor trips on reactor components whether the bounding locations were still valid. HSE therefore required BE to update the procedure for assessing the effect of reactor trips on the "incredibility of failure" (IOF) of components. Chemistry: The importance of water chemistry in preserving fuel pin integrity, minimizing the creation of radioactive waste, and minimizing operator doses, should be recognized by giving the water chemistry technical standards the appropriate emphasis in the plant's safety documentation. HSE therefore required BE to review the status of the chemistry technical standards in the Sizewell B safety documentation.

Control and Instrumentation, Safety and Computing Systems: HSE required BE to demonstrate that a rigorous review of control and instrumentation in the areas of comparison to modern standards, software tools, events/operational feedback, key skills, and obsolescence has been undertaken.

Wind Hazard Analysis: Because of the change in the wind hazard applicable code and the consequent changes to predicted wind pressures, HSE required BE to provide further justification of the effects of extreme wind on the structural capability of the reactor building.

\section{A.12.2 Aging Degradation and Management}

The PSR stated that Sizewell B is in a good position with respect to aging and equipment qualification in that these considerations were taken into account at the station design stage. Aging and equipment qualification are addressed in the station safety case, and the necessary procedures and processes to ensure compliance have been implemented. Although obsolescence was not explicitly addressed in the safety case, it is recognized that it will become an increasingly important issue over the next review period. There was a basic framework in place for managing obsolescence, but the recent emphasis on life-cycle management and setting up system health monitoring and asset management should bring improvements. The PSR concluded that there are adequate systems in place for managing aging and obsolescence and equipment qualification.

\section{A.12.2.1 Nuclear Fuels}

Change of Fuel Vendor due to Cladding Failure: See Section A.12.3.2 ("Operating Experience").

\section{A.12.2.2 Mechanical Systems}

Replacement of Reactor Head: The PSR stated that BE has taken account of international experience and is planning to replace the RPV head during its refueling outage in the autumn of 2006. This is because it was discovered in some French reactors in the 1990s that the control rod drive penetrations made from Alloy 600 were susceptible to SCC. The Sizewell B control 
rod drive penetrations are made from Alloy 600 and have been inspected at refueling outages. While minor cracking has been found, it is not regarded as a serious safety concern because the cracks are small, the rate of crack growth is slow, and the cracks will not propagate suddenly. The new head uses Alloy 690, a material that is not readily susceptible to SCC. See also Section A.12.1.1.

Welding Defect: A weld indication in the main steam line was discovered during a routine inspection in 2003. The plant was allowed to continue in operation based on many factors, including the high degree of defect tolerance in the piping material and high confidence that the indications were manufacturing defects that had not grown in service. Additional inspections are being carried out during subsequent refueling outages. HSE determined during the PSR that it is satisfied with the safety case analysis and concluded that the situation is secure for at least the next 10 years.

\section{A.12.2.3 Structural Systems}

The following items were identified in the PSR relating to structural systems:

Coastal Erosion: The PSR identified coastal erosion as an issue that needed to be addressed. The Sizewell Shoreline Management Steering Group was set up to provide a review of this issue. This steering group oversees the various inspections and surveys that are undertaken on coastal erosion. Hence, the PSR concluded that all reasonably practicable measures are being taken to ensure that the risk of flooding from this source is minimized. The PSR identified that the use of independent experts and the work of the Steering Group is considered to be a significant strength in maintenance of the safety of the design.

Prestressed Concrete Containment: HSE required BE to provide justification of the prestressed concrete containment structural integrity case, given the predicted confidence levels on the prestressing levels over the next 10 -year period. The PSR stated that BE is confident that the latest measurements of tendon loads will provide adequate structural integrity.

\section{A.12.2.4 Electrical Systems}

In review of main and essential electric systems, the PSR concluded that there were no significant shortfalls identified and that much of the electrical equipment can be expected to have a service life in excess of 30 years. The PSR stated that where aging phenomena are anticipated within the next 10 years, such as in capacitors in chargers and inverters, an adequate replacement program is in place. Nevertheless, two issues arose where NII needed to have additional assurance for the next 10 years of operation. First, there are parts of the station grounding system that are not normally accessible, and BE had no plans to inspect them. Because the integrity of that system is important for the correct operation of the electrical protection equipment, NII sought and received assurance that the scope of the inspection will be increased. Second, in February 2005, a significant defect was discovered in the rotor of one of the four emergency diesel generators. Similar but lesser defects were found in another two rotors. Although a safety justification was provided for continued operation, the longer-term strategy was not transparent to HSE. BE has formally defined its medium- and long-term strategy for dealing with this issue. 
The following item was identified in the PSR relating to central control and data processing systems:

Degradation of Control and Instrumentation Equipment: HSE noted that the physical degradation of some of the equipment in harsh environments and have asked BE to provide clarification on its approach to addressing the physical conditions of the control and instrumentation equipment. No details of the degradation are given in the PSR report.

\section{A.12.2.5 Auxiliary Systems}

Essential Services Water System (ESWS): The areas of concern in the auxiliary system were the physical condition of the ESWS and the high level of intrusive maintenance of its heat exchangers. In fact, the ESWS problems had been recognized before the PSR and a number of changes have already been implemented. The remainder of the work is tracked through the PSR process. No further details are provided in the PSR report.

\section{A.12.3 Performance and Feedback of Experience}

\section{A.12.3.1 Performance}

In general, HSE is satisfied with the safety performance at Sizewell B. This aspect is monitored regularly by HSE through site inspection activities, which include start-up and review meetings. In addition, the licensee reports events to HSE as required by the site license. Four events that are considered by HSE to be particularly significant are discussed in the following section.

\section{A.12.3.2 Operating Experience}

In the area of OpE, the PSR considered the following four events to be significant:

Defect in Isolation Valve Wiring Modification: In 1998, a modification to the wiring of the control systems associated with the main steam and main feed isolation valves introduced a defect that resulted in a degradation of the level of protection against faults. A rigorous system of modification implementation meetings has been introduced, and amendments to the modification review process have been carried out to ensure closer review where the potential for common mode failure exists.

Large Release of Reactor Cooling Water from Safety Relief Valves: In March 1999, shortly after the reactor was shut down for a refueling outage, a large quantity of reactor coolant system water was released to the containment building during in-situ testing of a safety relief valve. There were no injuries and no release of radiation outside the containment. The event was investigated by the licensee and independently by HSE. As a result of these investigations, these valves were removed for testing to a separate test facility. In addition, many of the station operating instructions were amended to better aid the operators in their response to alarms.

Radioactive Contamination Outside Control Area: In April 1999, radioactive contamination was detected outside the radiologically controlled area. The cause was established as cleaning of an item of contaminated equipment without the appropriate controls being in place. Although the levels of contamination were small and did not give a significant radiation dose to those involved, the event was treated very seriously. Improvements have since been made to 
communications procedures and pre-task briefings. Additional contamination monitors have been installed.

Reactor Coolant Leak between the Seal of Reactor Vessel and Vessel Head: In May 2001, the reactor was shut down to investigate high accumulations of water in the containment due to primary coolant leakage. The leak was discovered to have been escaping from the seal between the RPV and its head. The licensee investigated the event and many lessons were learned. These led to improvements in foreign material exclusion and actions to take upon discovery of water in the containment.

Cladding Failures: There have been a number of cladding failures in the initial fuel type. The affected assemblies were predominantly used in operating cycles 1 to 4 (1995-2000) and are being phased out and replaced by assemblies from a different manufacturer. Since the introduction of the new fuel, the number of cladding failures has reduced.

The PSR stated that, overall, the review of OpE has shown that the reactors have been safely operated and that radiation doses to workers have been well controlled.

\section{Other Operating Experience:}

A search of the literature revealed the following additional OpE:

Plant Shutdown due to Equipment Failure: In May 2008, the Sizewell B plant had its first unplanned shutdown in over 3 years, cutting off its supply to the National Grid. The cause was a failure of conventional equipment at the plant rather than any part of the nuclear reactor.

Plant Shutdown due to High Moisture in Containment Building: On March 2010, Sizewell B had an unplanned outage for over 6 months because of the detection of high moisture levels in the containment building due to an unspecified problem with a pressurizer electrical heater. The event has been rated zero on the INES safety scale, and has no safety significance (Nuclear Engineering International 2010).

Fire in Building Containing Charcoal Absorber: In July 2010, a fire broke out on the second floor of a building housing the charcoal absorber, which is used to filter for gases. The fire was brought under control the following day when the charcoal absorber was flooded (Wikipedia 2012; BBC News Suffolk 2010).

Monitoring Equipment Performance by On-Line Monitoring (OLM): In December 2009, the EPRI published a comprehensive three-volume report on data from the commercial application of OLM at the UK's Sizewell B (EPRI 2009). Sizewell B used the technique to extend the calibration intervals of all the pressure and differential pressure transmitters in the primary system as well as some in the secondary system. It also performs automated cross-calibration of resistance temperature detectors during cool-down and/or heat-up. Sizewell B's long-term goal is to expand on-line calibration monitoring from the initial set of about 200 transmitters to nearly 2500 transmitters, including many in the secondary side of the plant.

Sizewell B has two to three times as many instruments as an average U.S. plant due to the UK regulators' requirements for a fully redundant backup I\&C system. With on-line monitoring, 
equipment performance is monitored continuously as opposed to the conventional methods of calibration assessment that are conducted on periodic basis over extended period of time.

\section{A.12.3.3 Comparison of Operating Experience with U.S. Plant of Similar Design}

The U.S. plant similar in design to the Sizewell NPP is Callaway. Callaway submitted an LRA in December 2011 and no resulting SER is available yet. The Callaway LRA was reviewed to identify common areas of concern and to note similarities and differences in OpE and information for the period of extended operation. Since Sizewell B is a relatively new plant, few component failures associated with aging have been observed up to the present. A caution in making this comparison is that component equipment manufacturers and the manufacturing process may vary from plant to plant, thus limiting the value of such direct comparison. The following item was identified:

Reactor Vessel Head Replacement. According to the letter of AmerenUE's Response to State of Missouri Attorney General's Request on current conditions of the Callaway reactor vessel head (November 22, 2006), Callaway states that it will plan to replace the reactor vessel head before the period of extended operation because of extensive cracking at Alloy 600 weld penetrations. As indicated in Section A.12.2.2, Sizewell B also replaced its reactor vessel head during its refueling outage in the autumn of 2006 (AmerenUE 2006).

\section{A.12.4 Conclusions}

The Sizewell PSR concludes that the licensee has conducted a wide-ranging and comprehensive PSR of Sizewell B power station and the BE's programs of PSR follow-up work involving modifications, procedural changes, inspections, and further analysis will reinforce the safety case for longer-term operation.

The PSR also pointed out that it is important to note that although the PSR may conclude that the safety case is adequate for a further 10 years, this will be dependent upon continued satisfactory results from routine monitoring by the licensee and regulation by HSE. Should any safety-related factor emerge in the interim period that throws doubt upon the continuing validity of the safety case, HSE would expect the licensee to resolve the matter to HSE's satisfaction.

\section{A.12.4.1 Summary of Technical Issues that Merit Further Consideration}

- The Sizewell PSR identified coastal erosion near the plant as an issue that needed to be addressed, and a steering group was set up to oversee the various inspections and surveys that are undertaken on coastal erosion (Section A.12.2.3).

- The Sizewell PSR found that parts of the station grounding system are not normally accessible and the licensee had no plans to inspect them. The British regulators found that the integrity of the grounding system is important to the electrical protection equipment, and the licensee was required to expand the scope of the inspections to include the locations in question (Section A.12.2.4). 


\section{APPENDIX B REFERENCES}

10 CFR Part 50, Appendix B, Quality Assurance Criteria for Nuclear Power Plants and Fuel Reprocessing Plants, Office of the Federal Register, National Archives and Records Administration, 2007.

10 CFR Part 50, Appendix R, Fire Protection Program for Nuclear Power Facilities Operating Prior to January 1, 1979, Office of the Federal Register, National Archives and Records Administration, 2012.

10 CFR Part 50.49, Environmental Qualification of Electrical Equipment, Office of the Federal Register, National Archives and Records Administration, 2007.

10 CFR Part 50.59, Changes, Tests, and Experiments, Office of the Federal Register, National Archives and Records Administration, 2007.

10 CFR Part 50.65, Requirements for Monitoring the Effectiveness of Maintenance at Nuclear Power Plants, Office of the Federal Register, National Archives and Records Administration, 2007.

10 CFR Part 50.90, Application for Amendment of License, Construction Permit, or Early Site Permit, Office of the Federal Register, National Archives and Records Administration, 2007.

10 CFR Part 54, Requirements for Renewal of Operating Licenses for Nuclear Power Plants, Office of the Federal Register, National Archives and Records Administration, 2010.

AmerenUE, 2006, AmerenUE's Response to State of MO - Attorney General's Request on Current Conditions of the Callaway Reactor Vessel Head, Callaway, November 22. Available at https://www.efis.psc.mo.gov/mpsc/commoncomponents/viewdocument.asp?Docld=4229531. Accessed April 10, 2012.

American Nuclear Society, 1999, Radioactive Source Term for Normal Operation for Light Water Reactors, ANSI/ANS-18.1-1999, La Grange Park, IL (withdrawn 2009).

American Society for Testing and Materials, 1995, Standard Test Method for Determination of Reference Temperature, To, for Ferritic Steels in the Transition Range, ASTM Standard E1921-95, Conshohocken, PA.

ASME (American Society of Mechanical Engineers), 2004a, "Rules for Construction of Nuclear Facility Components," ASME Section III in The ASME Boiler and Pressure Vessel Code, as approved in 10 CFR 50.55a, New York, NY.

ASME, 2004b, "Rules for Inservice Inspection of Nuclear Power Plant Components," ASME Section XI in The ASME Boiler and Pressure Vessel Code, as approved in 10 CFR 50.55a, New York, NY. 
Arizona Public Service Company, 2009, Palo Verde Unit 1, Unit 2, and Unit 3 License Renewal Application, Supplement 1, Phoenix, AZ, April 10.

Autorité de Sûreté Nucléaire, 2011, Opinion No. 2011-AV-0120 of ASN (Nuclear Safety Authority) Dated 4 July 2011 Concerning the Continued Operation of Reactor No. 1 of the Fessenheim Nuclear Power Plant after 30 Years of Operation, Paris, July 4.

BBC News Suffolk, 2010, Fire Breaks Out at Sizewell B Nuclear Power Plant, July 3. Available at http://www.bbc.co.uk/news/10498164. Accessed March 5, 2012.

Cheongwadae (Office of the President of the Republic of Korea), 2011, Republic of Korea. Available at http://www-pub.iaea.org/MTCD/publications/PDF/CNPP2011_CD/ countryprofiles/Korea,Republicof/Korea,Republicof2011.htm. Accessed April 17, 2012.

CSN (Consejo de Seguridad Nuclear), undated, Periodic Safety Review Report, Sections 4.2 and 5, Spanish Nuclear Safety Council (Consejo de Seguridad Nuclear or CSN).

CSN, 2007, Spanish Nuclear Safety Council Report to the Parliament Year 2007 Summary. Available at http://www.csn.es/publicaciones/resing2007.pdf. Accessed April 10, 2012.

CSN, 2013, Almaraz. Available at http://www.csn.es/index.php?option=com content\&view=article\&id=12769\&ltemid=383\&lang=es. Accessed April 16, 2012.

ENSI (Eidgenössisches Nuklearsicherheits-inspektorat), 2009, Report Concerning the Periodic Safety Review of the Leibstadt Nuclear Power Plant, ENSI 12/1300, Würenlingen, Switzerland, August 10.

Entergy Nuclear Vermont Yankee, LLC, 2006, Vermont Yankee Nuclear Power Station, License Renewal Application, White Plains, NY, January 27.

EPRI (Electric Power Research Institute), 1999, BWR Core Shroud Inspection and Flaw Evaluation Guidelines, BWRVIP-76, EPRI TR-114232, Palo Alto, CA, November.

EPRI, 2005, Boiling Water Reactor Vessel and Internals Project, Boiling Water Reactor Core Shroud Repair Design Criteria, Revision 2, BWRVIP-02-A, Palo Alto, CA, February.

EPRI, 2009, Nondestructive Evaluation: Proposed Code Case Criteria for Technical Basis of Weld Overlay Indication Evaluation and Disposition Based on Advanced Technology Assessments EPRI Report 1019118, Palo Alto, CA, August.

First Energy Nuclear Operating Company, 2007, Application for Renewed Operating License, Beaver Valley Power Station, Akron, OH, August.

Gavrilas, M., P. Hejzlar, N. E. Todreas, and Y. Shatilla, 2000, Safety Features of Operating Light Water Reactors of Western Design, Second Edition, MIT Center for Advanced Nuclear Energy Systems.

GE Energy, 2005, "GE Energy to Supply Monitoring and Control Systems for Taiwan Nuclear Power Plant," Directions Magazine. Available at 
http://www.directionsmag.com/pressreleases/ge-energy-to-supply-monitoring-and-control-syste ms-for-taiwan-nuclear-power/106478. Accessed January 18, 2012.

HSK (Hauptabteilung für die Sicherheit der Kernanlagen), 2007, Safety Statement on the Periodical Safety Inspection of the Mühleberg Nuclear Power Station (KKM), HSK 11/1100, Würenlingen, Switzerland, November 12.

IAEA (International Atomic Energy Agency), 1994, Periodic Safety Review of Operational Nuclear Power Plants, IAEA Safety Series No. 50-SG-012, Vienna.

IAEA, 2003a, Periodic Safety Review of Nuclear Power Plants, IAEA NS-G.2.10, Vienna.

IAEA, 2003b, Seismic Evaluation of Existing Nuclear Power Plants, IAEA Safety Report No. 28, Vienna.

IAEA, 2010, Periodic Safety Review of Nuclear Power Plants: Experience of Member States, IAEA-TECDOC-1643, Vienna.

IAEA, 2011, Integrated Regulatory Review Service (IRRS) Report to the United States of America, IAEA-NS-IRRS-2010/02, Vienna.

IRSN (Institut de Radioprotection et de Sûreté Nucléaire), 2009, The Safety Review of 900 Mwe Pressurized Water Reactors Associated with their Third Ten-Yearly Outage, DSR REPORT No. 285, Paris.

IRSN, 2010, IRSN Annual Report for 2010, Paris. Available at http://www.irsn.fr/EN/publications/corporate/Documents/irsn_annual_report_2010.pdf. Accessed March 3, 2012.

Jin, T.E., H.Y. Roh, T.R. Kim, and Y.S. Park, 2009, "Current Status and Prospect for Periodic Safety Review of Aging Nuclear Power Plants in Korea," Nuclear Engineering and Technology 41(4), May. Available at http://article.nuclear.or.kr/jknsfile/v41/JK0410545.pdf. Accessed April 20, 2012.

Kruners, M., 1998, Analysis of Instability Event in Oskarshamn-3, Feb. 8, 1998, with SIMULATE-3K, ISSN 1104-1374, December. Available at http://www.stralsakerhetsmyndigheten.se/Global/Publikationer/SKI_import/010803/8996383162 2/98-42.pdf. Accessed March 11, 2012.

Lacoste, A.C., 2009, personal communication from Lacoste (Autorité de Sûreté Nucléaire) to the President of Electrcité de France, EDF's Pressurised-water Nuclear Reactors (PWR); ASN's Position on the Generic Aspects for the Extension of the Operating Lifetime of 900-MWe Reactors after the Third Decennial Visit (DEP-PRES-0077-2009), July 1.

Ministry of Science and Technology, 2006, Kori 3 and 4 Periodic Safety Evaluation Assessment Results, Korea Institute of Nuclear Safety (KINS), S. Korea, Daejeon, March.

Ministry of Science and Technology, 2007, Yonggwang Units 3 \& 4 Periodic Safety Evaluation Assessment Results, Korea Institute of Nuclear Safety (KINS), S. Korea, Daejeon, June. 
Ministry of Science and Technology, 2010, Uljin Units 3 \& 4 Periodic Safety Evaluation Assessment Results, Korea Institute of Nuclear Safety (KINS), S. Korea, Daejeon, April.

National Fire Protection Association, 2010, Performance-Based Standard for Fire Protection for Light Water Reactor Electric Generating Plants, 2010 Edition, NFPA 805, Qunicy, MA.

NEK (Nuklearna Elektrarna Krško), 2004, Nuclear Power Plant Krško Periodic Safety Review Project Summary Report, PSR-NEK-8.0, Rev. 0, Krško, Slovenia.

NEK, 2012, Krško Nuclear Plant 2011 Annual Report Available at http://www.nek.si/uploads/documents/LP_ANG_2011.pdf. Accessed February 11, 2012.

NRC (U.S. Nuclear Regulatory Commission), 1973, Quality Assurance Requirements for Protective Coatings Applied to Water-Cooled Nuclear Power Plants, Regulatory Guide 1.54, Washington, DC, June.

NRC, 1977a, Electrical Connector Assemblies, Bulletin 77-05, Washington, DC, November 8.

NRC, 1977b, Potential Problems with Containment Electrical Penetration Assemblies, Bulletin 77-06, Washington, DC, November 22.

NRC, 1978, Terminal Block Qualification, Bulletin 78-02, Washington, DC, January 30.

NRC, 1979, Environmental Qualification of Class IE Equipment, Bulletin 79-01, Washington, DC, February 8.

NRC, 1980a, Issuance Of NUREG-0588, Interim Staff Position On Equipment Qualifications Of Safety-Related Electrical Equipment, Generic Letter 80-010, Washington, DC, February 5.

NRC, 1980b, Qualification Of Safety Related Electrical Equipment, Generic Letter 80-013, Washington, DC, February 21.

NRC, 1980c, Orders On Environmental Qualification Of Safety Related Electrical Equipment, Generic Letter 80-104, Washington, DC, November 26.

NRC, 1981, Information Regarding The Program For Environmental Qualification Of

Safety-Related Electrical Equipment, Generic Letter 81-05, Washington, DC, January 19.

NRC, 1982a, Environmental Qualification of Safety Related Electrical Equipment, Generic Letter 82-09, Washington, DC, April 20.

NRC, 1982b, Deficiencies in Primary Containment Electrical Penetration Assemblies, Bulletin 82-04, Washington, DC, December 3.

NRC, 1984, Certification of Compliance to 10 CFR 50.49, Environmental Qualification of Electrical Equipment Important to Safety for Nuclear Power Plants, Generic Letter 84-24, Washington, DC, December 27. 
NRC, 1988a, NRC Position on IGSCC in BWR Austenitic Stainless Steel Piping, Generic Letter 88-01, Washington, DC, January 25.

NRC, 1988b, Modified Enforcement Policy Relating to 10 CFR 50.49, "Environmental Qualification of Electrical Equipment Important to Safety for Nuclear Power Plants", Generic Letter 88-07, Washington, DC, April 7.

NRC, 1988c, Loss of Decay Heat Removal, Generic Letter 88-17, Washington, DC, October 17.

NRC, 1989, Safety-Related Motor-Operated Valve Testing and Surveillance, Generic Letter 89-10, Washington, DC, June 28.

NRC, 1995, Pressure Locking and Thermal Binding of Safety-Related Power-Operated Gate Valves, Generic Letter 95-07, Washington, DC, August 17.

NRC, 1997, Degradation of Control Rod Drive Mechanism Nozzle and Other Vessel Closure Head Penetrations, Generic Letter 97-01, Washington, DC, April 1.

NRC, 2000a, Service Level I, II, and III Protective Coatings Applied to Nuclear Power Plants, Regulatory Guide 1.54, Rev. 1, Washington, DC, July.

NRC, 2000b, Alternative Radiological Source Terms for Evaluating Design Basis Accidents at Nuclear Power Reactors, Regulatory Guide 1.183, Washington, DC, July.

NRC, 2001a, Generic Aging Lessons Learned (GALL) Report, NUREG-1801, Rev. 0, Washington, DC, April.

NRC, 2001b, Risk Methods Insights Gained from Fire Incidents, NUREG/CR-6738, SAND2001-1676P, Sandia National Laboratories, Albuquerque, NM, September.

NRC, 2002a, Human-System Interface Design Review Guidelines, NUREG-0700, Rev. 2, Washington, DC, May.

NRC, 2002b, Standard Review Plan for the Review of Safety Analysis Reports for Nuclear Power Plants: LWR Edition, Appendix 8-A, Branch Technical Position PSB-1, NUREG-0800, Washington, DC, December.

NRC, 2002c, Safety Evaluation Report Related to the License Renewal of North Anna Power Station, Units 1 and 2, and Surry Power Station, Units 1 and 2, NUREG-1766 Washington, DC, December.

NRC, 2002d, Failure of Steam Dryer Cover Plate After a Recent Power Uprate, Information Notice 2002-26, Washington, DC, September 11.

NRC, 2003, Additional Failure of Steam Dryer After a Recent Power Uprate, Information Notice 2002-26, Supplement 1, Washington, DC, July 21. 
NRC, 2004a, Potential Impact of Debris Blockage on Emergency Recirculation during Design Basis Accidents at Pressurized-Water Reactors, Generic Letter 2004-02, Washington, DC, September 13.

NRC, 2004b, Additional Flow-Induced Vibration Failures after a Recent Power Uprate, Information Notice 2002-26, Supplement 2, Washington, DC, January 9.

NRC, 2004c, Safety Evaluation Report Related to the License Renewal of the Virgil C. Summer Nuclear Station, NUREG-1787, Washington, DC, March.

NRC, 2005a, Status Report on Power Uprates, SECY-05-0098, Washington, DC, June 2.

NRC, 2005b, Generic Aging Lessons Learned (GALL) Report, NUREG-1801, Rev. 1, Washington, DC, September.

NRC, 2006a, BWR Core Shroud Tie Rod Upper Support Cracking, Part Operations Center Event Report, Washington, DC, October 10 (ML 062850366).

NRC, 2006b, Reactor Oversight Process, NUREG-1649, Rev. 4, Washington, DC, December.

NRC, 2008, Safety Evaluation Report Related to the License Renewal of Vermont Yankee Nuclear Power Station, Units 1 and 2, NUREG-1927, Washington, DC, May.

NRC, 2009a, Safety Evaluation Report Related to the License Renewal of Vermont Yankee Nuclear Power Station, Units 1 and 2, NUREG-1927, Supplement 1, Washington, DC, September.

NRC, 2009b, Safety Evaluation Report Related to the License Renewal of Beaver Valley Power Station, Units 1 and 2, NUREG-1929, Washington, DC, October.

NRC, 2009c, Fire Protection for Nuclear Power Plants, Regulatory Guide 1.189, Rev. 2, Washington, DC, October.

NRC, 2010a, "Stress Corrosion Cracking," Chapter 4.9 in General Electric Advanced Technology Manual, Rev. 1210, Washington, DC, December (ML 11263A331).

NRC, 2010b, IRRS Mission to the United States, Module 11A: Periodic Safety Review, Washington, DC, July.

NRC, 2010c, Generic Aging Lessons Learned (GALL) Report, NUREG-1801, Rev. 2, Washington, DC, December.

NRC, 2011a, Safety Evaluation Report Related to the License Renewal of Vermont Yankee Nuclear Power Station, Units 1 and 2, NUREG-1927, Supplement 2, Washington, DC, March.

NRC, 2011b, Safety Evaluation Report Related to the License Renewal of Palo Verde Nuclear Power Station, Units 1, 2, and 3, NUREG-1961, Washington, DC, April. 
NRC, 2011c, Staff Action Plan to Address the Integrated Regulatory Review Service Mission, SECY-11-0084, Washington, DC, June 27.

NRC, 2011d, Advance Reference Materials for the IRRS Mission to the U.S., Module 11a, Washington, DC, September 9.

NRC, 2011e, Control Rod Blade Cracking Resulting in Reduced Design Lifetime, Information Notice 2011-13, Washington, DC, June 29.

Nuclear Energy Institute, 2005, Industry Guidelines for Implementing the Requirements of 10 CFR Part 54--the License Renewal Rule, NEl 95-10, Rev. 6, Washington, D.C., June.

Nuclear Engineering International, 2010, Sizewell B Outage Will Extend into Summer, June 11. Available at http://www.neimagazine.com/story.asp?storyCode=2056609. Accessed March 8, 2012.

Nuclear Engineering International, 2011a, Outage of the Year: Olkiluoto Wins the Gold, September 13. Available at http://www.neimagazine.com/story.asp?sc=2060616. Accessed December 10, 2011.

Nuclear Engineering International, 2011b, Almaraz 1\&2 Power Uprate. Available at http://www.neimagazine.com/story.asp?storyCode=2060519. Accessed April 9, 2012.

OKG (Oskarshamnsverkets Kraftrupp), 2007, Press Release: Reactor Trip at Oskarshamn 3 , January 7. Available at http://www.okg.se/templates/NewsPage 1105.aspx. Accessed October 22, 2011.

OKG, 2008, Press Release: Oskarshamn 3 Resumed Its Production - Later Than Foreseen, OKG, June 30, 2008. Available at http://www.okg.se/templates/NewsPage 1156.aspx. Accessed October 22, 2011.

OKG, 2011, Press Release: Unit Oskarshamn 3 Back in Operation after an Operational Disturbance, September. Available at http://www.okg.se/templates/NewsPage 1173.aspx. Accessed October 22, 2011.

République Française, 2010, Fifth National Report for the 2011 Peer Review Meeting: Fifth French Report under the CNS, Convention on Nuclear Safety, July. Available at http://www.french-nuclear-safety.fr/index.php/content/download/27163/163366/file/CNS_5erapport_anglais.pdf.

Sipro Inzeniring, 2012, RVCH Replacement and Upgrade with SHA. Available at http://www.sipro-inzeniring.si/index.php?option=com_content\&task=view\&id=55\&ltemid=33\&lan g=english. Accessed February 21, 2012.

SKI (Statens Kärnkraftinspektion), 2008, Study of OKG PLC's Periodic Overall Assessment of Security in Oskarshamn 3, SKI 2005/40, May 5.

South Carolina Electric \& Gas Company, 2002, Virgil C. Summer Nuclear Station, License Renewal Application, Columbia, SC, August 6. 
Stationery Office, 2006, Sizewell B Nuclear Power Station: The Findings of NII's Assessment of British Energy's Periodic Safety Review, Health and Safety Executive, Norwich, U.K., June.

Structural Integrity Associates, 2008 Contingency Flaw Evaluation Support for Perry, Calculation Package, File No. 0800439.307, Rev. 1, October (ML 090330371).

STUK (Säteilyturvakeskus Strålsäkerhetscentralen), 2010, Safety Assessment of Olkiluoto NPP Units 1 and 2, STUK-B 111, Helsinki, February.

swissnuclear, 2005, Summary of Operating Experience in Swiss Nuclear Power Plants. Available at http://www.swissnuclear.ch/upload/cms/user/Operating-experience05.pdf. Accessed February 25, 2012.

Taiwan Atomic Energy Council, 2006a, Reportable Event Report on the Chinshan Nuclear Power Plant Unit 1 Reactor Core Isolation Cooling System Anomaly and Inoperability, RER-9511-001. Available at http://www.aec.gov.tw/www/english/nuclear/files/RER-95-11-001.pdf. Accessed January 20, 2012.

Taiwan Atomic Energy Council, 2006b, Reportable Event Report on the Chinshan Nuclear Power Plant Unit 1 Reactor Core Isolation Cooling System Anomaly and Inoperability, RER-9511-001. Available at http://www.aec.gov.tw/www/english/nuclear/files/RER-95-11-002.pdf. Accessed January 20, 2012.

Taiwan Atomic Energy Council, 2009a, New Way to Fight Global Warming: Nuclear Power Uprates. Available at http://www.aec.gov.tw/www/english/historical/article.php?n=200902. Accessed January 20, 2012.

Taiwan Atomic Energy Council, 2009b, The Third Ten-Year Overall Safety Assessment Review Report of Nuclear Power Plant 1, Unit 1, NRD-SER-98-03, New Taipei City, Taiwan, June.

Tip News, 2011, "Swiss Parliament Approves Nuclear Plant Phase Out," September 28. Available at http://www.tipnews.info/business/NjU2OTU=/2011/09/28/swiss-parliament-approves-nuclear-pla nt-phase-out. Accessed February 25, 2012.

TVO (Teollisuuden Voima Oyj), 2010, Digital Systems - Reliability Analyses: OL 1/OL2 Plant Modifications - Examples, September 13. Available at http://www.nks.org/download/nks_r_digrel_14_september_2010/nksdigrelseminar_100914_att0 5_olkiluoto_1_and_2.pdf. Accessed December 10, 2011.

Virginia Electric and Power Company, 2001, North Anna Power Station Units 1 and 2, Application for Renewed Operating Licenses, Richmond, VA, May.

Virginia Electric and Power Company, 2008, North Anna Power Stations Units 1 and 2, Supplemental Response to NRC Generic Letter 2004-02, February 29, 2008 (ML 080650563) and Updated Supplemental Response, February 27 (ML 090641038). 
WANO (World Association of Nuclear Operators), 2008, "Practising for Precision," Inside WANO 16:12. Available at http://www.wano.info/wp-content/uploads/2010/06/Vol16No1_en.pdf. Accessed January 20, 2012.

Westin, J., et al., 2009, Stratification Issues in the Primary System. Review of Available Validation Experiments and State-of-the-Art in Modelling Capabilities (StratRev), NKS-202, NKS (Nordic Nuclear Safety Research), August. Available at http://www.nks.org/download/nks202_e.pdf. Accessed October 22, 2011.

Wood, J.K., 2001, personal communication from Wood (FirstEnergy Nuclear Operating Company) to NRC Document Control Desk, Perry Nuclear Power Plant, Power Uprate Test Report (TAC No. MA6459), June 14 (ML 011700406).

World Information Service on Energy, 2008, "Sweden: Cracked Control Rods; Gaping Holes in the Culture of 'Safety," Nuclear Monitor 679: 1. Available at

http://www.nirs.org/mononline/nm679.pdf. Accessed October 22, 2011.

World Nuclear Association, 2012, Nuclear Power in France. Available at http://www.world-nuclear.org/info/inf40.html. Accessed March 3, 2012.

World Nuclear News, 2011, New Nuclear Energy Policy for Taiwan, November 3. Available at http://www.world-nuclear-news.org/NP-New_nuclear_energy_policy_for_Taiwan-0311117.html. Accessed January 21, 2012. 




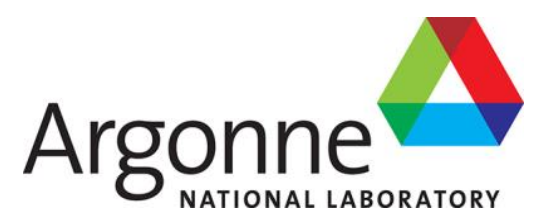

Environmental Science Division

Argonne National Laboratory

9700 South Cass Avenue, Bldg. 240

Argonne, IL 60439

www.anl.gov 